\title{
PROFILI GENERALI DELLA LOTTA AL DOPING EVOLUZIONE NORMATIVA E CONNESSIONE CON GLI ASPETTI FARMACOLOGICI
}

\author{
Pierluigi Raimondo ${ }^{1}$, Luca Zambelli ${ }^{2}$ \\ ${ }^{1}$ Professore a contratto di Diritto privato dello sport nell’Università di Bologna \\ ${ }^{2}$ Dottorando di ricerca nell’Università di Bologna e Avvocato nel Foro di Bologna
}

\begin{abstract}
L'ambito del doping rappresenta da sempre uno dei settori del diritto dello sport che maggiormente è soggetto a cambiamenti, sia per la rapidità nella ricerca medico-farmaceutica di nuove sostanze e nell'utilizzo di nuovi metodi di allenamento, sia per la dualità del sistema di norme sportive e statali che regolamentano il fenomeno. Dopo una breve ricostruzione delle principali tappe dell'evoluzione del fenomeno sia fattuale che normativo, l'articolo individua le principali aree di legislazione in cui vengono regolati i diversi aspetti del doping, partendo dal fenomeno della farmacodipendenza e l'utilizzo di integratori, nonché sulle sfide poste dalla farmacogenetica e dall'allenamento neurologico. È presente poi una seconda sezione in cui viene affrontata in dettaglio la legislazione e l'organizzazione delle strutture che si occupano di perseguire e studiare il fenomeno con particolare attenzione ai sistemi di indagine penale e disciplinare, alla loro connessione, nonché al ruolo delle istituzioni nella formazione di una cultura del benessere e della legalità sportiva attraverso la conoscenza delle norme.
\end{abstract}

Keywords: Formazione istituzionale, Indagini penali e disciplinari, Farmaco-dipendenza, Nuovi metodi

\begin{abstract}
The speed of pharmaceutical research into new substances and methods, coupled with the existence of two different punishment systems, one pursued by the State and one by sport institutions, generates confusion in a public which is largely ignorant about the workings of legal systems. This study aims to give a complete overview of the antidoping rules and It investigates whether the rules and controls are enough to fight the doping problem, given its technological development and the lack of knowledge evaluated in society, or whether it is necessary to improve awareness of this topic and specific training where necessary, above of all among young people. The research also goes on to focus on the phenomena of drug dependence and food integration, as well as new training methods with neurological impulses, and finally the article is concentrated on crime and disciplinary investigation and their connection to eachother. The results demonstrate how important it is for institutions to promote a new culture of well-being and legality while supporting the dissemination of projects directed to adolescents in particular.
\end{abstract}

Keywords: Anti-doping education - Investigations - Addictive drugs - Doping evolution 


\section{La farmacodipendenza nello sport}

Testimonianze dell'impiego di sostanze di origine naturale per migliorare la propria condizione fisica risalgono alle prime edizioni delle olimpiadi, allorquando gli atleti ingerivano sostanze stimolanti mescolate agli alimenti carnei e alle bevande. Da secoli l'uomo tenta di modificare la propria prestazione atletica oppure di diminuire il senso di fatica ${ }^{1}$ con mezzi non fisiologici, eventualmente anche illeciti, nel corso di competizioni sportive. A tale complesso e articolato fenomeno è attribuito dalla comunità scientifica internazionale il termine doping. ${ }^{2}$ Il fenomeno, tornato di moda con la reintroduzione delle moderne olimpiadi nel 1896, ha ripreso vigore fra gli atleti attraverso l'assunzione di sostanze naturali o sintetiche (sostanze zuccherine, caffè, alcool, stricnina, nitroglicerina, ecc.) pur di poter superare i propri limiti atletici ed incuranti degli effetti collaterali, talora invalidanti se non addirittura mortali. ${ }^{3}$ Nel secondo dopoguerra, durante gli anni Cinquanta esplose fra gli sportivi l'anomala tendenza di assumere anfetamine, ${ }^{4}$ all'epoca somministrata gratuitamente ai militari impegnati sui fronti di guerra ed ai reduci. Invece, verso la fine degli anni Settanta, l'assunzione di sostanze dopanti da parte delle donne arrivò a modificarne i tratti somatici, mascolinizzandole, mentre aumentavano i casi di insorgenze

1 "La fatica è una sindrome complessa che deriva da un lavoro protratto o eccessivo, e insorge con il concorso di vari fattori causali. Pur essendo dovuta soprattutto all'iperattività dell'apparato muscolare, si caratterizza in una tipica condizione psicofisica, nella quale il soggetto tende a ridurre la sua attività e avverte la necessità di interromperla. Nell'atleta la soglia della fatica determina una situazione di conflitto: fattori interni fisici e psichici lo inducono a non proseguire nello sforzo, mentre fattori esterni lo spingono a continuare. Esistono mezzi capaci di ritardare la condizione di affaticamento: l'allenamento, il riposo, l'alimentazione e la fisioterapia. Quando si ricorre ad altri metodi che non sono più naturali per ottenere la neutralizzazione della fatica e dei fenomeni fisici e psichici concomitanti, si entra nell'ambito del doping". G. Cantelli Forti, La farmacologia nello sport e il doping, in Enciclopedia dello Sport, 2003, consultabile in www.treccani.it. "Nel caso del ciclismo, ad esempio, il numero di giorni di gara è passato da 130 negli anni Ottanta agli attuali 80 giorni. Viceversa, in tutti questi sport, il numero di competizioni ad alto livello che richiedono una grande quantità di energia, è notevolmente aumentato. A questo occorre aggiungere carichi di allenamento in quantità e percentuale d'intensità estremamente elevate. Basandosi in ugual misura sui risultati dei colloqui con sportivi dopati e non dopati, la questione del dolore fisico e delle lesioni successive ai carichi di allenamento per preparare tali competizioni appare pertanto come il motivo più significativo di ricorso al doping”. C. Brissonneau, Il doping nello sport professionale, Université Paris Descartes (IP/B/CULT/IC/2007-067), giugno 2008, p. 7, consultabile in www.europarl.europa.eu.

2 L'assunzione di sostanze non consentite, farmacologiche o fisiologiche in quantità anomala, per incrementare le prestazioni dell'organismo, viene sinteticamente indicata col termine inglese doping, che così definiva l'usanza della popolazione africana dei Cafri di ingerire un estratto liquoroso eccitante (dopo) durante le cerimonie religiose. Si ritiene che il termine sia stato inizialmente utilizzato dagli inglesi verso la fine dell'Ottocento per indicare, nel corso delle competizioni ippiche, gli effetti sui cavalli da corsa di alcuni trattamenti stimolanti per migliorarne le prestazioni in gara. G. Palmieri, V. Pincolini, A. Casti, Doping 2004, Bologna, MNL, 2004, consultabile in www.medicinasportonline.eu. "Il termine doping appare per la prima volta in un dizionario inglese nel 1889 in riferimento a una mistura di oppio e narcotici usata per i cavalli [...] Antichi allevatori, quali gli sciti nella Russia meridionale, davano stimolanti ai loro cavalli prima di andare in battaglia, per renderli più aggressivi e focosi”. G. Cantelli Forti, La farmacologia nello sport e il doping, cit.

${ }^{3}$ La pratica del doping si configura senza dubbio come un comportamento plurioffensivo in quanto lede, da una parte, i principi di lealtà e correttezza sportiva, alterando la normale e sana competizione sportiva tra i partecipanti, mentre dall'altra danneggia e pregiudica il bene dell'integrità psicofisica di atleti e sportivi. Non esiste, infatti, farmaco o pratica che comporti benefici per la salute di un soggetto sano, anzi, in questi casi l'unico risultato certo è l'accresciuto pericolo d'insorgenza di effetti collaterali (c.d. adverse drug reaction). "I suoi effetti nocivi dipendono da numerosi parametri (tipologia delle sostanze assunte, durata dell'assunzione, condizioni di somministrazione e stato generale dello sportivo, quantità utilizzata). I rischi collegati al consumo di prodotti multipli, spesso a dosi soprafisiologiche, sono poco conosciuti, tanto più che l'etica medica e il divieto di doping non consentono l'esecuzione di studi sull'uomo". C. Brissonneau, Il doping nello sport professionale, cit., p. 6. Proprio nel 1896 si assistette alla prima morte "certificata" a causa di doping, il caso è quello del ciclista britannico Arthur Linton che durante la competizione "Parigi-Rubaix" fu colpito da una crisi cardiaca a causa di un sovradosaggio di sostanze stimolanti - tra cui caffeina e stricnina - e morì nei giorni successivi alla competizione A. Di Giandomenico, Doping, Roma, Ed. Nuova Cultura, 2011, p. 14.

${ }^{4}$ Le amfetamine con i loro derivati (desamfetamina e metamfetamina), sintetizzate negli anni Trenta, sono state fortemente somministrate, durante la Seconda guerra mondiale, agli aviatori inglesi che le utilizzavano per resistere più giorni senza riposare: oltre 72 milioni di compresse sono state distribuite ai soldati inglesi. Il successivo abuso da parte degli atleti ha dimostrato il potenziale lesivo di tale farmaco. Infatti, "i farmaci non vengono generalmente studiati per gli eventuali effetti collaterali che si possono determinare in condizioni estreme. La morte del ciclista inglese Tom SIMPSON al Tour de France del 1967 in seguito all'assunzione di amfetamine, fu probabilmente ascrivibile all'elevata produzione di calore e al notevole incremento della temperatura corporea durante la gara". G. Cantelli Forti, La farmacologia nello sport e il doping, op. cit. 
tumorali, conseguenti a prolungati periodi di assunzione di sostanze ormonali. Ma a ben più gravi riflessioni dovettero giungere gli organi sportivi internazionali quando, durante gli anni Novanta, appresero l'amara realtà che alcune nazioni, in particolar modo Germania dell'Est e Russia, ${ }^{5}$ avevano pianificato politiche aberranti di somministrazione di sostanze dopanti agli atleti per scopi di propaganda politica e per rinforzare il sentimento popolare nazionalistico e antioccidentale attraverso le vittorie sportive (c.d. "doping di Stato"), tutto questo mentre nel resto del mondo esplodeva il culto dell'edonismo sportivo, enfatizzazione estrema dell'aspetto estetico e affermazione del canone fisico della muscolarità ad ogni costo, e gli atleti di varie discipline continuavano ad assumere nandrolone, Epo, stimolanti, GH, ormoni femminili e si dedicavano all'autoemotrasfusione spesso sotto la diretta sorveglianza di medici sociali. Appare opportuno ricordare che anche in Italia sono stati vissuti riflessi di tale abnorme tendenza, così come dimostrato dall'inchiesta svolta dalla Procura della Repubblica di Ferrara. ${ }^{6}$

5 “Il fenomeno del doping ha avuto origine, nel panoramo europeo, a partire dagli anni '60, nei paesi dell'Est, ove veniva praticato in maniera sistematica nei confronti degli atleti partecipanti alle Olimpiadi, per poi diffondersi nel resto dell'Europa, non soltanto nell'ambito dello sport professionistico, ma anche di quello dilettantistico e addirittura dello sport amatoriale, toccando livelli di allarme sociale di estrema gravità”. G. Liotta, L. Santoro, Lezioni di diritto sportivo, Milano, Giuffrè, 2018, p. 276. Sicuramente sconcertanti appaiono nel merito le rivelazioni prodotte in un documentario mandato in onda sul canale tedesco ARD e intitolato Doping confidenziale: come la Russia fabbrica i suoi vincitori in cui è stato dimostrato come la Federazione sportiva russa abbia incentivato la pratica dell'utilizzo di sostanze anabolizzanti tra i propri atleti durante le ultime Olimpiadi. Nel filmato viene affermato "che nello scandalo sono implicati anche l'agenzia anti-doping russa, il laboratorio dei controlli sul doping di Mosca e l'Associazione Internazionale delle Federazioni di atletica leggera". F. Tortora, Un documentario tv smaschera il sistema del doping russo, in www.corriere.it., 4 dicembre 2014.

${ }^{6}$ All'inizio degli anni Ottanta venne stipulata una convenzione fra il CONI (firmata da F. Carraro) e il Centro di studi biomedici applicati allo sport dell'Università di Ferrara affinché l'equipe del Prof. F. Conconi seguisse i migliori atleti dello sport azzurro. Dietro all'asserita ricerca scientifica per migliorare le prestazioni degli atleti, si celava un sistema basato dapprima sull'emotrasfusione, poi sull'utilizzo di eritopoietina (EPO). Una volta bloccata la pratica della reinfusione del proprio sangue (emodoping), iniziò la seconda fase, quella dell'epodoping. A. Donati nel libro Lo sport del doping. Chi lo subisce, chi lo combatte, Torino, EGA, 2013, pp. 129-176. Per meglio comprendere la gravità della situazione riportiamo le parti principali dell'archiviazione dell'Ufficio di Procura Antidoping che si è dovuta esprimere a seguito della richiesta di archiviazione formulata dal Tribunale di Ferrara: "Giova ricordare che Conconi Francesco, Casoni Ilario e Grazzi Giovanni erano stati imputati, rispettivamente, in qualità di Direttore del Centro di Studi Biomedici applicati allo sport dell'Università di Ferrara, il primo, dipendente della medesima struttura, il secondo, e collaboratore della struttura nonché medico sociale della squadra ciclistica Carrera fino al 1995, il terzo, del reato p. e p. dagli artt. 81 cpv., 110 c.p. e 1 della legge n. 401/1989 aggravato per i primi due ai sensi dell'art. 61 numero nove c.p. perché, con più azioni esecutive del medesimo disegno criminoso, in tempi diversi ed in relazione a più competizioni sportive organizzate dalla FCI, dalla FISI e dalla FIDAL [...] compivano atti fraudolenti al fine di raggiungere, attraverso il miglioramento delle prestazioni agonistiche artificialmente determinate negli atleti, un risultato diverso da quello conseguente al corretto e leale svolgimento delle competizioni alle quali gli stessi atleti professionisti avrebbero dovuto partecipare (quali ad es.: Olimpiadi invernali, Campionati mondiali, Giro d'Italia, Tour de France); ciò, attraverso le seguenti condotte: somministrando eritropoietina, farmaco ad azione dopante la cui assunzione è vietata dall'ordinamento sportivo [....] eseguendo prelievi ed analisi ematiche ed altri test cinici e biomeccanici ed elaborando i dati delle analisi, con carattere di sistematicità sugli atleti professionisti indicati nell'elenco sotto riportato, curandone la preparazione fisica, in attuazione delle convenzioni stipulate dal Centro con il CONI e dei contratti con le predette federazioni sportive nazionali e squadre ciclistiche ovvero con i singoli atleti, e controllando nel contempo lo stato di salute degli atleti nei periodi di assunzione da parte degli stessi di eritropoietina nota agli imputati interagendo in tal modo con il trattamento e comunque agevolando, favorendo e contribuendo casualmente al doping degli atleti medesimi ... gli imputati hanno per alcuni anni e con assoluta continuità fiancheggiato gli atleti elencati nel capo di imputazione nella loro assunzione di eritropoietina, sostenendoli e di fatto incoraggiandoli nell'assunzione stessa ... I protagonisti, da un lato sono medici che mostrano di non avere scrupoli nello studiare e sperimentare gli effetti del doping sugli atleti, non lesinando i loro sforzi in tal senso e per giunta utilizzando, nel perseguire i propri scopi, il pubblico denaro sulla base di convenzioni stipulate con il CONI ed alcune Federazioni o squadre sportive, dall'altro sono atleti i cui nomi sono o sono stati di alta risonanza che, verosimilmente mossi dal miraggio dell'acquisizione di prestigiosi risultati a livello internazionale e di medaglie, si sono prestati a fungere da cavie e a sottoporre a gravissimo rischio la propria salute. Le prove che il Tribunale di Ferrara ha potuto raccogliere in ordine ai fatti verificatisi sino al considerare alla stessa stregua di una positività riscontrata all'esito di esami di laboratorio e tali da fornire lo stesso grado di certezza, ovverosia la certezza che promana da elementi aventi una forza probatoria pressoché insuperabile, per cui appare del tutto superflua l'audizione degli atleti sopra indicati [...] Tutto ciò premesso e ritenuto, questa procura, nel segnalare alla Presidenza del CONI l'opportunità di trasmettere alle federazioni interessate (FCI, FISI, FIDAL) il presente provvedimento e l'allegata sentenza n. 533/03 del Tribunale di Ferrara, giudice dott. Franca Oliva, affinché valutino le ripercussioni che la gravità dei fatti può avere sulla loro immagine e sulla credibilità dell'azione da loro prestata nell'interesse dello sport, dispone l'archiviazione degli atti del procedimento disciplinare per intervenuta prescrizione degli illeciti disciplinari con riguardo a tutti gli atleti compresi nell'elenco trascritto nella parte iniziale del presente provvedimento". Roma, 24 giugno 2004, Ufficio della procura antidoping del CONI, Procedimento d'indagine $n$. 
Nonostante le inchieste volte al contrasto del fenomeno, pratiche e prodotti utilizzati cambiano in funzione dei metodi antidoping impiegati trasformando gli atleti da consapevoli consumatori in compulsivi soggetti affetti da dipendenza da farmaci o target del doping cosmetico, chiara conferma della tendenza della nostra società ad essere sempre più farmacocentrica. Lo sport, infatti, inopinatamente chiede aiuto alla medicina al fine di mettere gli atleti in condizione di superare i propri limiti, in evidente contrasto con i principi di lealtà e correttezza, dando vita al fenomeno della "farmacomania", ovvero della tendenza della società a divenire sempre più farmacocentrica, sempre più orientata a trovare soluzioni nei farmaci anche per i problemi che nulla hanno a che fare con la medicina. ${ }^{7}$ Quest'ultima, per sua stessa natura, dovrebbe limitarsi a svolgere un'azione nell'ambito della prevenzione e della cura delle malattie. Pertanto, l'utilizzo di pratiche mediche dovrebbe essere limitato: alla prevenzione degli infortuni ed alla cura degli stati patologici, eventuale conseguenza dell'attività agonistica; al controllo dietetico e nutrizionale; al controllo dello stato di salute psico-fisico dell'atleta. ${ }^{8}$ Negli ultimi anni, invece, è stato peraltro registrato un aumento increscioso, fra gli atleti, del ricorso a sostanze farmacologiche anche per eludere i controlli antidoping. ${ }^{9}$ Per meglio comprendere l'estensione e la problematicità del fenomeno del mercato illegale delle sostanze dopanti, oltre le indagini italiane necessita prendere in considerazione anche

48/2004, provvedimento di archiviazione, in www.sites.google.com. La vicenda giudiziaria venne avviata nel 1998 dall'allora P.M. di Arezzo (V. Scolastico) che inviò per competenza alla Procura di Ferrara (P.M. P. Soprani) gli atti relativi al centro diretto dal prof. F. Conconi. Nel novembre 2000, dopo oltre due anni di indagini, la Procura chiese il rinvio a giudizio di Conconi ed altri sette suoi collaboratori per associazione per delinquere, frode sportiva, somministrazione di sostanze in modo pericoloso per la salute, truffa aggravata ed altre ipotesi di reato. Nel 2002 il g.i.p. del Tribunale di Ferrara stralciò ed inviò al Tribunale di Bologna gli atti relativi a Conconi mentre gli altri imputati vennero prosciolti. A causa di un errore clamoroso commesso dal g.i.p. il processo venne rinviato e nel 2003 Conconi, Grazzi e Casoni vennero assolti perché il reato contestato, nel frattempo, era caduto in prescrizione, rimanendo solo la condanna morale a carico dei medici rilevabili dalle motivazioni della sentenza. Esaminando la predetta sentenza del Tribunale di Ferrara e gli atti parlamentari del periodo interessato è stato possibile ricostruire che: 1) nel marzo del 1985, rispondendo ad una interpellanza parlamentare, l'allora Ministro della sanità, On. Degan, dichiarò inammissibile la pratica dell'emotrasfusione nello sport allo scopo di incrementare le prestazioni asserendo che la stessa era una pratica medica che andava realizzata solo nei casi gravi (interventi chirurgici, incidenti, malattie) che lo richiedevano; 2) i rapporti col prof. Conconi, l'Università di Ferrara ed il CONI sono proseguiti come attestato dalla delibera della G.E. del CONI del 31 maggio 1995 n.614 (convenzione e relativo finanziamento per il III piano biennale 1995/96); 3) il prof. Conconi proseguì con la somministrazione della pratica di cui al punto 1), come rivelato da diversi atleti, fino all'avvento dell'Epo, con cui sono stati "trattati" ulteriori 63 atleti; 4) negando l'evidenza dei fatti il presidente del CONI, Pescante, nel corso dell'audizione del 26 febbraio 1997 presso la VII Commissione del Senato, dichiarò che "[...] da molti anni il CONI non ha più rapporti di collaborazione con il Centro dell'Università di Ferrara”. G. Toti, Conconi spingeva gli atleti al doping, in www.archiviostorico.corriere.it, 11 marzo 2004.

7 "Si può dedurre che il problema del doping presenta tre aspetti principali. Il primo è di etica sportiva, la quale viene letteralmente sovvertita da chi ricorre a mezzi artificiali in una competizione dove tutti i concorrenti devono trovarsi nelle stesse condizioni dinnanzi alle stesse difficoltà. Il secondo è di indole clinico-tossicologica, concernente l'uso e l'abuso di medicinali assunti da un organismo che non ne necessita, o l'assunzione di sostanze tossiche perché prese a dosi elevate. Il terzo è di profilo giuridico... l'abuso di farmaci si realizza quando la dose di un farmaco eccede gli standard posologici e terapeutici e/o non ci sono indicazioni mediche al suo impiego... I farmaci sono utilizzati dagli atleti per ottenere una grande varietà di effetti indirizzati al miglioramento della prestazione, includendo l'aumento dell'aggressività e della forza fisica, l'attenuazione della fatica, il miglioramento delle capacità di concentrazione mentale, la diminuzione della frequenza cardiaca, l'incremento della massa corporea, i cambiamenti nei parametri ponderali e la prevenzione dell'ansia. È evidente la non eticità dell'uso di farmaci per es. per aumentare la forza muscolare e la resistenza fisica o per favorire l'aggressività". G. Cantelli Forti, La farmacologia nello sport e il doping, cit.

${ }^{8}$ La medicina non dovrebbe favorire la prestazione se non ottimizzando nutrizione e metodiche di allenamento. Le scelte mediche dovrebbero valutare il rapporto tra beneficio apportato alla salute dell'individuo ed il rischio che possono comportare per lo stesso: è chiaro che il beneficio delle manovre dopanti è nullo, per quanto riguarda la salute dell'atleta. Non esistendo studi documentati attestanti l'efficacia delle sostanze dopanti nel migliorare il rendimento agonistico dell'atleta, la relativa assunzione è semplicemente rischiosa per la salute. S. Garattini, La farmacomania sportiva, in Social News, 2007, VII, p. 4.

${ }^{9}$ Per manipolazione farmacologica, chimica o fisica quale metodo doping si intende "l'uso di sostanze e di metodi in grado di alterare l'integrità e la validità dei campioni di urine utilizzati per i controlli antidoping" quali la cateterizzazione, la sostituzione e/o la manomissione delle urine, l'inibizione della secrezione renale di sostanze (per esempio per mezzo del probenecid, agente mascherante che riduce la concentrazione urinaria di sostanze dopanti quali gli ormoni steroidei), l'applicazione di epitestosterone (somministrato per mantenere basso il rapporto urinario testosterone/epitestosterone). L'illiceità dell'uso dei diuretici (farmaci che causano l'eliminazione dei liquidi dai tessuti) in ambito sportivo è motivata dal fatto che questi farmaci inducono un rapido calo ponderale (utile negli sport che prevedono la suddivisione in categorie di peso) e possono mascherare l'identificazione di sostanze proibite in virtù dell'effetto di riduzione della loro concentrazione urinaria. G. Palmieri, V. Pincolini, A. Casti, Doping 2004, cit. 
quelle poste in essere in altri Paesi. ${ }^{10}$ Il potenziale target italiano di tale mercato è desumibile tenendo in considerazione il dato statistico secondo il quale gli individui che praticano regolarmente un'attività sportiva sono circa venticinque milioni: ${ }^{11}$ tra questi gli assuntori, saltuari e assidui, di sostanze vietate possono essere stimati in quasi due milioni. ${ }^{12}$ Desta maggiormente scalpore il dato emerso nel 2005 quando i pediatri dell'ospedale

${ }^{10}$ Secondo G. Spinosa, già P.M. della Procura della Repubblica presso il Tribunale di Bologna, il doping "è un mercato con fatturato miliardario che trae la propria manovalanza dalla malavita organizzata e si dirama in una rete di connessioni e connivenze che vanno dal medico al farmacista complice, al portantino dell'ospedale che trafuga prodotti vietati, al gestore di palestre". Cfr.: G. Spinosa, $L a$ nuova legge antidoping: tutela della salute e uso dei farmaci nella pratica sportiva, in G. Gambogi (a cura di), Profili attuali di diritto sportivo e nuova legge antidoping, Milano, Giuffrè, 2002, pp. 92-94; P. Mennea, L'allarme dei pediatri, in Social News, 2007, VI, pp. 11-12. Per quanto riguarda le indagini condotte all'estero "l'International Drug Policy del dicembre 2003 ha pubblicato un articolo che induce ad una profonda riflessione: una ricerca estesa a dieci anni (dal 1991 al 2001) presso i centri inglesi di assistenza ai tossicodipendenti che fanno uso di siringhe, ha evidenziato un aumento di sei volte degli assuntori di steroidi anabolizzanti ed ormai, tra i nuovi utenti, questa categoria di 'tossicodipendenti' è la più consistente rispetto alle altre, perciò anche rispetto agli eroinomani. La ricerca charity Drug-Scope del settembre 2006 ha indicato un ulteriore incremento: ad esempio, a Liverpool, dal 1994 al 2006, gli assuntori di steroidi anabolizzanti assistiti dai centri per la tossicodipendenza sono passati da 28 a più di 500". A. Donati, I traffici mondali delle sostanze dopanti, in www.libera.it, p. 75. Lo stesso autore aveva precedentemente precisato che: a) "nessuno o quasi si azzarda a dire che il doping rappresenta una piaga tra i militari e tra gli agenti di polizia [...]"; b) "la US DEA ha inoltre messo a conoscenza $[\ldots]$ che molti dei trafficanti di ormoni anabolizzanti coinvolti nelle indagini erano implicati con i traffici di altre droghe, specialmente cocaina"; c) "nel luglio 2005, un'indagine condotta dalla polizia italiana in collaborazione con i colleghi di altri Paesi ha dimostrato il diffuso coinvolgimento nell'assunzione di steroidi anabolizzanti dei soldati statunitensi impegnati in Iraq", mentre un'inchiesta di giornalisti dell'Associated Press erano arrivati ad analoghe conclusioni in Afghanistan ed in Kuwait; d) "all'inizio degli anni Ottanta, l'Ufficio regionale per l'Asia e il Pacifico della International Organization of Consumers Union con sede in Malesia [....] dimostra come [l'industria farmaceutica avesse somministrato] su vasta scala di steroidi anabolizzanti ai bambini denutriti"; e) che "nel Report che le autorità governative statunitensi hanno presentato a Sydney, nel novembre 1999, nel Summit internazionale sul doping nello sport, è indicato che nei mesi precedenti la US DEA aveva arrestato 15 membri della criminalità organizzata russa che avevano importato illegalmente negli Stati Uniti più di due tonnellate di steroidi anabolizzanti"; f) "il 16 marzo 2004, in una audizione davanti al Congresso americano, i responsabili della US DEA hanno affermato che gruppi criminali Russi, Rumeni e Greci sono i principali responsabili dell'importazione illegale degli steroidi negli Stati Uniti”; g) “i Paesi particolarmente rilevanti nella produzione e nell'esportazione delle sostanze e dei farmaci doping [...] sono: la Tailandia, la Cina e l'India"; h) "il 17 ottobre 2005 la multinazionale farmaceutica svizzera Serono è stata condannata dal tribunale di Boston per aver commercializzato in modo illegale, tra i malati di AIDS, il farmaco Serostim, a base di ormone della crescita [...] La gigantesca immissione di Serostim sull'intero mercato statunitense ha inoltre provocato l'esplosione di richiesta di Serostim a cui si è interessata la criminalità organizzata aprendo fabbriche clandestine rifornite di principio attivo dalla Cina o dall'Europa dell'est, per poi immettere nel mercato nero del doping enormi quantità di Serostim contraffatto destinato ai body builder ed agli atleti"; i) sul piano dell'utilizzo delle più moderne tecnologie rileva l'indagine (operazione "Cyber Chase") terminata "il 22 aprile 2005 dalla US DEA in collaborazione con numerosi organismi statunitensi e di altri Paesi" per smascherare "un traffico internazionale di grandi dimensioni realizzato per mezzo della rete internet (più di 200 websites distribuiti in ogni parte del mondo) nel quale la criminalità organizzata indiana, unitamente a quella statunitense, [...] dal luglio 2003 ad aprile 2005, è riuscita a vendere mensilmente circa 2,5 milioni di dosi di sostanze e farmaci doping, cioè circa 30 milioni di dosi annue".

${ }^{11}$ L'ultimo dato Istat disponibile è riferibile all'anno 2016 ed è consultabile in www.istat.it/it/archivio/204663.

${ }^{12}$ A. Rosano, Farmaci o integratori!, in Social News, 2007, VII, p. 1. Si noti anche il dato dallo studio condotto dall'UE su 23.000 centri sportivi in Belgio, Portogallo, Italia e Germania frequentati da circa 16 milioni di persone: il $6 \%$ assumeva regolarmente medicinali che aumentavano le prestazioni. Occorre altresì osservare che questa percentuale è addirittura superiore alla percentuale di atleti dopati $(1,72 \%)$ che le organizzazioni sportive continuano ad accreditare. Etica sport e doping, parere del 25 marzo 2010 della Presidenza del Consiglio dei Ministri, Comitato nazionale per la bioetica. in www.governo.it, p. 25. Un recente studio nel settore sportivo amatoriale ha ricostruito che il numero dei soggetti esposti al doping è di gran lunga maggiore rispetto a coloro che hanno dichiarato di farne uso e che i soggetti che utilizzano sostanze a scopo dopante sono quelli che ricercano maggiormente un aumento delle performance e della competizione, contrariamente a quanto avveniva durante gli anni '80, in cui l'assunzione di sostanze tra sportivi amatoriali avveniva maggiormente per uno scopo edonistico. Secondo questo studio il canale che viene maggiormente utilizzato per l'approvvigionamento di sostanze è la farmacia, in cui gli assuntori ricercano farmaci e integratori per poter recuperare più velocemente dallo sforzo fisico. R. Altopiedi, D. Scarscelli, Sport e devianza: uno studio esplorativo sul consumo di farmaci nello sport amatoriale, in Sociologia dir., 2017, III, pp. 185-207. L'ultimo dato disponibile per quanto riguarda la diffusione del fenomeno in Italia tra i giovani e gli amatoriali risale al 2018 in cui sono stati sottoposti a controllo antidoping 594 atleti, di cui 388 maschi $(65,3 \%)$ e 206 femmine (34,7\%). Il 21,5\% $(\mathrm{n}=128)$ degli atleti sottoposti a controllo antidoping dalla SVD, sono stati esaminati su specifica richiesta dei NAS. Di questi, 104 sono maschi $(81,3 \%)$ e 24 femmine (18,7\%). Dei 594 atleti sottoposti a controllo, 13 sono risultati positivi ai test antidoping (il $2,2 \%$ ); a differenza di quanto registrato negli anni precedenti, nel 2018 non è stata rilevata una significativa differenza di genere tra gli atleti risultati positivi: si osserva infatti che la percentuale di positività è pari al 2,3\% per gli uomini e all'1,9\% per le donne. Tra gli atleti sottoposti a controllo antidoping nel 2018, 320 (il 54,2\%) sono giovani fino a 23 anni di età, 208 (il 35,3\%) sono atleti di età compresa 
Bambino Gesù di Roma segnalarono che il doping era ormai presente anche tra i giovanissimi. ${ }^{13}$ Di fatto esiste anche un doping non sofisticato cagionato da sostanze semplici ed alla portata di tutti, si pensi ai diuretici o alla caffeina, ma il fenomeno che più preoccupa è quello dei consumatori di farmaci nei cui confronti dovrà aumentare l'azione degli educatori sportivi, dei preparatori atletici, e degli insegnanti di educazione fisica delle scuole, oltre quella dei mezzi di informazione. ${ }^{14}$ Orbene, l'atleta non compete solo con l'avversario ma si misura anche con se stesso, nel tentativo di spingersi fino e oltre i propri limiti ${ }^{15}$. È in quest'ultima fase che rischia la tentazione di chiedere aiuto al doping, proprio per evitare il confronto con la propria ansia positiva, allontanandosi dal percorso di autoconsapevolezza su cui si fonda l'attività agonistica e così tradire i valori base dell'attività sportiva: il corretto e leale confronto con sé stessi e con gli altri atleti, nel pieno rispetto dell'avversario e delle regole. Infatti, al danno diretto sulla salute, il doping associa la perdita della vera essenza della cultura sportiva che è la sana attività motoria, la temperanza morale, la costanza nel perseguire il proprio miglioramento fisico e mentale ed il rispetto delle regole e dell'avversario, nonché la fedeltà a quei principi di lealtà e correttezza che rendono il mondo degli sportivi unico e fonte di orgoglio per chi vi appartiene. Un'ultima doverosa considerazione deve essere rivolta nei confronti dei farmaci veterinari. Questi derivano dalla farmacopea per le persone dal momento che la differenza riguarda essenzialmente il grado di purezza e di raffinatezza: quella dei farmaci veterinari è di

tra i 24 ed i 38 anni, mentre 62 (il 10,5\%) sono atleti di oltre 39 anni di età. Prendendo tuttavia in esame la distribuzione percentuale delle positività rispetto alle suddette fasce d'età, si osserva che nei giovani fino a 23 anni, gli atleti positivi rappresentano lo $0,9 \%$ del campione, nella fascia d'età 24-38 anni sono pari al 3,4\% mentre negli over 39 sono pari al 4,8\%, delineando così un trend crescente in funzione dell'aumentare dell'età degli atleti. Inoltre, le percentuali più elevate di positività in rapporto al numero di atleti controllati, sono state registrate in atleti con età superiore ai 44 anni $(8,8 \%)$, mentre la percentuale più bassa è stata registrata tra gli atleti con età inferiore ai 19 anni $(0,8 \%)$. Ministero della Salute e Istituto Superiore di Sanità, Report attività di controllo antidoping (Report antidoping), 2018, p. 8.

${ }^{13}$ Cfr.: Relazione al Parlamento attività antidoping, anno 2005; M. Fanni Canelles, Un giorno da “leoni”, in Social News, 2007, VII, p. 3; P. Mennea, L'allarme dei pediatri, cit., p. 11. I pericoli dell'aumento di consumo di sostanze vietate da parte dei giovanissimi è stato studiato in ambito farmaceutico, infatti, "i molti cambiamenti fisiologici che occorrono durante l'adolescenza comportano una maggiore sensibilità agli effetti farmacologici e alla loro potenziale nocività. La crescita scheletrica, i mutamenti ormonali, le modificazioni cardiologiche sono elementi importanti della fisiologia della pubertà, rispetto ai quali l'abuso di farmaci può causare alterazioni sconosciute. Gli anni dell'adolescenza sono anche molto difficili dal punto di vista psicologico: i giovani atleti possono divenire farmaco-dipendenti per mantenere l'immagine che si sono originariamente costruiti e che hanno attribuito all'uso dei farmaci'. G. Cantelli Forti, La farmacologia nello sport e il doping, cit. Cfr., altresì, L. Mallia, F. Lucidi, A. Zelli, Doping Attitudes and the Use of Legal and Illegal Performance-Enhancing Substances Among Italian Adolescents, in Journal of Child \& Adolescent Substance Abuse, 2013, pp. 179-190.

14 "Non è facile convincere un giovane atleta sui rischi che corre assumendo sostanze dopanti dal momento che l'euforia di poter sostenere sforzi notevoli senza avvertire la stanchezza fa superare ogni paura e ignorare le dovute precauzioni. In realtà il suo cuore deve far fronte a richieste di prestazioni che progressivamente lo affaticano, dovendo provvedere a più estese masse muscolari e far circolare un sangue più denso e viscoso a causa del doping ematico; inizialmente la giovane età può compensare la sovrastimolazione, ma col tempo aumenteranno i rischi di ischemia miocardica e infarto. Contemporaneamente: il fegato viene progressivamente intossicato, facendo aumentare il rischio di patologie epatiche; lo stomaco può essere maggiormente interessato da gastriti e ulcere gastriche e duodenali; possono aumentare le disfunzioni renali col rischio di dover ricorrere precocemente alla dialisi; l'apparato scheletrico viene sollecitato in modo anomalo dando luogo a processi degenerativi e di invecchiamento precoce; i tendini vengono sollecitati da muscoli abnormi e le rotture tendinee nonché le infiammazioni croniche delle strutture legamentose sono spesso diretta conseguenza dell'assunzione incontrollata di sostanze dopanti; l'apparato muscolo scheletrico può incorrere nella decalcificazione ossea, con conseguente osteoporosi; i testicoli possono essere interessati da atrofia dei tessuti. Nelle donne l'assunzione di anabolizzanti induce irregolarità mestruali e accentuazione delle caratteristiche somatiche maschili. Cambio dei caratteri somatici può derivare anche dall'assunzione di ormoni della crescita. Infine, l'assunzione di anfetamine, sostanze tipiche utilizzate per dimagrire nei procedimenti di doping estetico, può comportare gravi irregolarità nei processi metabolici”. G. Palmieri, V. Pincolini, A. Casti, Doping 2004, cit.

${ }^{15}$ L'abnorme espansione del fenomeno doping negli ultimi decenni è legata anche alla grande pressione commerciale e al professionismo sportivo. Infatti, gli interessi commerciali dei sodalizi sportivi prevaricano i principi di lealtà e correttezza mettendo in condizione alcuni atleti, quando le loro condizioni fisiche sono deficitarie, di ricorrere al doping per ottenere l'ingaggio. Anche la febbre del record può indurre all'uso di metodi e sostanze dal momento che l'atleta spera di ottenerne quell'aumento in prestazione che gli possa consentire di diventare il migliore nella propria specialità. G. Cantelli Forti, La farmacologia nello sport e il doping, cit. Rileva la definizione di atleta fornita dalla Convenzione di Strasburgo secondo cui va considerato tale "chiunque partecipa regolarmente ad attività sportive organizzate" (art. 1). Si tratterebbe, quindi, di un'attività caratterizzata da un elemento di carattere cronologico legato all'abitualità (regolarmente) e da un elemento di carattere modale connesso con l'organizzazione (organizzate). 
standard meno elevato, soprattutto negli steroidi anabolizzanti utilizzati sugli animali allo scopo di gonfiarne i muscoli ed aumentarne sensibilmente il peso oppure per accentuarne la potenza. ${ }^{16}$

\section{Farmaci ed integratori, normativa vigente}

In base all'art. 1, comma primo, del d.lgs. 24 aprile 2006, n. $219^{17}$ deve intendersi come medicinale

1) ogni sostanza o associazione di sostanze presentata come avente proprietà curative o profilattiche delle malattie umane; 2) ogni sostanza o associazione di sostanze che può essere utilizzata sull'uomo o somministrata all'uomo allo scopo di ripristinare, correggere o modificare funzioni fisiologiche, esercitando un'azione farmacologica, immunologica o metabolica, ovvero di stabilire una diagnosi medica; ogni sostanza o composizione presentata come avente proprietà curative o profilattiche delle malattie umane o animali, nonché ogni sostanza o composizione da somministrare all'uomo o all'animale allo scopo di stabilire una diagnosi medica o di ripristinare, correggere o modificare funzioni organiche dell'uomo o dell'animale.

Si può plausibilmente affermare che la categoria dei farmaci che qui interessa tenere in considerazione è quella che appartiene al gruppo delle amine simpatico-mimetiche (anfetamina e suoi derivati) il cui principale effetto è di attenuare la sensazione di fatica, consentendo uno sforzo maggiore e più a lungo, agendo sul sistema nervoso centrale, creando eccitazione e provocando maggior lucidità psichica, prontezza di esecuzione e coordinazione di movimenti. In realtà la casistica d'interesse abbraccia anche la compagine dei farmaci contraffatti, quelli che di fatto difficilmente sono equivalenti, per qualità, sicurezza ed efficacia, ai farmaci originali. Infatti, anche quando sono di qualità adeguata e contengono la corretta quantità di principio attivo, la loro produzione non avviene secondo le cosiddette "norme di buona fabbricazione" (NBF). La potenziale pericolosità di un farmaco contraffatto può riguardare tutti i suoi componenti (il principio attivo che può essere assente, sotto dosato o diverso da quello dichiarato e/o gli eccipienti), il confezionamento, la non idonea conservazione, la possibilità che a farmaci scaduti vengano apposte nuove etichette con nuove date di scadenza. Per contrastare il fenomeno del commercio dei farmaci contraffatti è stato attuato il "progetto tracciabilità", attivato con il d.m. 15 luglio 2004, che consente di monitorare anche telematicamente tutte le transazioni di farmaci nella filiera legale attraverso un codice identificativo attribuito a tutti i soggetti coinvolti nel ciclo di vita di un medicinale, registrando le transazioni di tutte le confezioni trasmesse in una banca dati centrale. ${ }^{18}$ Infatti, grazie al quadro legislativo

16 "Essi sono stati studiati sugli atleti. È per questa ragione che presentano un grado di efficacia tale da poter essere utilizzati anche nell'essere umano. Sarà molto difficile che li assumano gli atleti di alto livello o i comuni praticanti sportivi che possiedono un minimo di informazioni e di disponibilità economiche, ma sarà piuttosto facile che li assumano frequentatori di palestre o sportivi amatoriali di più basso livello culturale o per i quali è importante risparmiare [...] secondo l'Associazione Australiana dei medici veterinari, è ben noto che una notevole percentuale degli steroidi anabolizzanti venduti nel mercato nero internazionale sono prodotti in Australia. In effetti, in un Report commissionato l'anno scorso dal Consiglio dei ministri, l'Australia è stata descritta come la capitale mondiale degli steroidi anabolizzanti ed è stato precisato che c'è un progressivo coinvolgimento della criminalità organizzata nei traffici illeciti di questi farmaci". A. Donati, I traffici mondali delle sostanze dopanti, cit., p. 94.

17 D.lgs. 24 aprile 2006, n. 219 "Attuazione della direttiva 2001/83/CE (e successive direttive di modifica) relativa ad un codice comunitario concernente i medicinali per uso umano, nonché della direttiva 2003/94/CE".

${ }^{18}$ Gestita dalla Direzione generale del sistema informativo del Ministero del lavoro, della salute e delle politiche sociali. Cfr. Linee guida per la predisposizione e la trasmissione dei file alla banca dati centrale, dicembre 2014, www.salute.gov.it, nella cui premessa è indicato che "l'art. 40 della legge 1 marzo 2002, n. 39, con l'inserimento dell'art. 5-bis nel d.lgs. 30 dicembre 1992, n. 540, prevede l'istituzione presso il Ministero della salute di una Banca dati centrale che, partendo dai dati di produzione e fornitura dei bollini numerati dei prodotti medicinali, raccolga e registri i movimenti delle singole confezioni. L'art. 40 stabilisce, inoltre, che tutti gli attori della filiera (produttori, depositari, grossisti, farmacie aperte al pubblico, centri sanitari autorizzati all'impiego di medicinali, aziende sanitarie locali e smaltitori) sono tenuti ad archiviare e trasmettere a tale Banca dati il codice prodotto ed il numero identificativo (numerazione progressiva del bollino) di ciascun pezzo uscito e la relativa destinazione, mentre coloro che ricevono sono tenuti ad archiviare il codice prodotto ed il numero identificativo di ciascun pezzo ricevuto. Il d.m. 15 luglio 2004 ha istituito la Banca dati definendone le regole per l'alimentazione, in attuazione del modello teorico definito dalla Legge 39/2002. Il campo di applicazione del d.m. 15 luglio 2004 è rappresentato da tutti $\mathrm{i}$ prodotti medicinali ad uso umano immessi in commercio in Italia, disciplinati dal d.lgs. 219/2006 (già d.lgs. 178/91)". La vigilanza e il controllo sui farmaci contraffatti è invece demandata all'agenzia italiana del farmaco (AIFA), al Ministero della salute, al Ministero dello 
delineato dal d.lgs. n. 219/2006, dal d.1. n. 223/2006 (conv. 1.4 agosto 2008, n. 248) e dal d.lgs. n. 274/2007, ${ }^{19}$ tutti i soggetti coinvolti nel ciclo di vita di un medicinale sono noti, in quanto oggetto di un provvedimento di autorizzazione o di notifica della loro attività. È pertanto possibile identificare i responsabili di eventuali attività illecite. Si noti che la responsabilità per i danni che la somministrazione di farmaci può causare ai pazienti ricade principalmente sulle case farmaceutiche ed i farmacisti. ${ }^{20} \mathrm{Il}$ farmacista può essere chiamato a rispondere per $\mathrm{i}$ danni subiti dal paziente in seguito alla somministrazione di una sostanza, solo nel caso di cattiva conservazione del prodotto. Invece, in capo al medico, oltre ad una responsabilità, a titolo di colpa, connessa all'utilizzo di farmaci, sussiste una responsabilità per i danni causati da cose in custodia. Al fine di contrastare tale linea di tendenza si è provveduto ad integrare quanto previsto dal d.m. 24 ottobre 2006, recante "modalità di trasmissione, da parte dei farmacisti, dei dati relativi alle quantità di principi attivi, appartenenti alle classi indicate nella lista dei farmaci e delle sostanze biologicamente o farmacologicamente attive e delle pratiche mediche, il cui impiego è considerato doping, ai sensi dell'articolo 2 della legge 14 dicembre 2000, n. 376, utilizzati nelle preparazioni estemporanee", con il d.m. 18 novembre $2010,{ }^{21}$ da leggere in relazione alle modifiche introdotte nella Lista delle sostanze vietate per doping con il decreto del 16 aprile 2018. Ai sensi dei suddetti decreti sono stati acquisiti, dalla Sezione di vigilanza, i dati da parte delle farmacie che allestiscono tali preparazioni e sono stati analizzati insieme alle dichiarazioni rese dagli atleti sottoposti ai controlli antidoping. ${ }^{22}$ I dati riferiti hanno confermato la tendenza dei praticanti l'attività sportiva ad assumere anche grandi quantità di farmaci non vietati per doping e di prodotti salutistici. Ovviamente, se introduciamo il concetto di prodotto salutistico non possiamo non affrontare la questione dell'integrazione dietetica, ovvero il ricorso a determinate sostanze che l'organismo umano consuma in misura superiore, quando viene sottoposto a sforzo fisico, rispetto ai periodi di inoperatività e che lo stesso organismo non è in grado di ripristinare adeguatamente senza un'introduzione suppletiva. Per fronteggiare tale carenza sovente si fa ricorso ai c.d. "nutrienti", integratori alimentari composti da sostanze comunemente presenti

sviluppo economico, all'Istituto superiore di sanità (ISS), ai carabinieri dei NAS, all'Agenzia delle dogane, al Ministero dell'Interno, alla Direzione centrale di polizia criminale (attraverso la quale sono coinvolte tutte le altre forze di polizia).

${ }^{19}$ D.lgs. 29 dicembre 2007, n. 274 "Disposizioni correttive al decreto legislativo 24 aprile 2006, n. 219, recante attuazione della direttiva 2001/83/CE relativa ad un codice comunitario concernente medicinali per uso umano".

${ }^{20} \mathrm{Si}$ cita ad esempio la nota vicenda del Trilergan, farmaco prodotto in Italia sulla base di varie componenti, fra cui un emoderivato, le gammaglobuline, importato dagli Stati Uniti e risultato infetto da HBV. La Corte di Cassazione, prima, (Cass. pen., 15 luglio 1987, n. 6241; Cass. pen., 27 luglio 1991, 8395, in www.pluris-cedam.utetgiuridica.it) e le corti di merito, in seguito, (App. Roma 17 ottobre 1990; Trib. Milano, 19 novembre 1987, in www.dejure.it) hanno riconosciuto la pericolosità dell'attività di produzione di farmaci $\mathrm{e}$ sancito l'applicabilità a tale attività dell'art. 2050 c.c., che stabilisce che: chiunque cagiona danno ad altri nello svolgimento di un'attività pericolosa, per sua natura o per la natura dei mezzi adoperati, è tenuto al risarcimento, se non prova di avere adottato tutte le misure idonee ad evitare tale danno. Il farmacista può essere chiamato a rispondere per i danni subiti dal paziente in seguito alla somministrazione di una sostanza, solo nel caso di cattiva conservazione del prodotto.

${ }^{21}$ Pubblicato nella G.U. n. 3 del 5 gennaio 2011, serie generale.

22 "La Sezione, attraverso il sistema informativo Reporting System Doping Antidoping, realizzato in collaborazione con l'Istituto Superiore di Sanità, ha svolto anche per il 2018 una elaborazione dei dati relativi all'uso da parte degli atleti di farmaci e/o prodotti salutistici consentiti, in base alle dichiarazioni rese da coloro che sono stati sottoposti ai controlli antidoping. I dati riferiti hanno confermato la tendenza dei praticanti l'attività sportiva ad assumere grandi quantità di farmaci non vietati per doping e di prodotti salutistici. "Tra gli atleti sottoposti a controllo, 417 ( $70,2 \%$ del totale) hanno dichiarato di aver assunto prodotti farmaceutici (compresi i prodotti omeopatici) e prodotti salutistici in genere (vitamine, sali minerali, aminoacidi, integratori) e 177 atleti $(29,8 \%)$ hanno dichiarato di non aver assunto alcun prodotto. Analizzando in dettaglio la distribuzione per sesso di coloro che hanno assunto prodotti non vietati per doping, si osserva che le donne sono quelle che in maggior numero hanno dichiarato di fare uso di queste sostanze. La percentuale delle atlete sul totale delle donne controllate è risultata pari al 76,7\% contro il 66,8\% degli uomini. [...] Relativamente alla tipologia dei prodotti assunti, dunque, il consumo di farmaci rappresenta il 64,4\% di tutte le dichiarazioni di assunzione di prodotti non vietati (farmaci e prodotti salutistici), consumo in aumento rispetto al 48,9\% registrato nel 2017. In particolare, risulta che i Farmaci Antinfiammatori Non Steroidei (FANS) sono i farmaci il cui uso è più frequentemente dichiarato dagli atleti: 321 dichiarazioni di assunzione pari al 30,2\% sul totale (1.062) delle preparazioni dichiarate (farmaci e/o prodotti salutistici) e al 46,9\% sul totale (684) dei farmaci utilizzati”. Report antidoping, 2018, pp. 23-25.

Gli integratori utilizzati sono rappresentanti per lo più da sali minerali, vitamine, aminoacidi e derivati ed integratori alimentari derivanti da formulazioni di varie associazioni dei prodotti sopraindicati o prodotti di erboristeria (p. 29). Particolarmente diffuso è risultato anche il consumo di farmaci antinfiammatori c.d. FANS (p. 32) spesso utilizzati non solo per lenire il dolore prima della gara o dell'allenamento, ma anche con l'erronea convinzione di prevenirne l'insorgenza. 
nel cibo, selezionate e concentrate industrialmente sotto forma di capsule, bustine, bevande, ecc., allo scopo di consentire più facilmente la copertura del fabbisogno giornaliero. In realtà una corretta alimentazione può compensare lo stato di necessità di apporto calorico giornaliero in relazione alle caratteristiche individuali, al tipo di sport praticato, alla durata, all'intensità ed alla frequenza degli allenamenti, nonché distribuito correttamente in relazione agli orari di allenamenti e gare. ${ }^{23}$ In caso di scelte nutrizionali particolari o assunzione di integratori sarebbe sempre opportuno un monitoraggio del medico nutrizionista, affinché nulla venga lasciato all'improvvisazione, dal momento che la notevole disponibilità di integratori alimentari, ${ }^{24}$ liberamente venduti senza prescrizione medica, può generare enorme confusione in ordine alla loro funzione ed efficacia ed in relazione alla posologia. ${ }^{25} \mathrm{Si}$ noti quanto stabilito dalla direttiva n. 2002/46/CE in base alla quale "gli integratori alimentari sono i prodotti alimentari destinati ad integrare la dieta normale e che costituiscono una fonte concentrata di sostanze nutritive o di altre sostanze aventi un effetto nutritivo o fisiologico". Le indicazioni della direttiva sono confluite nelle linee guida del Ministero della salute sugli integratori alimentari e alimenti arricchiti che indicano quali sono le varie categorie di integratori che non possono essere considerati "dietetici" in quanto non sono concepiti per rispondere ad esigenze nutrizionali o condizioni fisiologiche particolari ed il cui impiego ha il solo scopo di ottimizzare gli apporti nutrizionali e di fornire sostanze nutrizionali con effetto protettivo o trofico sui tessuti e per migliorare il metabolismo e le funzioni fisiologiche dell'organismo. ${ }^{26}$ Non essendo considerati farmaci, non sono sottoposti ad una rigorosa regolamentazione. Per quelli ad uso sportivo è prevista l'autorizzazione ministeriale, per altri la semplice notifica ministeriale, ma ve ne sono innumerevoli altri, come i prodotti salutistici (dai prodotti erboristici e dietetici a quelli omeopatici, dagli antiossidanti alle tavolette energetiche), che possono contenere sostanze dopanti. ${ }^{27}$ Una legislazione specifica che regolamenti il settore alimentare non esiste anche se la

23 "Le finalità di una lotta efficace contro il doping sembrano rivelare una mancanza di coerenza, che deriva dalla diversità dei singoli obiettivi. Lo scopo del mondo sportivo è innanzitutto il miglioramento delle prestazioni e la farmacopea, sia legale che illegale, rientra in questa logica. L'industria farmaceutica e l'industria degli integratori alimentari hanno lo scopo di ottimizzare i benefici offerti. Il mondo sportivo non rappresenta che una parte del loro mercato e la loro cattiva gestione delle vendite di prodotti con caratteristiche dopanti sono in molti casi il risultato più di una cattiva informazione delle richieste delle autorità antidoping che dell'intenzione di nuocere". C. Brissonneau, Il doping nello sport professionale, cit., p. 7.

${ }^{24}$ Secondo quanto indicato dal Ministero della salute col d.m. 19 novembre 2002 in G.U. n. 297, 19 dicembre 2002, suppl. ordinario, tra i prodotti dietetici erano compresi gli alimenti adattati ad un intenso sforzo muscolare, soprattutto per gli sportivi, e comprendono: a) prodotti finalizzati alla integrazione energetica; b) prodotti contenenti minerali per reintegrare le perdite idrosaline; c) prodotti per l'integrazione proteica; d) prodotti finalizzati all'integrazione di aminoacidi e derivati; e) altri prodotti con valenza nutrizionale, adattati ad un intenso sforzo muscolare; f) combinazione dei suddetti prodotti. G. Palmieri, V. Pincolini, A. Casti, Doping 2004, cit.

${ }^{25}$ Pur non configurando doping, l'assunzione di integratori provoca un aumento di sostanze già disponibili per l'organismo in quantità superiore al fabbisogno col rischio di concretizzare interventi farmacologici correttivi. L'assunzione di integratori è una pratica che ha forti affinità con la relativa cultura, ovvero con l'idea di intervenire farmacologicamente sul proprio corpo allo scopo di aumentarne le prestazioni. A. Rosano, Farmaci o integratori!, cit., p. 13.

${ }^{26}$ Essi sono: 1) integratori di vitamine e/o minerali; 2) altri fattori simil-vitaminici; 3) altri fattori nutrizionali; 4) aminoacidi; 5) derivati di aminoacidi di interesse nutrizionale; 6) integratori di proteine e/o energetici; 7) integratori per migliorare la prestazione sportiva; 8) integratori lipidici; 9) integratori biologico-vitaminici; 10) estratti ghiandolari d'organo; 11) enzimi; 12) integratori di fibra; 13) integratori per dimagrire; 14) complementi vegetali come ingredienti negli integratori alimentari utilizzati per il loro effetto anti ossidante. Emblematico è il caso dell'utilizzo della creatina come integratore nella pratica sportiva dal momento che non è una sostanza dopante nel senso tradizionale del termine, in quanto si tratta di una molecola fisiologica fondamentale per il metabolismo energetico. $\mathrm{Al}$ momento non v'è prova che la creatina stimoli direttamente la sintesi proteica muscolare e quindi non sembra essere dimostrabile un qualsiasi effetto anabolico anche se si può affermare che esiste un reale effetto ergogenico dell'integrazione con creatina valido essenzialmente solo per sforzi brevi, intensi e ripetuti. In Italia la creatina è commercializzata tra gli "alimenti destinati ad una alimentazione particolare" sia come integratore alimentare per la popolazione normale sia come alimento speciale adattato ad un'intensa attività sportiva ai sensi del d.lgs. 27 gennaio 1992, n. 111, e agli sportivi, in maniera specifica, ai sensi dell'Allegato I del decreto. Le modalità di commercializzazione sono state definite con la Circolare del Ministero del lavoro, della salute e delle politiche sociali del 5 novembre 2009 riportante le Linee guida sugli alimenti adattati ad un intenso sforzo muscolare soprattutto per gli sportivi. In tale circolare l'uso di creatina viene comunque controindicato in soggetti di età inferiore ai 14 anni.

${ }^{27}$ Accade spesso che vengano commercializzati illegalmente integratori provenienti da Paesi non soggetti a rigidi controlli sulla produzione (Cina in particolare) contenenti sostanze potenzialmente dannose e con etichettatura truccata. La Sezione di vigilanza antidoping, nell'ambito delle attività previste ai sensi dell'art. 3, comma primo, lett. $c$ ) ed $f$ ) della legge 376/2000, ha finanziato un progetto finalizzato all'analisi farmaco-tossicologica di integratori alimentari utilizzati in ambito sportivo e mappatura nazionale dell'offerta. L'obiettivo finale della ricerca è stato quello di verificare, in un campione di integratori utilizzati dai praticanti attività sportiva, la 
Circolare del Ministero del Lavoro, della Salute e delle Politiche Sociali del 5 novembre $2009^{28}$ all'Allegato 1 contiene le "Linee guida sulla composizione, etichettatura e pubblicità dei prodotti adattati ad un intenso sforzo muscolare, soprattutto per gli sportivi" che sono state semplificate ed aggiornate rispetto a quelle della Circolare n. 3 del 30 novembre 2005 del Ministero della Sanità, ${ }^{29}$ per evitare le sovrapposizioni tra le interpretazioni di integratori e prodotti dietetici, non essendo ancor'oggi intervenuti sviluppi normativi comunitari, in attesa della direttiva comunitaria, continua ad applicarsi ai prodotti dietetici per sportivi la procedura di notifica dell'etichetta ai sensi dell'art. 7 del d.lgs. n. 111/1992, secondo le modalità previste dalla circolare 17 luglio 2000, n. 11. Nel merito rileva il dettato dell'art. 10 della legge 26 novembre 2007, n. 230, recante "Ratifica ed esecuzione della Convenzione internazionale contro il doping nello sport, con allegati, adottata a Parigi nella XXXIII Conferenza generale UNESCO il 19 ottobre 2005", che stabilisce che gli Stati parte devono incoraggiare "i produttori ed i distributori di integratori alimentari a stabilire buone pratiche per la commercializzazione e la distribuzione dei suddetti integratori, ed in particolare a fornire informazioni circa la composizione analitica di tali prodotti e il certificato di qualità". ${ }^{30}$

\section{Le nuove frontiere del doping}

Fra le più recenti frontiere del doping annoveriamo certamente quello genetico ${ }^{31}$ la cui definizione è stata fornita dalla WADA che, a partire dal 2001, ha sviluppato una strategia di monitoraggio di tale fenomeno quando

presenza di sostanze vietate per doping e/o altre sostanze di interesse tossicologico. Cfr. Relazione al Parlamento attività antidoping, anno 2010. Il mercato degli integratori alimentari vale circa un miliardo di euro l'anno per l'Italia e riguarda il mondo dello sport ma anche quello delle diete. Tali prodotti possono essere una vera trappola per l'atleta dal momento che per immettere sul mercato un integratore non c'è bisogno di alcuna autorizzazione ma è sufficiente una semplice autocertificazione della composizione inviata al ministero competente. Dunque è possibile immettere nel mercato, senza alcun controllo, qualsiasi sostanza: metandienone, stanozololo, boldenone, nandrolone, fra gli anabolizzanti più noti, oltre stimolanti come efedrina, anfetamine varie, ecc. Interessante in proposito è lo strumento predisposto dal Global Drug Reference Online (Global DRO), istituzione a cui aderiscono alcune National antidoping organisations, che ha predisposto un motore di ricerca consultando il quale gli atleti possono verificare se una sostanza presente nei farmaci o negli integratori da loro assunti è presente all'interno della lista delle sostanze proibite dalla WADA.

${ }^{28}$ In G.U. n. 277 del 27 novembre 2009, serie generale.

${ }^{29}$ Oltre a dettare la composizione delle sostanze, per quanto riguarda l'etichettatura, la circolare prescrive l'inserimento di: "una dicitura del tipo: Il prodotto va utilizzato nell'ambito di una dieta variata ed equilibrata ed uno stile di vita sano. Per i concentrati proteici e/o aminoacidici, come per la presenza di creatina, va riportata anche la seguente avvertenza: Non superare le quantità di assunzione consigliate. Non utilizzare in gravidanza e nei bambini, o comunque per periodi prolungati senza sentire il parere del medico. La pubblicità deve essere coerente con le proprietà rivendicate in etichetta, non deve indurre in errore sul ruolo dei prodotti o promuovere un consumo non compatibile come componente di una adeguata razione alimentare. Inoltre, non deve tendere a far credere che una dieta equilibrata e variata non sia in grado di soddisfare i fabbisogni nutrizionali, né a sottovalutare l'esigenza di seguire una dieta adeguata e un sano stile di vita". Per quanto riguarda la composizione degli integratori rileva anche il "Provvedimento del 15 febbraio 2007 - Intesa, ai sensi dell'articolo 13 del d.lgs. 21 maggio 2004, n. 169, sul piano di vigilanza, per l'anno 2007, sugli integratori alimentari commercializzati come prodotti alimentari e presentati come tali”, adottato in seno alla Conferenza permanente per i rapporti tra lo Stato e le Regioni e le Province autonome di Trento e di Bolzano, (pubblicato in G.U. n. 57 del 9 marzo 2007, serie generale) in cui all'art. 2 del Provvedimento sono specificate le finalità di vigilanza sull'inserimento di alcune sostanze vegetali all'interno degli integratori alimentari: “1. Il piano di vigilanza per l'anno 2007 prevede che l'attività di controllo venga effettuata, con specifiche verifiche ispettive, presso strutture di vendita e di distribuzione di integratori alimentari, comprese palestre, centri fitness e simili. 2. Tali controlli hanno lo scopo di verificare, attraverso l'esame dell'etichetta, che gli integratori addizionati con ingredienti vegetali non contengano gli estratti vegetali non ammessi dal Ministero della salute, evidenziati nell'Allegato 1. 3. Le piante e derivati, evidenziati nell'Allegato 1, rappresentano ingredienti non ammissibili negli integratori alimentari; le ragioni di natura sanitaria e la valenza tossicologica delle sostanze di origine vegetale incluse nella predetta lista negativa, sono state valutate ed esplicitate dalla Commissione consultiva per i prodotti destinati a un'alimentazione particolare, oggi Commissione unica per la dietetica e la nutrizione (CUDN)". Questo provvedimento è stato più di recente affiancato dal d.m. del Ministero della salute del 9 luglio 2012 sulla "Disciplina dell'impiego negli integratori alimentari di sostanze e preparati vegetali” in G.U. n. 169 del 21 luglio 2012, serie generale, che integra il d.lgs. 21 maggio 2004, n. 169 di attuazione della direttiva europea sugli integratori alimentari (2002/46/CE).

30 "Si è inteso così dare attuazione, da parte di tutti gli Stati aderenti all'UNESCO, a misure adeguate (leggi, regolamenti, politiche o prassi amministrative) a livello nazionale e internazionale, conformemente a quanto sancito dal Codice mondiale antidoping. Tale Convenzione detta espressamente un richiamo al settore degli integratori alimentari, disponendo che produttori e distributori degli stessi devono fornire informazioni sulla composizione analitica di tali prodotti e il certificato di qualità". L. Di Nella, Manuale di diritto dello sport, Roma, Ed. Scientifiche Italiane, 2010, p. 309.

31 "DOPING GENETICO: Impiego a fini non terapeutici di cellule, geni, componenti genetici e/o in grado di modulare l'espressione 
la commissione medica del CIO si riunì per discutere le possibili implicazioni delle terapie geniche. Infatti, oltre ad aggiornare annualmente la lista delle sostanze e pratiche vietate nonché la concessione di esenzione per fini terapeutici, l'ente tiene conto dei progressi dell'ingegneria biogenetica mondiale all'uopo inserendo il doping genetico nella "lista delle sostanze e metodi proibiti", ${ }^{32}$ definendolo come "uso non terapeutico di cellule, geni ed elementi genetici o della modulazione dell'espressione genetica, con capacità di aumentare le prestazioni atletiche" (AMA-WADA, 2008). ${ }^{33}$ Sul piano prettamente scientifico, la terapia genica consiste nel trasferimento di materiale genico (DNA, RNA, o cellule geneticamente alterate) nelle cellule umane per il trattamento o la prevenzione di una malattia ${ }^{34}$ o di una disfunzione, ovvero per compensare il gene assente o sostituire quello anormale. Le informazioni fornite dalla comunità scientifica attestano che tutti i livelli di proteine presenti all'interno dell'organismo possono essere modulati attraverso la terapia genica ma le alterazioni delle linee germinative sono permanenti e vengono trasmesse anche alla prole: in questo caso, oltre al possibile rischio per la salute degli atleti, esistono anche dei rischi nei confronti dei posteri. Per la farmacogenetica l'obiettivo principale è quello di sviluppare medicine fatte su misura per ciascun individuo, ma molte di queste hanno un effetto completamente diverso a seconda di chi le assume dal momento che spesso non viene tenuto conto delle caratteristiche genetiche individuali, ma vengono sottoposti farmaci sperimentali creati su uno schema standardizzato per alcune categorie di persone. ${ }^{35}$ Se fossero applicabili agli atleti gli esiti degli esperimenti di terapia genica per malattie come l'ischemia cardiaca, oppure l'insufficienza arteriosa periferica ne risulterebbe un incremento del contenuto di ossigeno e nutrienti ai tessuti, ma soprattutto la possibilità di posticipare l'esaurimento del muscolo, sia cardiaco che scheletrico. ${ }^{36}$ Teoricamente la terapia genica è autorizzata esclusivamente per la sperimentazione clinica di prodotti di terapia genica somatica nell'uomo, escludendo tassativamente la possibilità di considerare proponibile qualsiasi tipo di terapia genica della linea germinale

genica, aventi la capacità di indurre un miglioramento delle prestazioni atletiche (definizione di doping genetico della WADA, World anti-doping agency). Un esempio di doping genetico è l'impiego di terapie geniche in via di sviluppo per il trattamento di patologie degenerative che agiscono a livello neuromuscolare o, più in generale, che interessano l'apparato locomotore". A. Greco, F. Botrè, Doping genetico (ad vocem), in Enciclopedia della Scienza e della Tecnica, www.treccani.it.

${ }^{32} \mathrm{Nel}$ definire il doping si è preferito effettuare il rinvio ad un elenco di comportamenti. In pratica la WADA non fornisce una definizione univoca e stringente del fenomeno, ma indica quali sono i comportamenti, fattivi o omissivi, vietati che nel loro insieme compongono la classe dei metodi ed attività dopanti, che in quanto tali sono disciplinarmente perseguiti dal Codice.

${ }^{33}$ La conferenza sul doping genetico che si è tenuta nel marzo del 2002 da parte di WADA e il Congresso Europeo del lavoro sull'armonizzazione e gli sviluppi futuri della politica antidoping che si è svolto ad Arnhem (Olanda), nello stesso anno, hanno dato la possibilità alla comunità scientifica, governi, organizzazioni antidoping e industrie farmaceutiche, di scambiarsi qualsiasi tipo di informazione sui risultati delle ricerche e dei metodi di rilevazioni riguardo questa nuova tecnica di doping. A partire dal $1^{\circ}$ gennaio del 2003 il CIO ha incluso il doping genetico nella lista delle classi di sostanze e metodi proibiti. Dal 2004 WADA si è assunta la responsabilità di pubblicare la lista internazionale del doping, che viene aggiornata ogni anno. La WADA ha giustificato il divieto del doping genetico attraverso i seguenti punti: a) prova scientifica, effetto o esperienza farmacologica provati, che le sostanze o metodi inclusi nella lista hanno la capacità di aumentare le prestazioni sportive; b) l'uso della sostanza o del metodo causa un rischio, vero o presunto, per la salute dell'atleta; c) l'utilizzo del doping viola lo spirito dello sport. Questo spirito è descritto nell'introduzione del Codice con riferimento a una serie di valori come l'etica, il fair play, l'onestà, la salute, il divertimento, l'allegria e il rispetto delle regole. Codice Mondiale Antidoping (versione $1^{\circ}$ gennaio, 2003), p. 16.

${ }^{34}$ Secondo prevalente giurisprudenza deve essere considerata malattia “qualsiasi alterazione anatomica o funzionale dell'organismo, ancorché localizzata, di lieve entità e non influente sulle condizioni generali”. Cass. pen., sez. V, 2 febbraio 1984, n. 1564, in www.pluris-cedam.utetgiuridica.it.

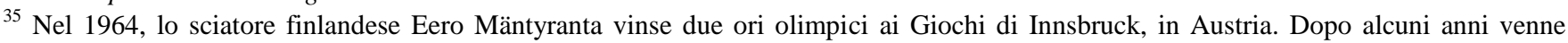
dimostrato che l'atleta era portatore di una rara mutazione nel gene per il recettore dell'eritropoietina con conseguente aumento nella capacità di trasporto dell'ossigeno e quindi incremento della resistenza alla fatica. In seguito, adeguate ricerche appurarono che egli ed altri membri della sua famiglia erano portatori di una rara mutazione del gene che produce l'ormone EPO. Venne quindi assolto, poiché il vantaggio di cui godeva proveniva dalla sua costituzione genetica e non da pratiche esterne, cui altri atleti in seguito cominciarono a ricorrere per ottenere lo stesso vantaggio (soggiorni di allenamento in altura, uso di tende iperbariche, introduzione dell'EPO con metodologie sempre più sofisticate). Etica sport e doping, cit., p. 16.

${ }^{36}$ I geni bersaglio della modificazione genetica negli atleti appartengono fondamentalmente a tre categorie: quelli mirati ad aumentare la massa muscolare; quelli che mirano ad aumentare la capacità di trasporto dell'ossigeno (tra cui troviamo l'eritropoietina o EPO, già una sostanza dopante per sé); quelli mirati ad aumentare la soglia del dolore (come le endorfine), la cui aumentata espressione fornisce all'atleta un vantaggio competitivo. Cfr. S. Camporesi, M. Mcnamee, Bioethics, Genetics and Sport, UK, Taylor \& Francis, 2018. 
umana. ${ }^{37}$ Utilizzare farmaci o geni in grado di migliorare la performance, presenta sempre un certo rischio, in quanto essi vengono studiati per curare le persone malate e non per aumentare le prestazioni di quelle sane come gli atleti. Le organizzazioni sportive hanno dedicato un notevole impegno al fine di contrastare questo fenomeno: ${ }^{38}$ la proibizione del doping genetico da parte della WADA e delle FSI fornisce una base forte per la sua eliminazione nello sport ma tutto dipenderà anche da come verranno accolte le varie regolamentazioni da parte degli atleti. Infatti, la maggior parte degli atleti non ha sufficiente cognizione del potenziale effetto negativo del doping genetico. ${ }^{39}$ In tale ambito solo una corretta attività di informazione rivolta a tutti $i$ soggetti dell'ordinamento sportivo potrà prevenirne il ricorso. È doveroso soggiungere che non sono state ancora stabilite con esattezza le modalità di rilevazione del doping genetico, anche perché il DNA che si trasferisce con la terapia genica è di origine umana e quindi non diverso da quello degli atleti che non ne fanno uso. ${ }^{40}$ Le terapie muscolari sono confinate al sito d'iniezione o al tessuto nelle dirette vicinanze, quindi, la maggior parte delle tecnologie geniche sui muscoli non potranno essere rilevate attraverso le classiche analisi antidoping dei campioni di urina o di sangue; sarebbe necessaria una biopsia muscolare che, però, risulta troppo invasiva per poter essere concepita come normale mezzo di controllo antidoping. Il relativo metodo di accertamento clinico è il matching, ovvero l'analisi comparativa del profilo del DNA ottenuto da tracce biologiche raccolte sul posto con altre in possesso. Ma il prelievo di un campione biologico finalizzato al matching deve essere attuato previo consenso informato (preventiva e completa informazione in ordine al tipo di trattamento, ai rischi ed agli effetti collaterali). ${ }^{41}$ Ancora irrisolto è il tema dell'utilizzo dei campioni di DNA in ordine alla protezione dei dati sensibili ed al rispetto delle fondamentali libertà personali dal momento che può fornire informazioni sui tratti ereditari così svelando

${ }^{37}$ Le regole sulla responsabilità professionale in generale sono applicabili anche all'ambito delle attività di sperimentazione. Non sorgono dubbi in ordine alla diretta applicabilità, in questo contesto, di quanto previsto dall'art. 2050 c.c. che sancisce l'obbligatorietà di adottare tutte le misure idonee ad evitare il danno. La colpa professionale va valutata con particolare rigore, giacché l'attività sperimentale richiede particolare diligenza, prudenza e perizia e non una loro eventuale attenuazione, fermo restando quanto previsto dalle norme vigenti in materia di responsabilità dello sperimentatore e dello sponsor nel merito della sperimentazione e delle sue conseguenze (spetta ai comitati etici indipendenti di approvare l'esecuzione delle singole sperimentazioni e i relativi protocolli sperimentali ed i documenti connessi, fatte salve le competenze attribuite al Ministero della sanità). Cfr. Recepimento delle linee guida dell'UE di buona pratica clinica per l'esecuzione delle sperimentazioni cliniche dei medicinali, in www.ausl.rn.it.

${ }^{38}$ Il direttore del Centro di genetica molecolare dell'Università di San Diego (USA) e consulente della WADA, ha svolto uno studio in cui ha evidenziato che già da diversi anni è possibile manipolare il genoma, modificare il DNA per migliorare le prestazioni atletiche, aumentare la produzione di globuli rossi nel sangue e l'ossigeno nei tessuti, gonfiare i muscoli, alzare la soglia del dolore, modificare il metabolismo introducendo nel corpo il "gene del vincitore". Alto è il rischio che qualcuno utilizzi le stesse tecnologie per migliorare le performances sportive con effetti irreversibili per chi si presta ad esperimenti di ingegneria umana. Si può divenire più resistenti alla fatica ma si rischiano reazioni organiche potenzialmente sconosciute che potrebbero avere conseguenze imprevedibili per la salute. Nelle conclusioni l'autore ammette che non esistono test per individuare le manipolazioni genetiche. T. Friedmann, Gene Doping and Sport, in Science, 2010, 327, pp. 647-648.

39 "Ancora molta incertezza circonda l'effettiva praticabilità di questa forma di doping. Occorre, infatti, ricordare che, allo stato delle attuali conoscenze, l'uso del trasferimento genico nei programmi di terapia genica somatica (iniziati già a partire dai primi anni Novanta) non ha ancora dato i risultati sperati e, talora, è stato accompagnato da gravissimi eventi avversi che hanno portato alla sospensione di alcuni di questi programmi. Ancora maggiore incertezza esiste sugli strumenti capaci di accertare l'eventuale uso di questa metodologia per scopi di doping. Il punto su questi programmi di ricerca è stato fatto nel corso del 'Gene Doping Symposium' organizzato dalla WADA a Saint Petersburg nel giugno 2008". Etica sport e doping, cit., p. 9.

${ }^{40}$ Il dott. Philippe Mouiller dell'Istituto nazionale francese della salute e della ricerca di Nantes ha pubblicato uno studio sul trattamento genetico delle disfunzioni muscolari dimostrando che si poteva produrre artificialmente un gene, quello dell'eritropoietina: l'EPO iniettata rimane rilevabile per anni ma l'introduzione del gene nel corpo lo trasformerebbe in un fantasma. Il prof. Lee Sweeney dell'Università della Pennsylvania prima dei Giochi di Sochi aveva dichiarato che quelle sarebbero state "le ultime olimpiadi senza doping genetico". Lo stesso direttore scientifico della WADA, Oliver Rabin, non è stato in grado di ammettere, nel 2014, che non esiste un test per scovare il gene della mutazione. E. Sisti, Germania, arresto per chi si dopa. Ma il doping genetico fa sempre più paura, in www.repubblica.it, 12 novembre 2014. Oltre alle difficoltà legate allo studio degli effetti sul corpo nel tempo del doping genetico, questo nuovo sistema porta con se nuove sfide di carattere etico che inducono ad una nuova riflessione sulla figura e sulla definizione di atleta, nonché sull'identità del fenomeno sportivo. E. Buzzi, Doping tradizionale e doping genetico: questioni etiche, in Medicina e morale, 2018, I, pp. 41-54.

${ }^{41}$ Cfr. M. Arpino, M. Ferrante, Poteri e limiti della giustizia sportiva: il matching del DNA nell'accertamento dell'assunzione di sostanze o il ricorso a metodi dopanti, in L. Cantamessa, G.M. Riccio, G. Sciancalepore (a cura di), Lineamenti di diritto sportivo, Milano, Giuffrè, 2008, pp. 479 ss. 
informazioni sulle generazioni precedenti e successive a quella dell'atleta interessato, fra le quali la previsione di future patologie. Nonostante le tecniche del doping genetico si evolvano costantemente e sia ancora particolarmente difficile ottenere la prova del loro utilizzo, i metodi di doping si stanno evolvendo verso nuove frontiere e nuove modalità che vedono degli interventi diretti sul sistema nervoso dell'organismo senza l'utilizzo di sostanze esterne, ma attraverso stimolazioni elettriche artificiali. ${ }^{42}$ La necessità di adoperarsi in modo sinergico e costantemente aggiornato in tema di contrasto al doping è sempre più ribadita in ambito internazionale. Anche la Commissione europea 1'11 luglio 2007, attraverso la stesura del Libro bianco sullo sport, sottolineò, partendo dal presupposto che lo sport è un fenomeno sociale ed economico d'importanza crescente che contribuisce in modo significativo agli obiettivi strategici di solidarietà e prosperità perseguiti dall'UE, che l'universo sportivo deve fronteggiare la minaccia del doping, considerandolo un fenomeno capace di minare alla radice il principio di una competizione aperta e leale, nonché la salute degli individui. ${ }^{43}$ Di conseguenza, sempre secondo la Commissione, tutti i soggetti responsabili della salute pubblica hanno il dovere di tenere conto dei rischi dovuti al doping, soprattutto le organizzazioni sportive, nell'elaborare norme di buona pratica per garantire una migliore informazione ed educazione dei giovani sportivi non solo per quanto riguarda le sostanze dopanti, i medicinali su ricetta che potrebbero contenere tali sostanze e i loro effetti sulla salute. Da qui l'esigenza di giungere ad un coordinamento a livello nazionale, come richiesto dalla stessa Convenzione internazionale contro il doping, approvata dall'Assemblea generale dell'Unesco il 19 ottobre 2005, tra tutti gli enti interessati alla lotta al doping, per garantire una maggiore efficacia e costanza delle azioni di prevenzione. ${ }^{44}$ Sul punto si segnala la recente istituzione, ad opera della NADO, del Comitato per l'Educazione, la Formazione Antidoping e la Ricerca (CEFAR), organo deputato al perseguimento della difesa dei valori dello sport e della tutela della salute degli atleti, mediante l'attuazione di programmi di formazione ed informazione (art. 19.1 NSA). In ogni caso l'utilizzo di sostanze per migliorare la propria performance non è confinata al solo universo sportivo.

Interessanti appaiono, nel merito, le indicazioni fornite dallo studio pubblicato dalla Direzione generale politiche interne dell'Unione ${ }^{45}$ in cui, oltre a sottolineare gli aspetti positivi e negativi delle tecniche di accertamento della

${ }^{42}$ Una nuova tecnica tuttora in fase di sperimentazione sugli sportivi è la stimolazione transcranica a corrente continua (tDcs), che venne sviluppata per permettere al cervello e al midollo spinale di recuperare da lesioni che vi fossero occorse in seguito a traumi o malattie. In sostanza la tDcs è stata testata per stimolare i centri neuronali che sono responsabili della sensazione di fatica derivante dal movimento muscolare. In questo modo si cerca di indurre l'organismo ad una minore percezione dello sforzo, con l'obbiettivo di performance di più lunga durata, o d'indurre una maggiore considerazione tramite un focus mirato dei centri neuronali sugli aspetti cognitivi. Questa pratica potrebbe risultare dunque particolarmente utile negli sport di fatica, come il ciclismo e la corsa di lunga durata, oltre che in attività sportive che richiedono particolare attenzione come gli sport di tiro, quelli motoristici nonché gli E-sports. Ad oggi la tDcs non è inserita all'interno della lista delle pratiche mediche vietate dalla WADA, ma è certo che la sua crescente diffusione pone diversi interrogativi sul fatto che possa essere o meno considerata una tecnica dopante. Si veda in proposito D. Holgado, A. Vadillo, D. Sanabria, “Brain-Doping," Is It a Real Threat?, in Front. Physiol., 2019, X, p. 483 ss.

${ }^{43}$ Alcuni atleti professionisti sanzionati per uso di sostanze dopanti hanno messo in discussione la compatibilità di alcune norme relative al controllo antidoping con la normativa comunitaria sulla concorrenza e sulla libera prestazione dei servizi lamentando l'adozione da parte del CIO di un meccanismo di responsabilità oggettiva oltre che l'instaurazione di organi competenti per la soluzione arbitrale delle controversie in materia di sport, insufficientemente indipendenti rispetto allo stesso CIO, rafforzando, così, la teoria del carattere anticoncorrenziale del procedimento oggetto della causa. Respingendo il loro ricorso, il Tribunale ha stabilito che i regolamenti antidoping sono inerenti all'organizzazione ed al corretto svolgimento della competizione sportiva e non possono essere considerati costitutivi di una restrizione delle norme comunitarie sulla libera circolazione dei lavoratori e sulla libera prestazione dei servizi. L'interdizione del doping è fondata su considerazioni esclusivamente sportive ed è, dunque, estranea a qualsiasi considerazione economica e, proprio alla luce di tale considerazione, la normativa antidoping non può rientrare nell'ambito di applicazione delle disposizioni del Trattato sulle libertà economiche e, in particolare, degli articoli 49, 81 e 82 del Trattato CE. Tribunale di primo grado delle Comunità Europee, sez. IV, 30 settembre 2004, T-313/02, Meca-Medina e Majcen / Commissione, in https://curia.europa.eu.

${ }^{44}$ L. Musumarra, Unione europea e doping, in Social News, 2007, VII, pp. 24-25. Nello stesso periodo veniva approvata la Risoluzione del Parlamento europeo (14 aprile 2005) sulla lotta contro il doping nello sport, in base alla quale "il numero di casi di doping rilevati nel corso dei Giochi olimpici di Atene del 2004 ha nuovamente dimostrato che il doping nello sport è più che mai una realtà da combattere. Partendo da tale constatazione il Parlamento europeo ha fra l'altro invitato la Commissione europea ad attuare una politica efficace e integrata in tutti i settori collegati alla lotta contro il doping, a sostenere una campagna intensiva di informazione e di sensibilizzazione, nonché a favorire la cooperazione fra gli Stati membri”.

45 Nella relativa premessa viene affermato che "occorre constatare che il problema del doping e la sua ricorrenza mettono in evidenza l'inadeguatezza non solo dei principi definiti nelle varie relazioni recentemente elaborate dall'Unione europea e dal Consiglio 
presenza di sostanze vietate (dirette ${ }^{46}$ e indirette ${ }^{47}$ ), sono stati rilevati dubbi che necessitano di un accurato futuro studio da parte delle organizzazioni governative e non; in particolare è stato riscontrato che gli sportivi sono di fatto discriminati e trattati diversamente rispetto ai cittadini ordinari dal momento che nessun tipo di controllo analogo viene legislativamente previsto per altre categorie di cittadini (per es., leader politici, grandi capitani d'industria, quadri dirigenziali, ecc.). ${ }^{48}$

\section{La Wada e il codice mondiale antidoping}

In ambito internazionale il fenomeno del doping è stato costantemente preso in considerazione dal $\mathrm{CIO}^{49}$ che ha dovuto, dalla fine degli anni Ottanta, rivisitare le proprie politiche antidoping affrontando il fenomeno attraverso tre principali punti cardine: 1) studiare il fenomeno attraverso propri esperti ed analizzare sostanze e metodi attraverso laboratori accreditati; 2) aggiornare le norme antidoping in costanza d'evoluzione del progresso scientifico, estendendo ed aumentando i controlli nei confronti non solo dei soggetti dell'ordinamento sportivo; 3 ) collaborare con le istituzioni governative, chiedendo alle stesse di aggiornare le proprie norme antidoping ma rimanendo sempre vigili nei loro confronti. Già la Conferenza mondiale permanente sul doping nello sport, tenutasi ad Ottawa nel giugno 1988 su iniziativa del CIO, aveva anticipato i temi contenuti la Carta olimpica internazionale contro il doping nello sport, periodicamente aggiornata dallo stesso Comitato olimpico. ${ }^{50} \mathrm{Ma}$ fu lo scandalo nel ciclismo durante la competizione del Tour de France del $1998,{ }^{51}$ quando venne scoperto un diffusissimo abuso di sostanze vietate, che evidenziò una certa confusione operativa da parte delle federazioni, al punto che alcune sanzioni antidoping vennero contestate o annullate in sede giurisdizionale. A quel punto il CIO fu costretto a convocare, nel febbraio 1999 a Losanna, la prima Conferenza mondiale antidoping durante la quale venne deciso di affidare ad un unico organo il potere di emanare normative in materia. Venne così istituita, il 10 novembre 1999 a Losanna, l'Agenzia mondiale antidoping (Agencie mondiale antidopage [AMA] o World antidoping agency [WADA]), fondazione di diritto privato internazionale, frutto della collaborazione di tutto il

d'Europa, ma anche la presunta efficacia della lotta contro il doping [...] Per essere inclusa nell'elenco delle sostanze vietate, una sostanza deve essere un agente mascherante o rispondere a uno dei tre criteri seguenti: 1) contribuisce o può contribuire al miglioramento delle prestazioni sportive; 2) comporta un rischio potenziale o reale per la salute; oppure 3) il suo utilizzo è contrario all'etica sportiva. Nessuno dei tre criteri indicati è sufficiente, da solo, a giustificare l'inclusione di una sostanza nell'elenco delle sostanze vietate". C. Brissonneau, Il doping nello sport professionale, cit., p. 5.

46 "Nonostante questi dati incoraggianti, la rilevazione è in realtà molto difficile e solo parzialmente efficacie per diversi motivi: 1) vengono ovviamente rilevate solo le classi di sostanze o i metodi ricercati; 2) falsi positivi (un errore può far ipotizzare il doping) o falsi negativi (alcuni prodotti sono già stati eliminati al momento del controllo o mascherati dall'assunzione di altri prodotti oppure non sono stati cercati)". Ibid.

${ }^{47}$ Il cui obiettivo è "dosare in un campione biologico alcuni marker che variano significativamente in caso di doping. Recentemente è stato creato un passaporto ematico, ma è lecito chiedersi se la sua attuazione non sia stata troppo repentina. La gestione, il metodo, la fase preanalitica, le tecniche, i kit utilizzati, i protocolli e l'attuazione non sembra siano stati sufficientemente valutati". Ibid.

${ }^{48} \mathrm{Nel}$ corso dello studio è stato constatato che: a) le leggi, i regolamenti e i controlli non risolvono il problema; b) i controlli rivelano dei "falsi positivi"; c) i controlli rivelano in modo massiccio il consumo di droghe c.d. leggere così ponendo la questione del diverso trattamento penale a seconda dei Paesi; d) la lotta e il controllo hanno comportato nel tempo un'accentuazione della devianza degli atleti e, soprattutto, lo sviluppo di un mercato nero; e) nonostante l'espansione del fenomeno sia in aumento, in alcuni sport non vengono mai rilevati o i casi rilevati vengono messi a tacere; $f$ ) non è dimostrabile che la lotta contro il doping protegga la salute degli atleti ma, forse, la peggiora; g) gli atleti sono più o meno discriminati a seconda dello sport praticato; h) la lotta contro il doping si intromette nella loro vita privata minacciandone, attraverso l'eccessiva invasività dei controlli, la libertà individuale (analisi del sangue e delle urine). Per fronteggiare il quadro così delineato l'autore ha indicato cinque scenari possibili. Ivi, p. 8.

${ }^{49}$ Il primo controllo antidoping ufficiale si svolse in occasione delle Olimpiadi di Città del Messico nel 1968. L. Di Nella, Manuale di diritto dello sport, cit., p. 307.

${ }^{50}$ La prima definizione ufficiale di doping adottata dal CIO nel corso del Congresso di Strasburgo del 1963 recitava testualmente: "Il doping è la somministrazione ad un soggetto sano o l'utilizzazione fatta dal soggetto stesso, con qualsiasi altro mezzo, di una sostanza estranea al suo organismo. E questo con il solo scopo di aumentare artificialmente ed in maniera sleale la prestazione del soggetto in occasione della sua partecipazione ad una competizione".

${ }^{51}$ Le autorità competenti fermarono senza preavviso il Tour de France quando un massaggiatore della squadra Festina venne sorpreso alla guida di un veicolo carico di prodotti dopanti. L'intera squadra venne espulsa dalla competizione mentre la gendarmeria procedeva alle relative indagini. Tre anni più tardi, nel 2001, l'evento si ripropose durante il Giro d'Italia, con le note perquisizioni durante la tappa di Sanremo. G. Palmieri, V. Pincolini, A. Casti, Doping 2004, cit. 
movimento olimpico mondiale con i governi di molte nazioni, composta da esponenti del mondo sportivo e da rappresentanti governativi; l'adesione dei governi e dell'UE ne ha assicurato un sostanziale riconoscimento giuridico e grazie all'intervento del Consiglio d'Europa, che ha fatto da collettore delle quote che gli Stati si sono impegnati a versare per il suo finanziamento, l'agenzia opera e ha prodotto un Codice mondiale antidoping unificato (world anti-doping code). ${ }^{52} \mathrm{~A}$ tali regole si devono attenere tutti gli organismi antidoping internazionali e nazionali che vi aderiscono. Infatti, il programma mondiale antidoping aveva due finalità principali: a) tutelare il diritto fondamentale degli atleti alla pratica di uno sport libero dal doping, promuovendo la salute, la lealtà e l'uguaglianza di tutti gli atleti del mondo; b) garantire l'applicazione di programmi antidoping armonizzati, coordinati ed efficaci sia a livello mondiale che nazionale, al fine di individuare scoraggiare e prevenire la pratica del doping. All'uopo, sono stati adottati standard internazionali operativi e tecnici relativi alla lista delle sostanze vietate e dei metodi proibiti, alle esenzioni a fini terapeutici, alle modalità dei controlli antidoping e ai laboratori antidoping. Il primo rilevante risultato dell'agenzia fu consolidato il 5 marzo 2003, a Copenaghen, con la sottoscrizione all'unanimità del Codice antidoping, i cui principali e più incisivi punti furono: 1) uguale trattamento sanzionatorio per tutti i Paesi aderenti (due anni di squalifica al primo episodio e radiazione a vita dalle federazioni al secondo); 2) unificazione e omogeneizzazione delle normative, delle procedure, dei prelievi dall'organismo e dei controlli antidoping per tutti i Paesi, federazioni e leghe professionistiche aderenti. Inoltre, il codice WADA impose il divieto di partecipare ai Giochi olimpici per quegli Stati i cui Comitati olimpici e Paralimpici e le cui Organizzazioni antidoping non prevedano una normativa antidoping conforme ai principi del codice (ciò vale anche nel caso in cui lo Stato non abbia ratificato la Convenzione internazionale contro il doping). ${ }^{53}$ Per evitare pratiche truffaldine la Medical commission e la Doping and biochemistry in sport pubblicano annualmente la lista delle "sostanze proibite" ed hanno sviluppato sofisticati sistemi per rivelare l'abuso di farmaci o droghe. ${ }^{54}$

${ }^{52}$ Il codice prevede un unico elenco delle sostanze e dei metodi vietati, che deve essere periodicamente aggiornato con l'inserimento di nuove sostanze che presentino ad almeno due delle seguenti caratteristiche: a) servano a miglioare la prestazione; b) comportino un rischio anche potenziale per la salute; c) il loro utilizzo sia contrario allo spirito sportivo come declinato dal codice; d) abbiano l'obiettivo di mascherare altre sostanze proibite. Grazie all'adozione di un codice unificato, sotto l'egida di un unico organismo, in cui sono rappresentati gli organi sportivi internaionali di vertice e i governi degli Stati, è stato possibile garantire una magiore ed effettività armonizzazione alla lotta al fenomeno del grazie ad un circuito sinergico tra procedimento disciplinare sportivo e quelli sanzionatori degli stati che hanno previsto delle apposite fattispiecie penali. Ciascuno Stato firmatario ha assunto l'impegno di introdurre regolamenti e procedure per far si che tutti gli atleti e le altre persone sotto la loro e le organizzazioni ad esso aderenti prestino il loro consenso a vincolarsi al rispetto del codice.

${ }^{53}$ La Convenzione internazionale contro il doping, adottando il codice WADA già nella sua introduzione, chiarisce che "il regolamento antidoping analogamente al regolamento di gara, è un regolamento sportivo che disciplina le condizioni cui attenersi nell'esecuzione di un'attività sportiva". R. Carmina, Appunti e considerazioni critiche sul doping nella sua duplice dimensione penalistica e disciplinare, in Rdes, III, 2014, p. 65. Residua però un problema, in quanto nonostante le disposizioni del Codice WADA siano attuate a livello globale, le stesse sono ancora confinate ad essere operative solamente nei confronti degli atleti che intendano partecipare alle competizioni olimpiche e ai circuiti federali, non potendosi applicare alle leghe professionistiche private del Nord America (come NBA, NFL, NHL e MLB), che tra l'altro rimandano la determinazione della lista delle sostanze alla contrattazione collettiva tra le leghe e le associazioni di giocatori, lasciando di fatto scoperto da controlli efficaci un fenomeno sportivo con un importante rilievo mediatico. L. Zambelli, International Doping, in Dir. dello sport., 2014, I-II, pp. 47-48.

${ }^{54}$ Il fenomeno coinvolge aspetti medici, farmacologici, sportivi e di costume che riguardano: a) i tipi di trattamento e le sostanze usate; b) le dosi; c) i tempi e le modalità di somministrazione; d) le persone coinvolte (non solo atleti, ma anche medici, allenatori, ecc.); e) le modalità dei controlli antidoping (qualità delle competizioni; criteri di selezione e numero degli atleti da sottoporre ai controlli); f) le sanzioni da applicare; g) la prevenzione e l'elaborazione di valide strategie antidoping. L'impiego di farmaci ed i dosaggi scelti costituiscono spesso una pratica empirica non sostenuta da alcun fondamento scientifico e a questo deve essere aggiunto che molti atleti assumono contemporaneamente più farmaci. La WADA “opera anche come centro di raccolta delle informazioni dei risultati relativi ai controlli antidoping, al fine di evitare inutili ripetizioni nell'esecuzione dei tests da parte delle varie organizzazioni antidoping. A tal riguardo, è stato istituito un sistema di amministrazione e gestione dei dati (c.d. Adams) contenente le indicazioni degli atleti (dati personali, programmi di allenamento, reperibilità degli stessi) al fine di effettuare controlli al di fuori dalle competizioni”. L. Di Nella, Manuale di diritto dello sport, cit., p. 310. "Per coordinare le informazioni relative ai controlli antidoping a livello internazionale è stata istituita un'apposita banca dati (Antidoping Administrations and Management System - Adams), il cui utilizzo funge da strumento per la condivisione dei dati da parte delle singole organizzazioni antidoping nazionali”. G. Liotta, L. Santoro, Lezioni di diritto sportivo, cit., pp. 278-279. La WADA è di recente intervenuta predisponendo un software di apprendimento online denominato "ADeL Anti- 


\section{Le norme statali antidoping prima della legge n. $376 / 2000$}

La legge 16 febbraio 1942, n. 426, relativa alla costituzione del CONI oltre a poter essere considerata la prima norma emanata in Italia contenente disposizioni contro il fenomeno doping, stabilì, con principio fissato all'interno dell'ordinamento sportivo e privo, comunque, di correlate sanzioni, che l'assunzione di sostanze farmacologiche e chimiche, per migliorare le potenzialità fisiche dell'atleta, era contraria alle regole di lealtà, correttezza e probità sportiva correlate alla necessità di intendere il perfezionamento atletico come connesso al miglioramento fisico e morale (art. 2). Successivamente, con la legge 28 dicembre 1950, n. 1055, venne assegnato alla Federazione medico sportiva italiana (FMSI) il compito di esercitare i controlli antidoping; ${ }^{55}$ competenza di seguito trasferita alle Regioni, in collaborazione col CONI, con la legge 26 ottobre 1971, n. 1099, recante "tutela sanitaria nelle attività sportive". Proprio tale ultima norma si è occupata, in ambito penale, del fenomeno doping punendo: 1) gli atleti che nell'ambito di competizioni sportive avevano fatto uso di sostanze nocive per la loro salute; 2) coloro che avevano somministrato le sostanze vietate; 3) chiunque veniva trovato all'interno degli spazi riservati agli atleti nel corso di manifestazioni sportive in possesso delle sostanze vietate. Tale legge di fatto non ha mai avuto concreta applicazione dal momento che: a) l'elenco delle sostanze vietate venne emanato solo nel 1975 e mai aggiornato, risultando ben presto inidoneo e superato dai ritrovati della ricerca scientifica; b) i reati previsti agli artt. 3, 4 e 5 erano puniti con la sola ammenda che a seguito del processo di depenalizzazione (legge 24 novembre 1981, n. 689) divennero semplici illeciti amministrativi. ${ }^{56}$ Il vuoto operativo creato dalla legge $\mathrm{n}$. 1099/1971 ha permesso al fenomeno doping di estendersi in sempre maggiori strati sociali sino a divenire interessante fonte di guadagno anche per le organizzazioni criminali. Negli anni Ottanta l'attenzione del legislatore venne assorbita da quella che possiamo pacificamente considerare l'emergenza sociale del momento ovvero l'abuso delle sostanze stupefacenti. Il fenomeno assunse in quel periodo un fortissimo impatto nella società al punto che l'attenzione delle organizzazioni mediche, scientifiche e giuridiche di quel periodo si concentrò sull'adozione legislativa di un approccio risolutivo dell'espansione dell'uso di sostanze naturali e di sintesi capaci di influenzare il comportamento umano attraverso la previsione della legge delega 26 giugno 1990, n. $162,{ }^{57}$ e l'approvazione del successivo d.P.R. 9 ottobre 1990, n. 309, "testo unico delle leggi in materia di disciplina degli stupefacenti e sostanze psicotrope, prevenzione, cura e riabilitazione dei relativi stati di tossicodipendenza". La scarsa attenzione prestata, invece, al fenomeno del doping è rilevabile dall'approvazione dell'unico testo approvato nel merito, la legge 11 marzo 1988, n. 67, con la quale venne istituito un fondo nazionale a sostegno delle iniziative antidoping, che, tuttavia, nella pratica non ha prodotto alcun risultato effettivo. ${ }^{58}$ All'uopo, la magistratura tentò di colmare l'evidente vuoto legislativo mediante un'interpretazione

Doping e-Learning", attraverso il quale offrire corsi ad atleti, allenatori, medici, manager e a tutti coloro che siano interessati ad approfondire la propria conoscenza dell'antidoping e dei valori sportivi.

${ }^{55}$ Nel 1962, la FMSI fornirà la seguente definizione di doping "È da considerarsi doping la sostanza diretta ad aumentare artificiosamente le prestazioni di gara del concorrente, pregiudicandone la moralità, l'integrità fisica e psichica". G. Cantelli Forti, La farmacologia nello sport e il doping, cit.

56 Alcuni autori paventarono che le disposizioni in questione, pur prevedendo la sola pena pecuniaria, non rientravano tra quelle depenalizzate ai sensi dell'art. 32 della legge n. 689/1981, sulla base dell'assunto secondo il quale "senza eccessive forzature, è possibile considerarle come norme relative alla prevenzione degli infortuni sul lavoro, come tali escluse dalla depenalizzazione ai sensi dell'art. 34, lett. n) legge n. 689/1981”. E. Fortuna, Somministrazione di medicinali in modo pericoloso per la salute pubblica (ad vocem), in Enc. Dir., vol. XLII, Milano, Giuffrè, 1990, p. 1284. La dottrina prevalente, invece, si orientò nella direzione opposta, dal momento che: a) la legge n. 689/1981 non conteneva un'espressa esclusione delle fattispecie di doping, come invece era avvenuto con la prima legge di depenalizzazione (la legge n. 706/1975 che aveva esplicitamente fatto salvi i reati di cui alla legge n. 1099/1971); b) il richiamo alla materia sugli infortuni e igiene del lavoro esige che il soggetto passivo sia parte di un rapporto di lavoro subordinato, mentre la tutela apprestata dalla normativa antidoping del 1971 si riferiva a qualsiasi atleta partecipante a competizioni sportive, professionista e non. V. Manzini, Trattato di diritto penale, VI, Torino, Utet, 1981, p. 470 Cfr., altresì, F. Mucciarelli, Medicinali guasti o pericolosi (ad vocem), in Dig. pen., VII, Torino, Utet, 1993, p. 584.

${ }^{57}$ Recante delega al Governo per l'emanazione di un testo unico in cui devono essere riunite e coordinate tra loro le disposizioni di cui alla legge 22 dicembre 1975, n. 685, del d.1. 22 aprile 1985, n. 144, convertito, con modificazioni, dalla legge 21 giugno 1985, n. 297, del d.1. $1^{\circ}$ aprile 1988 , n. 103, convertito, con modificazioni, dalla legge $1^{\circ}$ giugno 1988, n. 176, e della legge n. 162/1990.

58 "Fenomeno al quale si è cercato di porre rimedio sia con la 1.28 dicembre 1978, n. 833, di istituzione del Servizio sanitario nazionale, 
piuttosto estensiva del contenuto della legge 13 dicembre 1989, n. 401, recante "interventi nel settore del giuoco e delle scommesse clandestini e tutela della correttezza nello svolgimento di manifestazioni sportive". ${ }^{59}$ La norma si proponeva l'obiettivo di contrastare il preoccupante fenomeno delle scommesse clandestine e di tutelare il gettito derivante dalle scommesse sugli eventi sportivi. Attraverso tale norma, che era applicabile solo alle competizioni organizzate dal CONI o altri enti riconosciuti dallo Stato, la magistratura inquirente tentò di arginare il fenomeno del doping considerando i relativi comportamenti quali atti fraudolenti, ovvero artifici volti a falsare il risultato sportivo e il comportamento leale auspicabile in una competizione. ${ }^{60}$ Il dettato del relativo art. 1, comma primo, era talmente generico da sembrare poter ricomprendere al suo interno il fenomeno del doping ma l'ipotesi accusatoria seppur strenuamente difesa in giudizio non fece breccia in sede di vaglio di legittimità. ${ }^{61}$ Con la ratifica della Convenzione contro il doping di Strasburgo del 16 novembre 1989, attuata attraverso la legge 29 novembre 1995, n. 522, venne introdotta una più corretta definizione di doping ovvero "la somministrazione agli sportivi o l'uso da parte di questi ultimi di classi farmacologiche di agenti di doping o di metodi di doping, che si

diretta ad affidare alle (allora) U.s.l. il compito di provvedere alla medicina dello sport e alla tutela delle attività sportive, sia con la 1.11 marzo 1988, n. 67, volta ad istituire, ma con scarso esito, un fondo nazionale a sostegno delle iniziative antidoping". L. Di Nella, Manuale di diritto dello sport, cit. p. 313. Nel 1989 la Commissione affari sociali della Camera dei deputati deliberò di considerare il doping come un "impiego surrettizio di farmaci, agenti chimici o materiali biologici, allo scopo di avvantaggiarsi in o in vista di un confronto agonistico" e, pertanto, "costituisce doping l'utilizzazione da parte dell'atleta di interventi esogeni attuati con l'intento di migliorare le prestazioni al di fuori dell'adattamento indotto dall'allenamento. Per intervento esogeno si intende l'assunzione o la somministrazione, sotto qualsiasi forma, di sostanze o preparazioni naturali o di sintesi capaci di determinare nel ricevente una o più variazioni funzionali per interferenza delle loro proprietà con quelle della sostanza vivente”. G. Cantelli Forti, La farmacologia nello sport e il doping, cit.

${ }^{59}$ Prima dell'entrata in vigore della legge n. 401/1989 l'unica norma che avrebbe potuto prestarsi a reprimere il fenomeno, era quella sulla truffa (art. 640 c.p.). Per potere applicare tale norma occorreva, però, accertare una sequenza causale rappresentata da tre anelli fondamentali: gli espedienti o i raggiri dei giocatori, il risultato artefatto della gara conseguente a tali artifici, il danno patrimoniale conseguente al risultato artefatto. In definitiva, la difficoltà nell'accertamento concreto degli elementi costitutivi della truffa portarono, sia la dottrina che la giurisprudenza, ad esprimere numerose perplessità sulla applicabilità dell'art. 640 c.p. ai comportamenti tipici di frode sportiva. Cfr.: R. Borgogno, Sulla riconducibilità del doping al delitto "di frode in competizioni sportive" ex art. 1, legge 13 dicembre 1989, n. 401, in Arch. Pen., 1992, IV, pp. 610-626; A. Di Martino, Giuoco corrotto, giuoco corruttore: due problemi penali dell'homo ludens, in Riv. it. dir. proc. pen., 2002, 1, pp. 137-149. Infatti, "a fronte di alcune pronunce della Cassazione che tentavano di sopperire ad una evidente lacuna di tutela penale ritenendo configurabile la fattispecie, si evidenzia, ora l'impossibilità di provare il nesso causale tra la condotta dei giocatori incriminati e il risultato della gara e, quindi, il danno, ora la difficoltà di individuare i soggetti passivi e la conseguente impossibilità applicativa della norma, ora, infine, la mancanza dell'ingiusto profitto". A. Meyer, voce Sport (dir. pen.), in Dig. disc. pen., Torino, 1990, p. 580. In senso conforme: P. Nuvolone, L'illecito sportivo nella prospettiva dell'art. 640 c.p., in Indice pen., 1981, p. 25 ss.; G. Vassalli, La frode sportiva, in Riv dir. sport., 1963, p. 13 ss.; E.F. Barabba, Illecito sportivo e illecito penale, in Riv. dir. sport., 1981, p. 193 ss.

${ }^{60}$ La condotta descritta nella seconda parte della disposizione ("ovvero compie altri atti fraudolenti volti al medesimo scopo"), infatti, per la sua genericità, è apparsa suscettibile di applicazione anche alle condotte di doping riguardanti gli atleti impegnati in attività agonistiche, integrando l'assunzione e la somministrazione di sostanze e farmaci al di fuori di ogni necessità terapeutica, un artificio idoneo ad alterare il naturale esito della competizione. Una tale operazione ermeneutica, però, non ha sempre incontrato il favore della giurisprudenza per la quale il vero nodo interpretativo è rappresentato dalla possibilità o meno di ricondurre alla nozione di "altri atti fraudolenti" non soltanto la condotta di chi somministra o prescrive all'atleta sostanze e farmaci vietati (c.d. doping esogeno) ma anche quella dell'atleta che assume volontariamente sostanze vietate (c.d. doping autogeno) con la possibilità di giungere persino al paradosso secondo cui "se così non fosse, qualsiasi illecito sportivo, dallo spintone al calciatore in corsa alla spinta del gregario al campione ciclista in difficoltà, siccome oggettivamente volti a provocare un esito della gara diverso da quello cui avrebbe dato luogo una leale competizione, dovrebbero rientrare nella previsione della normativa in esame: il che all'evidenza non è’. In tal senso S. Bonini, Doping e diritto penale prima e dopo la L. $376 / 2000$, in S. Canestrari, G. Fornasari (a cura di), Nuove esigenze di tutela nell'ambito dei reati contro la persona, Bologna, CLUEB, 2001, p. 278, secondo cui "responsabili degli atti fraudolenti di cui alla seconda parte del comma primo dell'art. 1 legge n. 401/1989 potranno essere esclusivamente soggetti estranei alle gare, mentre ricomprendere fra i soggetti attivi anche i partecipanti alle competizioni significherebbe operare un'inammissibile interpretazione in malam partem della norma".

${ }^{61}$ L'interpretazione estensiva dell'art. 1 della legge n. 401/1989 non trovò concorde la Suprema Corte secondo cui "scopo della legge n. 401/1989 è quello di evitare l'irruzione nel mondo dello sport delle attività di gioco e di scommesse clandestine: gli atti fraudolenti volti al medesimo scopo, di cui all'art. 1, legge n. 401/1989, devono pertanto essere identificati alla stregua degli atti espressamente individuati nell'offerta o promessa di denaro o altra utilità a taluno dei partecipanti ad una competizione sportiva: pertanto, l'ambito di applicazione della legge non può essere esteso ai fenomeni autogeni di doping che trovano la loro esclusiva sanzione negli ordinamenti sportivi”. Cass. pen., 25 gennaio 1996, n. 3011, in Riv. pen. ec., 1997, p. 129. 
intendono come le classi di agenti di doping o di metodi di doping vietati dalle organizzazioni sportive internazionali competenti e che figurano su liste approvate dal gruppo di vigilanza". Come verrà illustrato a breve, nell'ottica di dotarsi di una organica disciplina antidoping, il Legislatore italiano, tra i primi nel panorama internazionale, all'inizio degli anni 2000 si è dotato di una nuova disciplina volta a raccogliere le istanze di regolazione del fenomeno promananti dalle diverse istituzioni internazionali.

\section{La legge n. 376/2000 e i successivi interventi normativi in materia di doping}

La legge 14 dicembre 2000, n. 376, recante la "Disciplina della tutela sanitaria delle attività sportive e della lotta contro il doping" spicca all'interno dell'ordinamento legislativo italiano per aver concretizzato il contemperamento della previsione dell'art. 32 Cost., ${ }^{62}$ ovvero tutelare la salute di chi partecipa a qualsiasi attività motoria ${ }^{63}$ col principio di cui all'art. 1 della legge n. 91/1981 ("l'esercizio dell'attività sportiva ... è libero"), attraverso l'enunciato del proprio art. 1 secondo cui "l'attività sportiva è diretta alla promozione della salute individuale e collettiva e deve essere informata al rispetto dei principi etici e dei valori educativi [...] e non può essere svolta con l'ausilio di tecniche, metodologie o sostanze di qualsiasi natura che possano mettere in pericolo l'integrità psicofisica degli atleti"; ${ }^{64}$ nel contempo, la norma ha avuto il pregio di dotare gli organi inquirenti dei necessari strumenti investigativi. ${ }^{65}$ Il legislatore ha deciso di seguire il metodo tabellare, già sperimentato con il

${ }^{62}$ Cfr.: G. Aiello, Prime riflessioni sulla legge antidoping, in Riv. dir. sport., 2000, I-II, pp. 7-21; G. Aiello, La legge antidoping e i suoi riflessi sull'assetto dei rapporti tra ordinamento statale ed ordinamento sportivo, in G. Gambogi, Profili attuali di diritto sportivo e nuova legge antidoping, cit., pp. 47-65; S. Bonini, Doping e diritto penale prima e dopo la L.376 /2000, cit., pp. 255-336; M. Jovino, La repressione del doping: profili penali, in C. Bottari (a cura di), La tutela della salute nelle attività motorie e sportive: doping e problematiche giuridiche, Rimini, Maggioli, 2004, pp. 117-204.

${ }^{63}$ Quello dell'integrità personale è un bene che trascende la libera disponibilità del singolo, per effetto della sua diretta connessione con valori costituzionali quali quello della dignità umana e, più specificamente, quello della salute che l'ordinamento giuridico riconosce $\mathrm{e}$ tutela come fondamentale diritto dell'individuo ma anche interesse della collettività. Cfr.: R. Guariniello, La legge sul doping tra Corte di cassazione e ministero della salute, in Foro it., 2002, 5, I, pp. 1378-1391; R. Guariniello, Reati di doping: nuovi insegnamenti della corte di cassazione, in Foro it., 2003, 5, II; M. Cingolani, Il doping secondo la Cassazione: qual è il bene giuridicamente tutelato dalla L. 376/2000?, in Riv. it. med. leg., II, 2003, pp. 236-237. Di particolare rilievo le conclusioni di alcune indagini condotte verso la fine degli anni Novanta dal dott. Guariniello che, monitorando l'universo della pratica amatoriale, ha rilevato come solo in Piemonte la vendita dell'ormone GH era sei volte superiore al quantitativo necessario per curare i veri malati.

${ }^{64}$ L'art. 1 esordisce con un'enunciazione di principio già contenuta nella Convenzione contro il doping di Strasburgo. Appare necessario sottolineare che la norma è con tutta evidenza tesa ad armonizzare la finalità della prevenzione e repressione del doping con quella di garantire all'atleta i trattamenti necessari, farmacologici e non, per la cura di traumi o affezioni morbigene, evitando tuttavia abusi e comportamenti pretestuosi, necessitando di una diagnosi medica debitamente certificata e una stretta correlazione tra lo stato morboso in diagnosi, la natura e il dosaggio del farmaco, che devono corrispondere alle specifiche esigenze terapeutiche "secondo le modalità indicate nel relativo e specifico decreto di registrazione europea o nazionale e i dosaggi previsti dalle specifiche esigenze terapeutiche"; l'atleta dovrà, però, "tenere a disposizione delle autorità competenti la relativa documentazione e può partecipare a competizioni sportive, nel rispetto di regolamenti sportivi, purché ciò non metta in pericolo la sua integrità psicofisica". G. Parisi, Doping, diritto alla vita e diritto all'integrità fisica, in L. Cantamessa, G.M. Riccio, G. Sciancalepore (a cura di), Lineamenti di diritto sportivo, 2008, Milano, p. 447 ss. Secondo alcuni autori il mancato rispetto dell'obbligo dell'atleta di tenere la documentazione attestante le condizioni patologiche per cui si è reso necessario l'intervento terapeutico (art. 9, comma quarto), seppur foriero di conseguenze probatorie non comporta di per sé l'esclusione dell'esistenza di una condizione patologica. Nel merito "[...] arricchente è la spiegazione circa le caratteristiche di idoneità e adeguatezza dell'assunzione del farmaco rispetto al trattamento di una malattia in corso: come a dire che non conta tanto, a fini penali, e ad substantiam, il rispetto dell'iter documentale previsto dall'art. 1, co. 4, della 1. 376, la cui rilevanza si apprezza essenzialmente in ambito regolamentare e disciplinare rileverà invece nel contesto penalistico uno stato patologico riscontrabile naturalisticamente, obiettivamente, dovendosi peraltro dimostrare una stretta correlazione fra l'esigenza oggettiva di curare una data malattia e la posologia in concreto praticata che dovrà corrispondere ai dettami della migliore scienza medica del momento storico (ovvero che potrà essere applicata solo in mancanza di una ragionevole terapia alternativa) [...]". In sede processuale, pertanto, non è ammissibile l'inversione dell'onere della prova, ovvero non può questa essere "rovesciata" sulla difesa: "non sarà dunque l'atleta, che sul piano obiettivo della tipicità è imputato di doping, a dover provare che egli non ha agito dolosamente ovvero che egli non ha avuto la peculiare finalità di alterare l'esito di gara. Al contrario, sarà l'accusa a dover dare nel processo la prova dell'elemento soggettivo, così come richiesto per qualsiasi altro reato". S. Bonini, Doping tra sanzione penale e giustizia sportiva: il ruolo discriminante del dolo specifico, nota a Tribunale di Torino, 6 luglio 2012, in www.penalecontemporaneo.it, 2013 , p. 22.

${ }^{65}$ Rileva quanto stabilito dalla Sezione di vigilanza che in ordine all'inserimento del principio attivo del nandrolone nelle tabelle delle sostanze soggette al controllo del d.P.R. 9 ottobre 1990, n. 309, a seguito della proposta del Consiglio superiore di sanità dell'8 aprile 
d.lgs. 9 ottobre 1990, n. 309, ai fini della repressione dell'uso delle sostanze stupefacenti, rimettendo ad una fonte secondaria il compito di precisare ed integrare il precetto penale, determinando in concreto le sostanze ed i metodi vietati (art. 2, legge n. 376/2000). Il sistema tabellare consente di trovare adeguate definizioni delle fattispecie criminose con elevato grado di esaustività dal punto di vista giuridico e scientifico in un ambito, come quello della farmacologia, che è notoriamente caratterizzato da una costante evoluzione; infatti, detto sistema, consentendo continui aggiornamenti degli elenchi delle sostanze e dei metodi vietati, accresce la capacità e la tempestività della risposta sanzionatoria. ${ }^{66}$ In breve sintesi, le principali novità introdotte nell'ordinamento dalla legge n. 376/2000 sono state: a) previsione, quale ipotesi di reato, della condotta di chi assume o cede sostanze dopanti ${ }^{67}$ b) indicazione di specifiche sanzioni accessorie, quali l'interdizione temporanea o permanente dell'attività sportiva o sanitaria, per chi assume e per chi somministra le sostanze e pratiche vietate; c) istituzione di una Commissione di vigilanza e di controllo (cd. Commissione antidoping - oggi Sezione) di nomina ministeriale; d) obbligo dei tesserati di dichiarare la propria conoscenza dei regolamenti in materia di doping. All'uopo, gli artt. 3, 4 e 5 della legge n. 376/2000 affrontano gli aspetti pratici dell'applicazione della legge. Infatti, l'art. 3 disciplina la struttura della Sezione per la vigilanza ed il controllo sul doping e per la tutela della salute nelle attività sportive, ${ }^{68}$ attribuendole $\mathrm{i}$ seguenti compiti: a) predisporre in classi $\mathrm{i}$ farmaci, le sostanze biologicamente $\mathrm{o}$ farmacologicamente attive e le pratiche mediche vietate, provvedendo alla relativa revisione; ${ }^{69}$ b) determinare $i$ casi, i criteri e le metodologie dei controlli antidoping, individuando competizioni ed attività sportive nei cui confronti porre in essere il controllo sanitario ${ }^{70} \mathrm{c}$ ) effettuare i controlli sanitari antidoping ${ }^{71}$ e quelli di tutela della

2010 ha stabilito che "tale inserimento permette alle Forze di polizia e alle Autorità giudiziarie di poter combatterne l'uso ed il commercio illegale con strumenti di indagine e sanzionatori maggiormente efficaci, quali l'acquisto simulato ed il ritardare l'esecuzione delle misure cautelari" inoltre "è stato pertanto stipulato con l'Istituto superiore di sanità un accordo di collaborazione per la realizzazione dei seguenti progetti: 1) percorsi di aggiornamento per la magistratura per l'applicazione della legge 376/2000; 2) Master per ispettore investigativo antidoping-NAS [...]”. Relazione al Parlamento attività antidoping, anno 2010. La sostanza nel 2017 è stata poi trasferita nella classe $\mathrm{S} 1$.

${ }^{66}$ O. Forlenza, Dubbia la sussistenza dell'illecito penale senza la tabella delle sostanze proibite, in Guida dir., 2002, p. 88.

${ }^{67}$ Cfr. le seguenti sentenze consultabili in www.pluris-cedam.utetgiuridica.it: Cass. pen., S.U., 11 maggio 2005, n. 17706; Cass. pen., S.U., 25 gennaio 2006, n. 3087; Cass. pen., sez. III, 2 dicembre 20014, n. 46764 (sentenza Gillet); Cass. pen., sez. II, 19 gennaio 2004 , n. 949 (sentenza Petrarca).

${ }^{68}$ Il d.m. 31 ottobre 2001, n. 440, pubblicato in G.U. del 20 dicembre 2001, n. 295, Serie Generale, ne disciplina l'organizzazione ed il funzionamento. La Commissione, che opera presso la Direzione generale della ricerca scientifica e tecnologica, dura in carica due anni. L'ultima modifica della struttura ed organizzazione della Commissione è stata prevista dal d.p.r. 28 marzo 2013, n. 44, recante il regolamento di riordino degli organi collegiali e degli altri organismi operanti presso il Ministero della salute, ai sensi dell'art. 2 , comma quarto, della legge 4 novembre 2010, n. 183. In particolare l'art. 2 prevede l'istituzione del Comitato tecnico sanitario, mentre l'art. 4 stabilisce che esso si articoli in tredici sezioni, tra le quali la sezione h), denominata sezione per la vigilanza e il controllo sul doping e per la tutela della salute nelle attività sportive. Con successivo decreto del Ministero della salute 20 maggio 2015 è stata definita la ripartizione dei componenti del Comitato tecnico sanitario tra le diverse sezioni. La Sezione per la vigilanza e il controllo sul doping e per la tutela della salute nelle attività sportive si compone di undici membri: tre designati dal ministero della Salute; tre designati dalla Presidenza del Consiglio dei Ministri - Dipartimento per gli affari regionali, il turismo e lo sport; due designati dalla Conferenza Stato-Regioni; uno designato dal CONI; un ufficiale del Comando carabinieri per la tutela della salute, designato dal Comandante; uno designato dall'Istituto superiore di sanità, assegnato contestualmente alla sezione f), denominata Sezione per i dispositivi medici. Relazione al Parlamento attività antidoping, anno 2017.

${ }^{69}$ Con il d.m. 15 ottobre 2002 venne approvata la prima lista di farmaci, sostanze biologicamente o farmacologicamente attive e pratiche mediche; la norma dava concreta attuazione all'adeguamento alla lista internazionale di riferimento, emanata annualmente dalla WADA, ai sensi della legge n. 230/2007. L'ultima revisione della lista dei farmaci, delle sostanze biologicamente o farmacologicamente attive e delle pratiche mediche, il cui impiego è considerato doping, ai sensi della legge 14 dicembre 2000, n. 376 , è stata pubblicata il 5 giugno 2018 in G.U. n. 128, serie generale. Giova sottolineare che, ai sensi dell'art. 3, comma primo, lett. b), della legge n. 376/2000, nel predisporre l'elenco delle sostanze e dei metodi vietati, la Commissione deve tener conto di almeno due delle seguenti caratteristiche: a) migliorino la prestazione; b) rappresentino un rischio anche potenziale per la salute; c) il loro uso sia contrario allo spirito sportivo descritto nel codice; d) mascherino altre sostanze proibite.

70 “Ogni sport ha il suo doping: ogni attività sportiva, cioè, per le peculiari caratteristiche del suo gesto atletico, può essere resa più semplice, e quindi la relativa performance atletica può essere migliorata, con sostanze diverse, che esaltano quelle che sono le caratteristiche psicofisiche ottimali per eccellenza in essa”. E. Grappiolo, Profili penali del doping, Firenze, Tassinari, 2002 , p. 41.

${ }^{71}$ Rileva quanto stabilito col d.m. Salute 14 Febbraio 2012, in G.U. del 23 marzo 2012 n. 70, serie generale, recante "Norme procedurali per l'effettuazione dei controlli anti-doping e per la tutela della salute, ai sensi dell'art. 3, comma primo, della legge 14 dicembre 2000 , 
salute, in gara e fuori gara, ${ }^{72}$ predisponendo, altresì, i programmi di ricerca sulle sostanze e pratiche in argomento; d) individuare le forme di collaborazione in materia di controlli antidoping con le strutture del SSN; e) intrattenere i rapporti operativi con l'UE e con gli organismi internazionali, garantendo la partecipazione a programmi di interventi contro il doping; f) promuovere ricerche sui farmaci, sulle sostanze e sulle pratiche mediche utilizzabili a fini di doping ${ }^{73}$ g) promuovere campagne informative per la tutela della salute nelle attività sportive e di prevenzione del doping, specie negli istituti scolastici. Fra le altre attività svolte dalla predetta Sezione va annoverata anche l'azione tesa a ridurre gli ambiti di criticità, ${ }^{74}$ nonché la redazione di proposte di modifica della legge n. 376/2000. ${ }^{75}$ Interessante, a tal riguardo, è la discussione tesa ad equiparare la fattispecie sanzionatoria penale prevista dal successivo art. 9 con quanto previsto dall'art. 186 del c.d.s., relativo al rifiuto di sottoporsi al

n. 376", in virtù delle disposizioni introdotte dal d.lgs. n. 196/2003 successivamente sostituite dal Reg. UE n. 679/16, del precedente d.m. 7 agosto 2002, in base al quale il relativo controllo sanitario viene effettuato sulle urine degli atleti scelti dalla Commissione. Prima del termine della gara vengono resi noti gli atleti da controllare che hanno l'obbligo di recarsi nei locali messi a disposizione ed informati sul trattamento dei dati sensibili, ai sensi dell'art. 13 del reg. UE n. 679/16, n. 196; per i controlli fuori gara il medico che effettua il prelievo notifica i termini e il luogo per l'effettuazione del controllo; a fattor comune gli atleti devono rimanere nel previsto locale sino alla sigillatura delle borse di trasporto dei campioni (art. 4); ogni operazione di prelievo deve essere verbalizzata (art. 6); le borse devono essere aperte solo nel laboratorio antidoping al momento delle relative analisi, il relativo esito viene comunicato esclusivamente alla Sezione nella cui sede viene accertata la reale identità dell'atleta risultato positivo ai fini della immediata comunicazione all'A.G., all'atleta, alla società sportiva di appartenenza, al CONI, alla FSN, nonché al CIO ed alle FSI (art. 7); sono previste analisi di revisione su richiesta dell'atleta. Si noti che nel corso del 2010 la Sezione (allora Commissione) ha dovuto ridurre il numero di controlli rispetto agli anni precedenti in considerazione delle minori risorse finanziarie, indirizzandoli su quelle discipline nelle quali era risultata una maggiore diffusione dell'uso di farmaci o pratiche vietate per doping, ovvero il ciclismo, l'atletica leggera, il nuoto e gli sport invernali nelle categorie amatoriali e giovanili su manifestazioni organizzate da FSN, DSA e da EPS.

${ }^{72} \mathrm{Nel}$ corso del 2013 sono stati sottoposti a controllo antidoping 1.390 atleti, di cui 916 maschi $(65,9 \%)$ e 474 femmine (34,1\%): è risultato positivo ad una o più sostanze il 3,8\% degli atleti uomini e lo $0,8 \%$ delle atlete donne, con una percentuale aggregata del $2,8 \%$ del campione totale. Rispetto al precedente anno, è stata, quindi, registrata una diminuzione della percentuale dei casi di positività. Il 74,4\% degli atleti risultati positivi aveva assunto una sola sostanza, mentre il restante $25,6 \%$ risultava aver assunto due o più principi attivi vietati per doping. É interessante notare che alcune sostanze vietate per doping presenti nella lista sono anche inserite nelle tabelle delle sostanze stupefacenti o psicotrope secondo il d.P.R. n. 309/1990. Relazione al Parlamento attività antidoping, anni 2010 e 2013. Nel corso del 2017 il numero dei controlli ha subito una flessione del 12\%; infatti, sono stati controllati 1.211 atleti, ma la ripartizione tra maschi $(821$, il $67,8 \%)$ e femmine $(390$, il $32,2 \%)$ è rimasta perlopiù invariata rispetto al 2010 e con un ritorno ad una maggiore attenzione rivolta alla popolazione femminile rispetto al 2016, quando le atlete controllate erano state 223 (il 27,7\% del totale). Sempre nel 2017, il 28,4\% (344) degli atleti sottoposti a controllo antidoping, sono stati esaminati su specifica richiesta del Comando Carabinieri per la tutela della salute (NAS), che, ai sensi del decreto ministeriale 14 febbraio 2012, partecipano all'individuazione preliminare di gare e atleti "con elevati profili di rischio", selezionati attraverso attività informative e operative svolte e raccolte sul territorio. Tutti i suddetti controlli antidoping sono stati effettuati in competizione e nessuno fuori competizione.

73 "Farmaco è qualsiasi sostanza o prodotto usati o che si intenda usare per modificare o esplorare sistemi fisiologici o patologici con beneficio di chi lo riceve. Col termine pratiche mediche ci si riferisce a quelle procedure mediche dirette a migliorare le prestazioni fisiche dello sportivo senza il ricorso alla somministrazione di farmaci. L'esempio tipico è quello del c.d. doping ematico, che consiste in una procedura ergogenica nella quale viene indotta un'eritrocitemia normovolemica o attraverso l'infusione di globuli rossi autologhi (reinfusione del sangue dello stesso atleta) o omologhi (trasfusione di sangue da donatore compatibile)". G. Micheletta, I profili penalistici della normativa sul doping, in Ind. pen., 2001, III, p. 1317.

${ }^{74} \mathrm{Si}$ rimanda alla lettura delle relazioni al Parlamento per la disamina delle varie proposte formulate. Appare però opportuno rilevare la ravvisata necessità di procedere ad una revisione dell'Atto d'intesa del 4 settembre 2007 tra il Presidente del CONI, il Ministro della salute ed il Ministro per le politiche giovanili e le attività sportive, avente ad oggetto "la necessità di coordinare gli interventi in materia di lotta al doping, da parte del CONI e della Sezione per la vigilanza ed il controllo sul doping e per la tutela della salute nelle attività sportive, nell'ambito delle rispettive competenze". Elementi centrali dell'Accordo risultano essere i primi due punti: 1) di considerare le attività sportive non agonistiche e le attività sportive agonistiche non aventi rilievo nazionale oggetto prevalente dell'attività antidoping della Sezione per la vigilanza ed il controllo sul doping e per la tutela della salute nelle attività sportive; 2) di considerare le attività sportive agonistiche di livello nazionale e internazionale (delegate dagli organismi sportivi internazionali) oggetto prevalente dell'attività antidoping del CONI. "In merito alle strategie di contrasto al doping, la Sezione ha intensificato le iniziative in un settore che è senz'altro nevralgico per affrontare precocemente il fenomeno: il controllo delle categorie giovanili anche amatoriali nel contesto delle attività svolte nell'ambito delle FSN, delle DSA e degli EPS. Come attesta una consolidata serie di indicatori è proprio nell'ambito dell'attività giovanile che gli atleti attivano scelte e comportamenti non salutari". Relazione al Parlamento attività antidoping, anno 2017.

${ }^{75}$ Cfr. d.d.1. 1637, 1660, 1714, 1945-A, $12^{\circ}$ Commissione permanente (Igiene e Sanità), Senato della Repubblica, XIII Legislatura, in www.senato.it 
test alcolimetrico; infatti, attualmente il rifiuto si sottoporsi a test antidoping è sanzionato solo in ambito sportivo, in virtù di quanto disposto dall'art. 6 , comma primo, della presente norma, dal momento che sono in aumento $\mathrm{i}$ casi di rifiuto registrati. ${ }^{76}$ L'art. 4 della legge n. 376/2000 riguarda i laboratori "accreditati dal CIO o da altro organismo internazionale riconosciuto in base alle disposizioni dell'ordinamento internazionale vigente, sulla base di una convenzione stipulata con la Commissione" (comma primo) che sono preposti allo svolgimento dei controlli antidoping in relazione alle attività sportive individuate dalla Commissione ${ }^{77}$ e secondo le disposizioni previste da questa, mentre viene sancita espressamente la cessazione delle attività del CONI in materia di controllo sui laboratori accreditati; gli stessi eseguono anche programmi di ricerca sui farmaci, sulle sostanze e sulle pratiche mediche utilizzabili a fini di doping nelle attività sportive e collaborano ai fini della definizione dei requisiti dei controlli sulle competizioni sportive diverse da quelle individuate all'art. 3, comma primo, lett. b) della legge n. 376/2000. Pur non essendo stati ancora risolti i problemi relativi all'ambito di competenza a seguito dell'entrata in vigore della legge 26 novembre 2007, n. 230, la Commissione antidoping esamina il rinnovo del certificato LAD di accreditamento. ${ }^{78}$ L'art. 5 della legge n. 376/2000 attribuisce alle Regioni il coordinamento delle attività dei laboratori di cui all'articolo precedente e la funzione, nell'ambito dei piani sanitari, di pianificare le attività di prevenzione e di tutela della salute nelle attività sportive. Il successivo art. 6 , invece, risponde alla necessità di un coordinamento tra l'ordinamento statale e l'ordinamento sportivo nella lotta al doping, stabilendo l'obbligo del CONI e degli enti ad esso federati di adeguare i propri regolamenti alle disposizioni della presente legge, con l'espressa previsione di stabilire sanzioni disciplinari per la somministrazione o l'assunzione di sostanze o pratiche vietate, non comprese nell'elenco di cui al decreto ministeriale, a condizione che tali sostanze o pratiche siano considerate dopanti nell'ambito dell'ordinamento sportivo internazionale. ${ }^{79}$ A tutela dei consumatori, invece, l'art. 7 prevede l'onere, a carico dei produttori, importatori e distributori di farmaci contenenti sostanze indicate nell'elenco di quelle vietate, di trasmettere annualmente al Ministero del lavoro, della salute e delle politiche sociali "i dati relativi alle quantità prodotte, importate, distribuite e vendute alle farmacie,

\footnotetext{
${ }^{76}$ Per ovvia ed evidente scelta difensiva, potendosi così rischiare solo la sanzione disciplinare e non anche quella penale. Di fatto, "sembra che il legislatore abbia inteso aggirare l'ostacolo affidando all'ordinamento sportivo l'adozione di meccanismi di coercizione indiretta alla sottoposizione al controllo, esponendosi l'atleta in caso di rifiuto a pesanti squalifiche, sanzionate automaticamente e gravemente penalizzanti per la sua carriera sportiva”. G. Ariolli, V. Bellini, Disposizioni penali in materia di doping, Milano, Giuffrè, 2005 , p. 37.

${ }^{77}$ Sono sottoposti a controlli sia le attività sportive c.d. ufficiali (organizzate dalle FSN o FSI, i cui controlli sono affidati ai laboratori accreditati CIO-WADA) che quelle c.d. amatoriali (organizzate da enti locali, palestre, ecc., i cui controlli sono svolti da laboratori, i cui requisiti sono stabiliti con d.m. Ministro della sanità con delega di funzioni alle Regioni).

${ }^{78}$ Rileva l'accordo siglato il 28 luglio 2005 tra il Ministero della salute, le Regioni e le Province autonome di Trento e di Bolzano, in base al quale sono state definite le "Linee guida sui requisiti organizzativi e di funzionamento dei laboratori antidoping regionali". I laboratori devono garantire non solo l'effettuazione dell'attività di controllo antidoping, ma anche la tutela della salute dei praticanti l'attività sportiva, soprattutto a livello amatoriale. Lo scambio di informazioni e le buone pratiche tra governi, organizzazioni antidoping e laboratori (nazionali e regionali) è l'auspicio rivolto dalla Commissione europea nel Libro bianco sullo sport per combattere il dilagante fenomeno del doping. L. Musumarra, Unione europea e doping, cit., pp. 24-25. "In base all'accordo Statoregioni e province autonome del 28 luglio 2005, concernente le 'Linee guida sui requisiti organizzativi e di funzionamento dei laboratori antidoping regionali' sono state delineate le procedure per l'accreditamento dei laboratori antidoping regionali (LAD) da parte del Ministero della salute previa valutazione dell'Istituto superiore di sanità. Lo scopo è quello di assicurare standard minimi di sicurezza e qualità in favore della tutela degli atleti e dell'intera società. La richiesta va presentata all'Istituto superiore di sanità, che provvederà alle verifiche tecniche dei requisiti strutturali, strumentali, funzionali e di dotazioni posseduti dai laboratori che avanzeranno la richiesta. Successivamente, la Sezione di vigilanza doping, verificata la documentazione, proporrà al Ministro della salute l'attribuzione del certificato LAD al laboratorio, di validità triennale". Provvedimento del 28 luglio 2015 in www.salute.gov.it.

${ }^{79}$ L'art. 6 rimette alle FSN la possibilità di stabilire sanzioni disciplinari per la somministrazione o l'assunzione di farmaci o di sostanze $o$ per il ricorso a pratiche mediche rispondenti ai requisiti di cui alla definizione di doping "anche nel caso in cui questi non siano ripartiti nelle classi di cui all'art. 2, comma primo, a condizione che tali farmaci, sostanze o pratiche siano considerati dopanti nell'ambito dell'ordinamento internazionale vigente". Tale previsione legislativa, infatti, va evidentemente riferita a quelle c.d. "sostanze specifiche", che - pur considerate dopanti nell'ambito dell'ordinamento internazionale vigente, ove vengono definite "specified substances" - possono essere o meno incluse nei regolamenti nazionali. Trattasi, per lo più, di sostanze che sono particolarmente suscettibili di violazioni non intenzionali delle norme antidoping, a causa della loro larga diffusione nei prodotti medicinali, o che sono meno suscettibili di essere utilizzate con successo come agenti dopanti.
} 
agli ospedali o alle altre strutture autorizzate" ${ }^{80}$ oltre quello di rendere nota la qualità dopante della sostanza contenuta mediante apposizione di specifico contrassegno sull'involucro esterno della confezione e sul foglio illustrativo; quest'ultimo deve, altresì, aver presente un paragrafo contenente le precauzioni per coloro che praticano attività sportiva. Inoltre, sussiste l'obbligo a carico del Ministero della sanità, in base all'art. 8, di tenere informato, mediante una relazione annuale, il Parlamento sullo stato di attuazione della legge e sull'operato della Commissione. $^{81}$

Sul piano dei comportamenti sanzionabili, l'art. 9 ha individuato tre nuove ipotesi di reato: 1) il procurare, somministrare, assumere o favorire l'utilizzazione di farmaci o di sostanze biologicamente o farmacologicamente attive $^{82}$ che non siano giustificati da condizioni patologiche e siano idonei a modificare le condizioni psicofisiche o biologiche dell'organismo, al fine di alterare le prestazioni agonistiche degli atleti, ovvero siano diretti a modificare i risultati dei controlli sull'uso di tali farmaci o sostanze ${ }^{83} 2$ ) il sottoporsi a pratiche mediche non

${ }^{80} \mathrm{Nel} 2017$ la percentuale più elevata di principi attivi rilevati ai controlli antidoping appartiene alla classe degli agenti anabolizzanti $(48,3 \%)$; a seguire gli stimolanti $(17,2 \%)$ e poi i corticosteroidi ed i diuretici ed agenti mascheranti $(8,6 \%)$. Nel corso del 2017 è possibile osservare come, per la prima volta da quando sono iniziati i controlli antidoping da parte della SVD, si rilevi una positività al JW1516, un antagonista del recettore delta attivato dal proliferatore del perossisoma (PPAR $\delta$ ) appartenente alla classe doping S4 (Modulatori ormonali e metabolici). Dall'analisi dei dati relativi alle preparazioni galeniche dichiarate dai farmacisti nel 2017, si nota una inversione di tendenza rispetto a quanto osservato nel 2016 (5.636 preparazioni nel 2016 vs. 6.172 nel 2017), quando era stata registrata una diminuzione nel numero delle preparazioni rispetto al trend essenzialmente in crescita osservato negli anni precedenti. Da sole, queste tre classi, rappresentano il $63,2 \%$ del totale delle dichiarazioni rilasciate dai farmacisti. La percentuale relativa alle preparazioni galeniche riconducibili ai diuretici ed agenti mascheranti, nel corso del 2017 ha fatto registrare una significativa variazione rispetto all'anno precedente: erano il 23,6\% delle preparazioni nel 2016, sono il $15,2 \%$ nel 2017. Si segnala inoltre un significativo aumento delle dichiarazioni relative alla classe degli stimolanti (14\% nel 2017 contro il 4,2\% nel 2016). Nel periodo 2003-2017 i principi attivi maggiormente utilizzati nelle preparazioni allestite dai farmacisti sono stati il deidroepiandrosterone ed il testosterone, entrambi agenti anabolizzanti. Relazione al Parlamento attività antidoping, anno 2017, p. 3.

${ }^{81}$ Cfr., nel presente testo, le relazioni degli anni 2010, 2013 e 2017.

${ }^{82}$ Rileva nel merito la decisione della Suprema corte secondo cui "le ipotesi di reato previste dall'art. 9 legge 14 dicembre 2000 n. 376 (disciplina delle attività sportive e della lotta contro il doping) sono configurabili anche per i fatti commessi dalla sua entrata in vigore $\mathrm{e}$ prima della emanazione, in data 15 ottobre 2002, del decreto del Ministro della salute, con il quale, in applicazione dell'art. 2 della stessa legge, sono stati ripartiti in classi i farmaci, le sostanze biologicamente o farmacologicamente attive e le pratiche mediche il cui impiego è considerato doping, e ciò in quanto la ripartizione in classi demandata al decreto ministeriale non può escludere farmaci, sostanze e pratiche mediche già vietati dalla convenzione di Strasburgo contro il doping, ratificata con legge 29 novembre $1995 \mathrm{n}$. 522 , e dalle Organizzazioni sportive internazionali competenti”. Cass. pen., S.U., 29 novembre 2005 n. 3087, in www.pluriscedam.utetgiuridica.it. L'orientamento è stato ribadito dal momento che "la lista dei farmaci contenuta nel d.m. Salute del 15.10 .02 ha natura 'ricognitiva' non 'costitutiva' per cui le ipotesi di reato previste dall'art. 9 della legge n. 376/2000 sono configurabili anche per i fatti commessi prima dell'emanazione del decreto". Cass. pen., sez. III, 3 settembre 2014, n. 36700, in www.pluriscedam.utetgiuridica.it.

${ }^{83}$ Non è punibile chi distribuisce sostanze dopanti nelle palestre se tale condotta non ha l'obiettivo di alterare le prestazioni agonistiche degli atleti. Cass. pen., sez. III, ord. 20 marzo 2002 n. 11277, con nota di M. Gingolani, Il doping secondo la Cassazione: qual è il bene giuridicamente tutelato?, in Riv. it. med. leg., 2003, pp. 423-426. "L'alterazione della prestazione agonistica come proiezione del dolo specifico deve esprimere qualcosa di differente rispetto a uno scontato richiamo alla voglia d'emergere e di primeggiare, e questo qualcosa in più non può allora essere che l'alterazione degli esiti di competizioni ufficialmente e professionalmente organizzate". Infatti, "se l'espressione legislativa si presta a comprendere anche i circuiti del dilettantismo, siano in ogni modo la ratio dell'intervento e le relative finalità general-preventive a restringere l'operatività della 1.376 al professionismo. Ergo, essa si applicherà alle competizioni organizzate o gestite dal CONI (o che si svolgono sotto lo scudo del CONI) o dalle singole federazioni sportive (in tutte le rispettive articolazioni nazionali, regionali o provinciali) e dalle società affiliate, oppure dalle associazioni sportive e dagli enti di promozione sportiva pubblica e privata, che richiedano a scopo di partecipazione il rispetto delle norme sull'abilitazione alla pratica sportiva agonistica e nel dettaglio il possesso del certificato di idoneità agonistica rilasciato da uno specialista in medicina dello sport: così, costituirà competizione sportiva la maratona organizzata da una data società nell'ambito dell'agenda delle manifestazioni della FIDAL, mentre sarà eccettuata la gara promossa dalla medesima società esclusivamente fra i propri associati e del tutto svincolata dall'egida federale. E ancora: non sempre la qualità di tesserato fa assumere alla pratica sportiva carattere di prestazione agonistica. Se, infatti, di regola il tesseramento è strumentale alla partecipazione alle gare, non possono escludersi casi di adesioni volte a un esercizio di attività sportiva slegato dall'iscrizione a competizioni, e proprio per tale ragione una buona parte di federazioni prevede il rilascio, ai soci dei sodalizi affiliati, di tessere non agonistiche. È evidente che in quest'ultima ipotesi sarà più difficile fornire la prova del dolo specifico (e anzi per lo più esso sarà da negare in radice) qualora scatti un controllo ma lo sportivo non risulti iscritto a una competizione e non abbia partecipato a precedenti manifestazioni. Pacifica è poi la non punibilità del culturista che assuma il doping al solo fine di soddisfare esigenze estetiche e che frequenti una palestra del tutto indipendentemente dallo svolgimento di gare ufficiali nel 
giustificate da una situazione patologica in atto e che siano idonee a modificare le condizioni psicofisiche o biologiche dell'organismo allo scopo di alterare le prestazioni agonistiche degli atleti (per es. il c.d. doping ematico o autoemotrasfusione) o siano dirette a modificare i risultati dei controlli medici, ${ }^{84} 3$ ) il commerciare ${ }^{85}$ farmaci o sostanze farmacologicamente o biologicamente attive fuori dai luoghi legalmente adibiti a ciò (farmacie aperte al pubblico ed altri luoghi equiparati). ${ }^{86}$ Attraverso tale ultima norma è, dall'entrata in vigore, possibile

senso di cui sopra, e che non risulti neppure tesserato a una federazione (a es. Federazione italiana pesistica), o a un organismo riconosciuto dal CONI o ad altro ente di promozione sportiva privato [...] Il concetto di prestazioni agonistiche cui si riferisce il dolo specifico è da intendere estensivamente e teleologicamente quale comprensivo di qualsiasi manifestazione sportiva competitiva, incluse fasi come quelle di allenamento strumentali e/o finalizzate alla gara in senso proprio: considerazione deducibile sia dalla previsione di controlli fuori gara ai sensi della lett. c) del co. 1 dell'art. 3 1. 376; sia dall'insensatezza, nei giochi di squadra, di esonerare dai test gli atleti non schierati; sia ancora dal testuale impiego della formula prestazioni anziché di un comunque più delimitato competizioni”. S. Bonini, Doping tra sanzione penale e giustizia sportiva: il ruolo discriminante del dolo specifico, cit., p. 19. Cfr., altresì, G. Lageard, Doping. Non è reato somministrare sostanze anabolizzanti senza fine di alterare la prestazione agonistica, in Dir. pen. proc., 2002, VIII, pp. 1004-1007. Per quanto riguarda l'effettiva incidenza delle sostanze assunte sulla prestazione agonistica è necessario partire dall'orientamento della giurisprudenza che specifica che la legge 376/2000 è posta sia a presidio della regolarità delle competizioni sportive, sia a tutela della salute. Cfr. Cass. pen., sez. II, 11 marzo 2010, n. 12744, in Rass. dir. farm., 2010, p. 753 ss.; Cass. pen., S.U., 29 novembre 2005 - 25 gennaio 2006, n. 3089, in Foro it., 2006, VII-VIII, p. 442 ss. Ne discende che la prevalente corrente di legittimità ritiene che sia sufficiente l'assunzione con il fine di alterare le prestazioni agonistiche, senza che sia necessario che le sostanze dopanti abbiano realmente alterato la prestazione agonistica, in quanto l'utilizzo di sostanze integra un "reato di pura condotta (poiché la legge non richiede che l'azione produca anche un determinato effetto esteriore) e di pericolo presunto (per la sua funzione di tutela anticipata dei beni protetti)". Cfr. Cass. pen., sez. III, 21 giugno 2007, n. 27279, in Cass. pen., 2008, VI, p. 2573 ss. Al contrario si rinviene una pronuncia del Tribunale di Roma che si pone in contrasto con l'orientamento prevalente che stabilisce che non può considerarsi verificata la condizione necessaria per la configurazione degli elementi strutturali del reato di assunzione di doping qualora venga dimostrato l'utilizzo delle sostanze proibite ma non ne venga accertata l'effettiva incidenza sulle prestazioni agonistiche dell'atleta che ne ha fatto uso. Nel caso deciso dal Tribunale, nei campioni di urina di un ciclista dilettante era stata rinvenuta la presenza di efedrina in misura superiore a 10 microgrammi per litro e di due metaboliti di cocaina, ma al termine del processo non era stata raggiunta la prova della permanenza dell'efficacia alteratrice della sostanza assunta al momento della competizione e per tanto l'atleta fu assolto. Cfr. Trib. Roma, sez. VIII pen., 3 ottobre 2013 n. 16116, con nota di L. Zambelli, Doping autogeno: è necessaria l'effettiva incidenza delle sostanze sulla prestazione agonistica?, in Dir. dello sport, 2013, III-IV, p. 237 ss.

${ }^{84}$ Il divieto è esteso al c.d. "doping genetico". Con riferimento specifico alla condotta di sottoposizione, si è inteso sanzionare tutti quei comportamenti con cui l'atleta acconsente a seguire cicli di cure o altri trattamenti proibiti nella consapevolezza che agli stessi non corrisponde un'esigenza terapeutica e anche nella fattispecie in esame il legislatore richiede che le pratiche mediche siano idonee a modificare le condizioni psicofisiche o biologiche dell'individuo. Essendo la condotta destinata, di regola, a protrarsi nel tempo, il reato è generalmente di natura permanente. Rileva, per tale aspetto specifico, il termine di prescrizione vigente che decorre dal giorno in cui è cessata la permanenza o, nei casi in cui la condotta sia invece istantanea, dal momento in cui la condotta stessa è stata posta in essere. Cfr. G. Ariolli, V. Bellini, Disposizioni penali in materia di doping, cit., pp. 91-96.

${ }^{85}$ Giova precisare, al riguardo, come la giurisprudenza abbia rilevato che "il termine commercio non può che evocare concetti tipicamente civilistici ed essere inteso, dunque, nel senso di un'attività di intermediazione nella circolazione dei beni che, sia pure senza il rigore derivante dal recepimento della definizione mutuata dagli artt. 2082 e 2195 c.c., sia tuttavia connotata dal carattere della continuità, oltre che da una sia pur elementare organizzazione". Cass. civ., sez. VI, 11 aprile 2003, n. 17322, in www.pluris-cedam.utetgiuridica.it. Ripetuti chiarimenti hanno riguardato la nozione di commercio, inteso in via generale in un senso "simil-civilistico", come attività che, anche al di là del rigore di cui agli artt. 2082 e 2195 del c.c., sia connotata dal carattere della continuità e da una almeno elementare organizzazione. Cfr. Cass. pen., sez. II, 9 ottobre 2003, n. 7081; Cass. pen., sez. III, 27 febbraio 2007, n. 21092; Cass. pen., sez. II, 11 marzo 2010, n. 12744, tutte consultabili in www.pluris-cedam.utetgiuridica.it. Si noti che l'attività di fornitura di anabolizzanti nell'ambito di una società commerciale va qualificata come commercio clandestino di sostanze farmacologicamente attive e non quale somministrazione ex legge n. 376/2000, in quanto il commercio clandestino realizza una fattispecie più grave, che dunque assorbe la condotta di somministrazione e che richiede unicamente il dolo generico. Cass. pen., 28 febbraio 2017, n. 19198, in www.dejure.it.

${ }^{86} \mathrm{Si}$ trattava di un reato comune, in quanto poteva essere commesso da qualunque soggetto, e di mero pericolo, non rilevando che le sostanze illegalmente commerciate siano state successivamente impiegate, la cui condotta incriminata era quella dello smercio nel mercato nero di qualsiasi sostanza, farmaci compresi, avente effetti dopanti. Era necessario il mero dolo generico (l'intenzionalità di commercializzare sostanze dopanti in assenza delle prescritte autorizzazioni ed abilitazioni) e non quello specifico, come nelle fattispecie di cui ai primi due commi dell'art. 9. La previsione incriminatrice risponde unicamente all'esigenza di evitare che tali sostanze siano immesse sul mercato al di fuori delle rigorose prescrizioni di cui all'art. 7 e non richiede, invece, che la condotta del soggetto agente sia finalizzata ad alterare le prestazioni agonistiche o i risultati dei controlli effettuati; la mancata previsione del fine specifico consente di estendere l'ambito della fattispecie anche oltre i ristretti limiti delle competizioni agonistiche, per punire il commercio clandestino destinato ai non atleti, con particolare riferimento ai frequentatori di palestre. Infatti, secondo concorde giurisprudenza, "per la configurabilità del delitto di commercio di sostanze farmacologicamente o biologicamente attive (cosiddette 
perseguire l'eterodoping, ${ }^{87}$ che si ha nell'ipotesi in cui si procuri ad altri (attività di mera intermediazione) ${ }^{88}$ si somministri (che si configura attraverso la consegna per utilizzo immediato ma anche futuro), ${ }^{89} \mathrm{o}$ si favorisca l'utilizzazione (qualsiasi condotta che, non rientrando nel procacciamento e nella somministrazione, faciliti l'utilizzo di sostanze vietate) $)^{90}$ di farmaci o di sostanze vietate oppure si adottino pratiche mediche vietate (che

anabolizzanti), previsto dall'art. 9, comma settimo, della 1. 14 dicembre 2000, n. 376, in materia di lotta contro il 'doping', non è richiesto il dolo specifico, in quanto il commercio clandestino di tali sostanze viene punito indipendentemente dal fine specifico perseguito dal soggetto agente e configura un reato di pericolo, diretto a prevenire il rischio derivante dalla messa in circolazione di tali farmaci, al di fuori delle prescrizioni imposte dalla legge, per la tutela sanitaria delle attività sportive". Cass. pen., sez. II, 15 novembre 2011, n. 43328, con nota di G. Rotolo, In tema di esercizio abusivo della professione medica, truffa e commercio illegale di sostanze dopanti, in Riv. it. med. leg. dir. san., 2012, II, pp. 742-747. Infine, il delitto deve essere considerato come abituale: ai fini della responsabilità sarà, pertanto, necessario accertare una reiterazione della condotta protratta nel tempo, che faccia apparire $i$ singoli episodi che la compongono come momenti di una più ampia attività. Diversamente, potrà ipotizzarsi soltanto la più lieve ipotesi di procacciamento. Si noti che la condotta di "procurare ad altri" sostanze dopanti, prevista e punita dal comma primo, si distingue dal "commercio" proprio in ragione del profitto, che solo chi fa commercio persegue e consegue.

${ }^{87} \mathrm{Si}$ configura quale reato comune, realizzabile sia da soggetti totalmente estranei al mondo sportivo, sia da medici sociali, preparatori atletici e "coloro che, nell'economia della gara, apprestano un indispensabile supporto all'attività agonistica degli atleti". G. Vidiri, $L a$ frode sportiva: soggetti e condotta del reato (art. 1 legge 13 dicembre 1989, n. 401), in Riv. dir. sport., 1992, I, p. 129. L'artefice del delitto, al pari di quanto accade nei casi di doping autogeno, agisce con dolo specifico, giacché l'intento è quello specifico di "alterare le prestazioni agonistiche degli atleti, ovvero [...] modificare i risultati dei controlli sull'uso di tali farmaci o sostanze". M. Pittalis, Sport e diritto. L'attività sportiva fra performance e vita quotidiana, Milano, WKI, 2019, p. 730. La condotta volontaria, spontanea e consapevole dell'atleta può comportare l'applicazione all'autore del reato di eterodoping dell'attenuante di cui all'art. 62, n. 5, c.p., consistente nel concorso del fatto doloso della vittima con l'azione o l'omissione del colpevole. Cfr. S. Bonini, Doping e diritto penale, Padova, Cedam, 2006, p. 226.

${ }^{88}$ Non è necessaria, ai fini della consumazione del reato, la sua effettiva consegna al consumatore finale, che sembra essere, invece, necessaria nel caso della somministrazione. Nel concetto di "procurare" sembra rientrare sia la fattispecie dell'intermediazione per la messa a disposizione della sostanza proibita, sia quella della sua vendita a titolo oneroso, sia quella della cessione a titolo gratuito. G. Lageard, Sport e diritto penale: il legislatore introduce il reato di doping, in Dir. pen. e proc., 2001, IV, p. 434. Cfr., altresì, E. Grappiolo, Profili penali del doping, cit., p. 81. Si reputa penalmente perseguibile chi svolge un'attività di intermediazione finalizzata ad ottenere la disponibilità di prodotti dopanti per cederli successivamente a terzi, nonché chi si limita ad indicare allo sportivo il nome di un venditore o a instaurare un contatto tra i due, senza che divenga necessaria la dazione materiale della sostanza. G. Gambogi, Profili attuali di diritto sportivo e nuova legge antidoping, cit., p. 61.

${ }^{89}$ Situazione nella quale ci si trova di fronte ad una prescrizione medica volta a consentire a taluno la disponibilità di sostanze dopanti ma, a differenza della fattispecie prevista dall'art. 445 c.p. nel quale per somministrazione deve intendersi qualsiasi vendita, consegna o distribuzione, anche a titolo gratuito, purché effettuata in rapporto al pubblico, la previsione in esame sembrerebbe specificatamente finalizzata alla repressione delle attività mediche legate all'assunzione di sostanze dopanti. Lo testimonia l'autonoma rilevanza attribuita alla condotta di procurare ad altri sostanze proibite e l'introduzione di una specifica ipotesi di interdizione all'esercizio della professione, quando i fatti siano commessi da chi esercita la professione sanitaria (art. 9, comma quarto). Alla fattispecie in esame vanno ricondotte anche quelle situazioni in cui l'assunzione delle sostanze dopanti avvenga sulla base di una prescrizione medica, ma in assenza di una condizione patologica accertata. Rispetto alla condotta di somministrazione l'atleta assume la veste necessaria di oggetto materiale (colui sul quale cade l'attività illecita), pur con la particolarità che, nel contempo, è anche soggetto attivo di altra fattispecie di reato: quella di assunzione, sempreché consapevole e volontaria. Appare importante sottolineare che l'espressa previsione di una condotta di assunzione escluderà, il più delle volte, il concorso di persone tra l'atleta e l'extraneus che abbia provveduto alla somministrazione, anche se non può escludersi che un atleta possa istigare o concorrere materialmente con lo stesso (ad es. il medico sociale) nella somministrazione a sé medesimo o ad un altro atleta. Cfr. G. Ariolli, V. Bellini, Disposizioni penali in materia di doping, cit., p. 91, e A. Traversi, Diritto penale dello sport, Milano, Giuffrè, 2002, p. 119.

${ }^{90}$ Perché sia integrata questa fattispecie è sufficiente che l'autore abbia fornito un contributo finalizzato a creare le condizioni che rendano più agevole l'utilizzo delle sostanze proibite. Dunque, ogni forma di interposizione agevolatrice dell'uso di sostanze dopanti (es.; mettere a disposizione degli atleti la chiave di un armadietto ove sono contenuti farmaci; predisporre appositi locali in un impianto sportivo; procurare gli strumenti necessari per la somministrazione o assunzione delle sostanze dopanti). S. Bonini, Doping e diritto penale, cit., pp. 230-231. Alla condotta di procacciamento può essere ricondotto anche l'acquisto collettivo operato da parte di alcuni atleti per conto di altri e la successiva ripartizione tra i committenti (costoro risponderanno a titolo di concorso, con un aggravamento di pena qualora si tratti di cinque o più atleti, ai sensi dell'art. 112 c.p. G. Ariolli, V. Bellini, Disposizioni penali in materia di doping, cit., p. 70. Sul punto è particolarmente interessante la sentenza del Tribunale di Bolzano del 25 gennaio 2018 (che è stata però impugnata e al momento il procedimento è ancora pendente innanzi alla Corte d'Appello) con cui due medici ed un segretario della FIDAL sono stati condannati a pene pecuniarie, inibitorie (assunzione di incarichi presso il CONI e società sportive), interdittive (sospensione dall'esercizio della professione medica) e detentive per aver omesso di denunciare l'assunzione da parte del marciatore Alex Schwarzer 
riguardano la prescrizione ma anche la predisposizione di locali e attrezzature per agevolare attività come nel caso delle trasfusioni ematiche), ma anche l'autodoping (che si configura in caso di assunzione di farmaci o sostanze dopanti oppure nel caso di sottoposizione a pratiche mediche vietate). ${ }^{91}$ Occorre evidenziare che le fattispecie incriminatrici di cui all'art. 9, commi primo e secondo, sono, per la giurisprudenza della Suprema Corte, dei reati a struttura permanente, atteso che il momento consumativo del reato non si esaurisce con l'assunzione della sostanza dopante ma si protrae fino a quando la sostanza vietata è idonea ad alterare le condizioni psicofisiche dell'organismo dello sportivo che 1'ha utilizzata. ${ }^{92}$ Sempre nel merito della struttura del reato, la citata Sezione antidoping ha auspicato una rimodulazione dell'art. 9 che da reato a dolo specifico e di pura condotta, dovrebbe divenire a dolo generico al fine di non confinare l'operatività delle norme penali al solo circuito delle competizioni svolte sotto l'egida del CONI, in quanto le suddette fattispecie di reato si applicano solamente qualora il fine dell'assunzione o delle altre condotte vietate sia finalizzata all'alterazione delle prestazioni agonistiche degli atleti, dove per atleti la giurisprudenza ha individuato solamente coloro che partecipano alle competizioni organizzate da FSN, DSA e EPS, oltre ad avvertire l'esigenza di configurare un autonomo reato per la condotta del medico e non solo definirlo quale circostanza aggravante. Anche la figura del farmacista che, nello

durante la sua preparazione ai Giochi Olimpici di Londra del 2012. Nel procedimento sportivo innanzi al TNA l'atleta fu squalificato, mentre i medici coinvolti non furono considerati responsabili né dalla PNA, né successivamente dal TNA. La situazione è quindi inedita, infatti, mentre da un lato i giudici sportivi hanno considerato non rilevante la condotta omissiva in un contesto, come quello sportivo, in cui la fattispecie di omessa denuncia costituisce uno dei capi saldi del principio di lealtà e correttezza che pervade tutto l'ordinamento, dall'altro i giudici statali hanno posto l'accento proprio su quanto previsto dalla legge 376/2000 (ora art. 586-bis c.p.) per quanto riguarda la fattispecie di favoreggiamento. Tra le considerazioni del Tribunale di Bolzano è stato posto l'accento proprio sul "silenzio" dei medici e sulla loro inerzia nei confronti del marciatore, che di fatto avrebbero contribuito a rafforzare il suo convincimento nel proseguire l'assunzione di sostanze dannose per la sua salute, che si ricorda essere uno dei beni protetti dalla normativa statale antidoping. Ad ogni modo, l'opposto risultato raggiunto al termine dei due processi, quello sportivo e quello statale, pone ancor'oggi in evidenza il disallineamento delle diverse normative in materia di doping, che invece dovrebbero trovare un punto d'incontro proprio in considerazione di quanto enunciato dall'art. 6, comma primo della legge 376/2000 "il C.O.N.I., le federazioni sportive, le società affiliate, le associazioni sportive, gli enti di promozione sportiva pubblici e privati sono tenuti ad adeguare i loro regolamenti alle disposizioni della presente legge, prevedendo in particolare le sanzioni e le procedure disciplinari nei confronti dei tesserati in caso di doping o di rifiuto a sottoporsi ai controlli". Cfr. G. Caristi, La responsabilità del medico sportivo in ipotesi di doping, in Olympialex Review, 2018, II, pp. 113-123, e L. Zambelli, Doping autogeno, cit., p. 247.

${ }^{91}$ Si punisce l'atleta che ricorre al doping autogeno perché si mira a proteggere la regolarità delle competizioni, offese dalla sleale alterazione della propria capacità di prestazione, laddove per tutela della regolarità della competizione occorre intendere non già una tutela ideale dei valori olimpici ma una protezione rivolta a una serie di interessi patrimoniali concreti, che vanno dalle promesse di premi in danaro ai vincitori alle scommesse e ai pronostici sulle gare, dalle sponsorizzazioni alle quotazioni in borsa di società sportive, senza trascurare che l'alterazione della performance da parte di un atleta danneggia i concorrenti che gareggiano con lealtà e correttezza lavorando solo ed unicamente sulle proprie forze. Si noti che lo scenario emotivo del reato si fonda sulla paura dell'insuccesso e/o di vedere scemata la propria quotazione tecnica ed economica: ansia che può manifestarsi in forma acuta (c.d. sindrome preagonistica) $o$ cronica (c.d. sindrome del campione). Sebbene si tratti di reato comune, va osservato che, con riguardo alla condotta di assunzione, soggetto attivo del reato sarà sempre l'atleta e ciò risulta dalla stretta relazione che deve intercorrere tra l'assunzione della sostanza interdetta, i suoi effetti modificativi e lo svolgimento della prestazione agonistica. All'uopo, "il delitto di doping autogeno non costituisce reato comune, bensì reato proprio, alla stregua del fatto che può essere commesso da chi possiede particolari requisiti”. M. Pittalis, Sport e diritto, cit., p. 726. Rileva il problema della disparità di trattamento di condotte del tutto simili, in particolare per il trattamento peggiore riservato dal legislatore all'assuntore di sostanze dopanti rispetto all'assuntore di sostanze stupefacenti o psicotrope, che invece non è sottoposto ad alcuna pena in quanto per il nostro ordinamento tale fatto non costituisce reato. G. Marra, Tutela della salute umana ed etica sportiva nella nuova legge contro il doping. Profili penalistici, in Cass. pen., 2001, X, p. 2859. Si noti che per la configurabilità del delitto di uso di sostanze farmacologicamente o biologicamente attive (c.d. anabolizzanti), previsto dall'art. 9 legge 14 dicembre 2000 n. 376, non è richiesto che l'attività sportiva sia svolta a livello professionistico o comunque agonistico. Cass. pen., sez. III, ord. 18 aprile 2013, n. 32963, in www.pluris-cedam.utetgiuridica.it.

${ }^{92} \mathrm{La}$ struttura è di particolare rilievo in quanto il delitto "si perfeziona nel momento dell'assunzione della sostanza vietata [...] pertanto la competenza territoriale va individuata in relazione al luogo in cui la sostanza viene somministrata, assunta o favorita l'assunzione" Cass. pen., sez. VI, 22 giugno 2017 n. 39482 in Cass. pen., 2018, II, pp. 632 ss., In caso contrario "potrebbe pervenirsi, tra l'altro, all'inaccettabile conseguenza che un atleta deliberatamente decida di assumere detta sostanza nel territorio di uno Stato che non reprime o che comunque disciplina con regole più benevoli il fenomeno doping, con la finalità di effettuare poi la prestazione agonistica [...] nel territorio dello Stato italiano, pretendendo di non violare, attraverso tale espediente, la normativa penale vigente nel nostro Paese, che è rivolta invece anche a salvaguardare i principi etici ed i valori educativi espressi dall'attività sportiva”. Cass. pen., sez. III, 12 luglio 2007, n. 27279, in Guida dir., 2007, p. 83. 
svolgimento della sua attività professionale, venda sottobanco sostanze e farmaci destinati a finalità non coincidenti e anzi alternative rispetto a quelle codificate dovrebbe, all'uopo, essere sanzionata con autonoma previsione. ${ }^{93}$ Numerose sono le critiche mosse alla norma, ${ }^{94}$ purtuttavia, la stessa è considerabile, al momento, l'unica soluzione legislativa in grado di arginare il fenomeno in discussione. Nonostante le diverse istanze di revisione ed integrazione delle norme incriminatrici in materia di doping, le uniche modifiche che sono state apportate alla legge statale si devono al d.lgs. n. 21 del $1^{\circ}$ marzo $2018^{95}$ che nell'ambito di un riordino complessivo delle leggi penali sparse per l'ordinamento ha previsto l'abrogazione dell'art. 9 della 1. 376/2000, trasponendo poi quasi integralmente le sue disposizioni nel nuovo art. 586-bis del codice penale. Le norme sono rimaste, così, sostanzialmente invariate, se non per quanto riguarda la condotta che punisce il commercio di sostanze dopanti. ${ }^{96}$ Infatti, durante la trasposizione la norma è stata modificata aggiungendo il nuovo elemento costitutivo del dolo specifico consistente nella finalità "di alterare le prestazioni agonistiche degli atleti", così come previsto per le altre due disposizioni incriminatrici di cui ai commi primo e secondo. In questo modo anche il traffico delle sostanze dopanti viene circoscritto alle ipotesi in cui la commercializzazione dei prodotti avviene all'interno di un circuito finalizzato alla cessione delle sostanze agli atleti rientranti nella definizione di cui al comma primo, di fatto rischiando di sottrarre alle indagini e ai provvedimenti dell'A.G. tutta quella categoria di soggetti che non sono tesserati presso FSN, DSA o EPS. ${ }^{97}$ Per la sussistenza del reato il legislatore ancora oggi chiede la presenza, in capo all'agente, di un dolo specifico, consistente nella coscienza e volontarietà di porre in essere la condotta incriminata con la finalità di alterare le prestazioni agonistiche degli sportivi o di modificare i risultati dei controlli antidoping; analoghe considerazioni non valgono per l'illecito sportivo per la cui sussistenza non è richiesto l'accertamento dell'elemento soggettivo, in quanto quest'ultimo rileva solo in sede di determinazione della misura della pena, salvo in casi eccezionali. Conseguentemente nel caso in cui la condotta dell'agente realizzi un reato a questo si accompagnerà quasi sempre un illecito sportivo, mentre se si pone in

\footnotetext{
${ }^{93}$ Relazione al Parlamento attività antidoping, anno 2013.

${ }^{94}$ Secondo alcuni autori la legge n. 376/2000 "presenta almeno tre grandi lacune: a) persegue e punisce (sostanzialmente) solo gli atleti professionisti (e non anche quindi quelli dilettanti ed amatoriali, come invece era previsto nel testo licenziato dal Senato prima della sua modifica definitiva), né - tantomeno - ad es. il cittadino che frequenta una palestra; b) fa riferimento ad un elenco di sostanze e di pratiche dopanti che, seppure aggiornato, come per legge, con cadenza semestrale, non assicura la possibilità di individuare le varie metodiche e i prodotti dopanti che sono in continua evoluzione; c) difetta di prevedere responsabilità penali a carico di chi rifiuta di sottoporsi ai controlli antidoping - oggi punito solo dal punto di vista sportivo [...]". A. Foggia, Corpi perfetti tra pillole e falsi traguardi, in Social News, 2007, VII, pp. 26-27.

95 "Disposizioni di attuazione del principio di delega della riserva di codice nella materia penale a norma dell'art. 1, co. 85, let. q) della 1. 23 giugno 2017" in G.U. n. 68 del 22 marzo 2018, serie generale ed entrato in vigore il 6 aprile 2018. In realtà in precedenza era stata approvata la legge 11 gennaio 2018, n. 3, che aveva aggiunto il comma 7-bis all'art. 9 della legge n. 376/2000, prevedendo l'applicazione della pena di cui all'art. 9, comma 7, anche "al farmacista che, in assenza di prescrizione medica, dispensi i farmaci e le sostanze farmacologicamente o biologicamente attive ricompresi nelle classi di cui all'articolo 2, comma uno, per finalità diverse da quelle proprie ovvero da quelle indicate nell'autorizzazione all'immissione in commercio". La norma è rimasta in vigore solo per pochi mesi sino all'introduzione dell'art. 586-bis c.p. adopera del d.lgs. n. 21/2018 che non prevede più la fattispecie riguardante il farmacista. M. Pittalis, Sport e diritto, cit., p. 735.
}

${ }^{96}$ Quando era vigente l'art. 9 della legge n. 376/2000 le relative sanzioni erano della reclusione da tre mesi a tre anni e la multa da 2.500 a 50.000 euro. L'attuale previsione sanzionatoria è mutata in ordine ai soli importi della multa, attualmente da "euro 2.582 a euro 51.645". Invariata è la previsione di aumento di pena a carico di chi: a) somministra, utilizza, procaccia o cede sostanze o pratiche mediche vietate da cui sia derivato un danno alla salute; b) se il fatto sia stato commesso nei confronti di un minorenne; d) se il fatto sia stato commesso da un componente o da un dipendente del CONI o di una FSN, di una società, di una associazione o di un ente riconosciuto dal CONI. Invariate, altresì, le pene accessorie quali: l'interdizione temporanea dall'esercizio della professione, se il fatto è commesso da chi esercita una professione sanitaria; l'interdizione permanente dagli uffici direttivi del CONI, delle FSN, società, associazioni ed EPS riconosciuti dal CONI, nel caso previsto dal comma terzo, lett. c). Invariata, infine, la previsione di confisca dei farmaci, delle sostanze farmaceutiche e delle altre cose servite o destinate a commettere il reato.

${ }^{97}$ Nei lavori preparatori alle modifiche di cui al d.lgs. n. 21/2018 non si rinviene alcuna relazione sulla necessità di questa modifica, tanto che il Tribunale di Brescia ha già dichiarato non manifestamente infondata la questione della legittimità costituzionale dell'art. 2 , co. 1 lett. d) del d.lgs. $1^{\circ}$ marzo 2018 n. 21 nella parte in cui prevede che il nuovo art. 586-bis comma 7 aggiunga l'elemento del dolo specifico alla condotta di commercio di sostanze. Il giudice ha poi considerato non rilevante per il caso di specie la questione, che dunque non è stata rimessa alla Corte costituzionale. La sentenza è consultabile. Trib. Brescia, Sez. I, 9 maggio 2018 n. 1642 , in Cass pen., 2018, 9, pp. 3018 ss. 
essere un illecito sportivo di doping la responsabilità penale dipenderà dall'ulteriore requisito soggettivo del dolo sia nella sua declinazione generica che in quella specifica. ${ }^{98}$ Sempre sul piano dei più recenti interventi normativi dello Stato in tema di lotta al doping vanno evidenziati: a) il d.P.C.M. 12 gennaio 2017 (all. 1) ${ }^{99}$ che definisce i livelli essenziali di assistenza in ambito sanitario (LEA) prevedendo l'adozione di "programmi di prevenzione e contrasto al doping" nell'ambito della promozione dell'attività fisica e tutela sanitaria dell'attività fisica; b) l'erogazione, nel 2018, di fondi ad enti pubblici - diversi dalla Sezione di vigilanza e controllo sul doping - per progetti di ricerca e formazione ed informazione sul doping all'interno del "piano delle performance 2018-2020" adottato dal Ministero della salute. ${ }^{100}$ Con questo intervento le Aziende Sanitarie vengono fornite di una dotazione finanziaria che potrà permettere alle diverse unità di Medicina dello sport di organizzare degli interventi formativi riguardo ai rischi del doping che sono ancora in gran parte ignorati dalla popolazione che pratica abitualmente attività fisica, ${ }^{101}$ soprattutto nella fascia giovanile, età in cui la Sezione di vigilanza e controllo sul doping ha recentemente dimostrato che avviene la prima scelta di utilizzare prodotti non salutari. È evidente il tentativo di sviluppare un nuovo approccio alla lotta al doping in passato demandato solo al CONI e alla Sezione di vigilanza e controllo sul doping attraverso la formazione di una coscienza sui rischi dell'uso di sostanze dopanti quanto più esteso possibile nel campo medico e sanitario.

\section{Organi e procedure antidoping. Le indagini disciplinari}

La finalità dell'antidoping in ambito sportivo è quella di tutelare in primis la lealtà sportiva e la correttezza nelle competizioni sportive e solo secondariamente la salute degli atleti dal momento che tale funzione viene svolta essenzialmente dalla normativa penale. Già con la delibera del 22 luglio 1988, n. 487, il CONI aveva recepito le direttive antidoping del CIO dettando una disciplina uniforme per tutte le FSN. ${ }^{102}$ Queste ultime, successivamente, istituirono, con proprio regolamento, un sistema di controlli ed il relativo regime di sanzioni

${ }^{98}$ Il calciatore Andreoni venne squalificato in primo grado per un periodo di quattro anni mentre in secondo grado il TNA rideterminò la squalifica a due anni sulla base del fatto che "il periodo di squalifica previsto dal CSA a fronte dell'accertata presenza di sostanze specificate in un campione biologico è di quattro anni di squalifica se l'UPA è in grado di provare che la violazione è intenzionale, di due anni in caso di siffatta prova (art. 4.2.2. C.S.A)". F. Ferrari, Il doping e lo sport: il caso Andreoni, in Riv. dir. econ. sport., 2016, I, p. 123.

${ }^{99}$ G.U. n. 65 dell'8 marzo 2017, serie generale.

${ }^{100}$ L'erogazione di fondi è stata confermata anche nel Piano delle Performance del 2019-2021, entrambi i documenti sono consultabili in www.salute.gov.it.

${ }^{101}$ Questo non significa che gli organi che si occupavano già di formazione anti doping debbano smettere di fare ricerca e sensibilizzazione sull'argomento, in proposito nel corso del 2017 sono stati individuati 4 progetti di formazione tra cui si evidenzia il progetto "Effetti della criosauna sui meccanismi infiammatori e sull'assetto ormonale degli atleti” realizzato dall'Università degli Studi di Modena e Reggio Emilia. Il progetto ha come obiettivo principale quello di osservare le modificazioni indotte dalla criosauna sul sistema immunitario e sulla regolazione del processo infiammatorio nell'atleta. Le intenzioni sono principalmente quelle di indagare gli effetti della criosauna sulla salute dell'atleta e su un eventuale effetto dopante di tale pratica. La criosauna (Whole Body Criotherapy) è una metodica molto diffusa tra gli atleti e pochi sono ancora gli studi sui relativi effetti sulla salute ed i presunti benefici sul recupero da infortunio. Il progetto offre un valido contributo scientifico per una migliore valutazione della criosauna ed il relativo impatto di questa pratica su salute e prestazione dell'atleta. Un altro progetto che ha ricevuto i finanziamenti è "Implementazione e valutazione dell'efficacia di un intervento di Media Literacy sull'uso di sostanze dopanti in studenti di scienze motorie", che ha l'obiettivo di implementare e testare, su un ampio campione di atleti/studenti di scienze motorie di quattro differenti atenei del territorio italiano, un intervento di Media Literacy recentemente sviluppato e testato in ambito scolastico dai proponenti. L'intervento, mirato allo sviluppo di competenze che contrastino le pressioni dei media verso l'uso di doping, consiste in 12 sessioni nell'arco di 6 mesi. Attraverso un disegno pre/post con gruppo di controllo verrà valutata anche l'efficacia dell'intervento sulle competenze legate ai media degli studenti di scienze motorie (conoscenze, senso critico, coscienza del potere persuasivo, ecc.), sui loro sistemi di credenze, e sui loro comportamenti riguardo l'uso di sostanze illegali (doping) e legali (integratori) nello sport. Inoltre verrà attivato il progetto: "Prevenzione del doping: elaborazione di uno strumento permanente di educazione coordinato dai dipartimenti di prevenzione del SSN" che offre lo spunto per la realizzazione di uno strumento utile alla formazione costante degli operatori sanitari dei Dipartimenti di Prevenzione sul territorio nazionale in merito alle tematiche del doping. Relazione al Parlamento attività antidoping, anno 2017.

102 "La mancanza di uniformità tra i diversi regolamenti delle singole FSN permetteva che due atleti, positivi per la stessa sostanza, potessero essere giudicati in modo differente perché praticanti discipline diverse”. L. Di Nella, Manuale di diritto dello sport, cit., p. 317. 
dirette agli atleti risultati "positivi” ed alle società di appartenenza. ${ }^{103}$ Attualmente vigono le Norme sportive antidoping (NSA) ${ }^{104}$ che disciplinano la materia dell'antidoping e le condizioni cui attenersi nell'esecuzione dell'attività sportiva, composte da: 1) Codice sportivo antidoping (CSA); 2) Disciplinare dei controlli e delle investigazioni (D-CI); 3) Disciplinare per le esenzioni ai fini terapeutici (D-EFT).

Il coordinamento fra normativa di fonte statale e quella di fonte domestica è stato sancito dall'art. 6 della legge n. 376/2000 che ha imposto l'obbligo al CONI, alle FSN, agli EPS, alle società affiliate ed alle associazioni sportive di adeguare i propri regolamenti alle disposizioni della predetta norma, prevedendo sanzioni per i soggetti dell'ordinamento sportivo risultati positivi ai controlli antidoping (anche nel caso di semplice rifiuto di sottoposizione agli accertamenti), nonché aggiornare e informare costantemente i dirigenti, tecnici, atleti e operatori sanitari sulle problematiche riguardanti il doping. ${ }^{105}$ L'incisività delle NSA è meglio comprensibile alla luce di quanto disposto dagli artt. 2 e 3 NSA che danno vita all'elenco dei comportamenti perseguiti disciplinarmente e che nel loro insieme costituiscono l'essenza di ciò che è considerabile, dal punto di vista sportivo, doping: ${ }^{106}$

Articolo 2 (Violazioni del Codice WADA) 2.1 La presenza di una sostanza vietata o dei suoi metaboliti o marker nel campione biologico dell'atleta ${ }^{107} \ldots$ 2.1.1 Ciascun atleta deve accertarsi personalmente di non assumere alcuna sostanza vietata ${ }^{108}$ poiché sarà ritenuto responsabile per il solo rinvenimento nei propri campioni biologici di qualsiasi sostanza vietata, metabolita o marker. Ai fini dell'accertamento della violazione delle NSA, infatti, non è necessario dimostrare il dolo, la colpa, la negligenza o l'uso consapevole da parte dell'atleta ${ }^{109} \ldots 2.2$ Uso o

${ }^{103}$ In base all'allora vigente art. 1 CGS vi era l'obbligo di mantenere una condotta conforme ai principi sportivi della lealtà, della probità e della rettitudine, nonché della correttezza morale e materiale in ogni rapporto di natura agonistica, economica e sociale; lo stesso codice sanzionava l'uso, doloso o colposo, di sostanze dopanti (art. 32).

${ }^{104}$ La versione vigente delle NSA in Italia è la n. 1/2020, approvata da NADO ITALIA in data 15 aprile 2020 approvata dalla Giunta nazionale del CONI il 4 giugno 2020.

${ }^{105}$ In base al quarto comma dell'art. 6 legge n. 376/2000 "Gli atleti aderiscono ai regolamenti di cui al comma 1 e dichiarano la propria conoscenza ed accettazione delle norme in essi contenute", mentre il successivo comma 5 prevede che "Il CONI, le federazioni sportive nazionali e gli enti di promozione dell'attività sportiva curano altresì l'aggiornamento e l'informazione dei dirigenti, dei tecnici, degli atleti e degli operatori sanitari sulle problematiche concernenti il doping. Le attività di cui al presente comma sono svolte senza ulteriori oneri a carico della finanza pubblica".

${ }^{106}$ L'art. 1 NSA (definizione di doping) cita testualmente "Per doping si intende la violazione di una o più norme contenute negli articoli dal 2.1 al 2.10 del presente Codice. Altre violazioni della normativa antidoping sono stabilite all'articolo 3 del presente Codice".

107 "Se l'evoluzione del sistema definitorio in materia è segnale di come il fenomeno si sia evoluto e di come ci sia dovuti porre di fronte ad esso scientificamente e giuridicamente in forma diversa [...] In tutte le definizioni ricorre, infatti, il termine atleta. Il fenomeno di massa alla base del problema rimane ignorato nella convinzione, forse, che il movimento olimpico sia rappresentativo esclusivamente degli atleti agonisti”. R. Nicolai, La lotta al doping tra ordinamento sportivo e ordinamento statale, in C. Bottari (a cura di), La tutela della salute nelle attività motorie e sportive: doping e problematiche giuridiche, cit., pp. 40-41. Rileva nel merito il caso di Alex Schwarzer, campione olimpico dei $50 \mathrm{~km}$ di marcia alle Olimpiadi di Pechino del 2008. Il 7 agosto 2012 l'allora Ufficio della Procura Antidoping (UPA), oggi Procura Nazionale Antidoping (PNA) provvide a iscrivere un procedimento disciplinare a carico dell'atleta ed ha richiesto al TNA, contestualmente, la sospensione immediata dello stesso da ogni attività agonistica, sulla base della comunicazione inviata dal CIO il 6 agosto 2012 relativo alla positività dell'esame dell'urine (Eritropoietina ricombinante) del 30 luglio 2012, costituente violazione dell'art. 4.2 delle allora vigenti NSA.

108 "Particolare importanza è riconosciuta al diritto/dovere di informazione dell'atleta: oltre a non far uso di tali sostanze, egli ha l'obbligo di informarsi su tutti i prodotti e metodi a lui prescritti e somministrati, nonché degli elenchi aggiornati delle sostanze o metodi vietati”. L. Di Nella, Manuale di diritto dello sport, cit., p. 309.

109 "Ciò significa che il semplice ritrovamento di sostanze vietate, non soltanto in relazione ai luoghi ove si svolge l'attività sportiva (ad esempio l'armadietto dell'atleta negli spogliato)i, ma altresì in relazione ai luoghi ove si svolge la sua vita privata (ad esempio, l'armadietto delle medicine presso la sua abitazione), costituisce accertamento di violazione che espone l'atleta alla sanzione, salva la prova contraria di non essere a conoscenza, senza sua colpa, della presenza di tali sostanze". G. Liotta, L. Santoro, Lezioni di diritto sportivo, cit., p. 288. La norma conclude prescrivendo che: "2.1.2 Uno dei seguenti casi costituisce prova sufficiente di violazione della normativa antidoping ai sensi dell'articolo 2.1:- la presenza nel campione biologico A di una sostanza vietata o dei suoi metaboliti o marker nel caso in cui l'Atleta rinunci all'analisi del campione biologico B e quest'ultimo non venga analizzato; - la presenza nel campione biologico B di una sostanza vietata o dei suoi metaboliti o marker che confermi l'esito delle analisi effettuate sul campione biologico A. il campione biologico B dell'Atleta viene suddiviso in due flaconi e le analisi del secondo flacone confermano la presenza di una sostanza vietata o dei suoi metaboliti o marker rinvenuta nel primo flacone. 2.1.3 La mera presenza di un qualsiasi quantitativo 
tentato uso di una sostanza vietata o di un metodo proibito da parte di un atleta ${ }^{110} \ldots 2.3$ Eludere, rifiutarsi od omettere di sottoporsi al prelievo dei campioni biologici. Eludere il prelievo dei campioni biologici, ovvero, senza giustificato motivo, rifiutarsi di sottoporsi al prelievo dei campioni biologici previa notifica, in conformità alla normativa antidoping applicabile... 2.4 Mancata reperibilità (Whereabouts Failures) ${ }^{111}$... 2.5 Manomissione o tentata manomissione in relazione a qualsiasi fase dei Controlli antidoping ${ }^{112}$... 2.6 Possesso di sostanze vietate e ricorso a metodi proibiti ${ }^{113}$... 2.7 Traffico illegale o tentato traffico illegale di sostanze vietate o metodi proibiti... 2.8 Somministrazione o tentata somministrazione ad un Atleta durante le competizioni, di una qualsiasi sostanza vietata o metodo proibito, oppure somministrazione o tentata somministrazione ad un Atleta, fuori competizione, di una sostanza o di un metodo che siano proibiti fuori competizione... 2.9 Complicità. Fornire assistenza, incoraggiamento e aiuto, istigare, dissimulare o assicurare ogni altro tipo di complicità intenzionale in riferimento a una qualsiasi violazione o tentata violazione delle NSA o violazione dell'articolo 4.12.1 da parte di altra persona $^{114}$... 2.10 Divieto di associazione ${ }^{115} \ldots$ Articolo 3 - Le seguenti voci costituiscono altre violazioni delle

di una sostanza vietata, dei suoi metaboliti o marker nel campione biologico dell'atleta costituisce di per sé una violazione delle NSA, fatta eccezione per le sostanze per le quali la Lista delle sostanze e dei metodi proibiti indica specificamente un valore soglia. 2.1.4 In deroga alla norma generale prevista dall'articolo 2.1, la Lista delle sostanze e dei metodi proibiti ovvero gli Standard Internazionali possono fissare alcuni criteri specifici per la valutazione delle sostanze vietate che possono essere prodotte per via endogena".

110 "2.2.1 Spetta ad ogni atleta accertarsi personalmente di non assumere alcuna sostanza vietata o di non utilizzare alcun metodo proibito. Ai fini dell'accertamento della violazione delle NSA, non sarà necessario dimostrare che vi sia dolo, colpa, negligenza o l'uso consapevole da parte dell'atleta. 2.2.2 Il successo o il fallimento dell'uso o del tentato uso di una sostanza vietata o di un metodo proibito non costituiscono un elemento essenziale. È sufficiente, infatti, che la sostanza vietata o il metodo proibito siano stati usati o si sia tentato di usarli per integrare una violazione delle NSA".

111 "Ogni violazione delle condizioni previste per gli Atleti che devono sottoporsi ai Controlli fuori competizione, incluse la mancata presentazione di informazioni utili sulla reperibilità e la mancata esecuzione di test in base a quanto previsto dal D-CI. Ogni combinazione di 3 (tre) Mancati controlli e/o omesse comunicazioni, così come definito dall'ISTI, entro un periodo di 12 (dodici) mesi da parte di un Atleta inserito in un RTP".

112 "Condotta volta a minare la procedura di controllo antidoping ma che non rientra nella definizione di pratiche vietate. La manomissione comprende, a titolo puramente esemplificativo, intralciare o tentare di intralciare intenzionalmente l'operato di un addetto al controllo antidoping, fornire informazioni fraudolente ad una Organizzazione Antidoping ovvero intimidire o tentare di intimidire un potenziale testimone".

113 "2.6.1 Possesso da parte di un atleta, durante le competizioni, di qualsiasi sostanza vietata o il ricorso a qualsiasi metodo proibito, oppure possesso da parte di un atleta, fuori competizione, di un metodo o di una sostanza espressamente vietati fuori competizione, a meno che l'atleta possa dimostrare che il possesso sia dovuto ad un uso terapeutico consentito nelle forme e nei modi di cui agli articoli 14 e $15 \mathrm{o}$ ad altro giustificato motivo. 2.6.2 Possesso da parte del personale di supporto dell'atleta, durante le competizioni, di qualsiasi sostanza vietata o di qualsiasi metodo proibito, oppure il possesso da parte del personale di supporto dell'atleta, fuori competizione, di una sostanza o di un metodo espressamente vietati fuori competizione, in relazione a un atleta, una competizione o un allenamento, a meno che il personale possa dimostrare che il possesso sia dovuto ad un uso terapeutico consentito nelle forme e nei modi di cui agli articoli 14 e 15 o ad altro giustificato motivo".

114 Secondo la sentenza del 16 gennaio 2015 del TNA del CONI, sez. II, Carolina Kostner, condannata a 16 mesi di squalifica per violazione dell'art. 2.9 delle NSA, mentì consapevolmente all'ispettore della WADA che si presentò a Oberstdorf, il 30 luglio del 2012 , per un controllo a campione a carico di Alex Schwarzer. All'atleta, a cui è stata riconosciuta l'attenuante di essere all'epoca dei fatti innamorata di Schwarzer, non è stato contestato l'aver coperto l'uso di sostante dopanti assunte dall'allora fidanzato, di cui non sapeva, né il non averlo denunciato per la frequentazione del dottor Ferrari. I giudici hanno però riconosciuto la sussistenza di fattori che hanno attenuato il suo grado di colpevolezza, riducendo la sanzione rispetto ai due anni altrimenti applicabili, ovvero l'aver agito sulla base di una richiesta della persona amata, al carattere subitaneo della richiesta, che esigeva una risposta nel giro di pochi secondi, all'assenza di elementi che facciano ritenere che il comportamento sia stato premeditato, al fatto che l'atleta si sia immediatamente attivata affinché Schwarzer si recasse nel luogo in cui poteva essere sottoposto al controllo (la stessa sera a Racines, a casa sua, dove venne riscontrata la positività all'eritropoietina) ed alla circostanza che l'atleta, pur consapevole dell'aiuto all'elusione del controllo, non sapeva che Schwarzer facesse uso di sostanze vietate. La sentenza, che poteva essere oggetto d'appello al TAS da parte della Kostner, della Procura antidoping del CONI o della WADA, è stata appellata proprio da tale ultimo ente, ma la vicenda si è conclusa con un "Consent agreement" tra l'Atleta e l'accusa in base al quale la squalifica della pattinatrice azzurra - in precedenza aumentata da 16 a 21 mesi dai giudici svizzeri, rispetto alla pronuncia di primo grado del TNA - è stata retrodatata al primo aprile 2014 in quanto il TAS ha ritenuto che "le lungaggini procedurali non erano attribuibili all'atleta". In questo modo la pattinatrice ha potuto partecipare ai Giochi Olimpici invernali del 2016. www.archiviostorico.corriere.it (5 ottobre 2015).

115 "L'atleta o altra persona soggetti alla autorità di una ADO, che in veste professionale o in altra veste sportiva si è associata, ovvero si è avvalsa o ha favorito la consulenza di Personale di supporto dell'Atleta: 2.10.1 Soggetto all'autorità di una Organizzazione Antidoping che stia scontando un periodo di squalifica, ovvero 2.10.2 Non soggetto all'autorità di una Organizzazione Antidoping, qualora la 
NSA: 3.1 Qualsiasi violazione riferita alle fasi del controllo antidoping disposto dalla CVD di cui alla legge 376/2000. 3.2 La mancata collaborazione da parte di qualunque soggetto per il rispetto delle NSA, ivi compresa l'omessa denuncia di circostanze rilevanti ai fini dell'accertamento di fatti di doping. 3.3 La condotta offensiva nei confronti del DCO e/o del personale addetto al controllo antidoping, la quale non sia configurabile come violazione dell'articolo 2.5 del CSA.

Gli organismi sportivi che hanno competenza nella lotta contro il doping sono il CIO, i comitati olimpici nazionali e le singole FSN. Si noti che il CONI, quale Organizzazione nazionale antidoping (NADO), ${ }^{116}$ è l'ente al quale compete la massima autorità e responsabilità in materia di adozione ed attuazione del programma mondiale antidoping WADA ivi comprese la pianificazione ed organizzazione dei controlli, la gestione dei risultati dei test e la conduzione dei dibattimenti. Gli organi previsti e disciplinati dalle NSA (che a loro volta sono le uniche disposizioni concernenti la lotta al doping che si applicano nell'ambito dell'ordinamento sportivo nazionale e che sono mutuate dal codice WADA) sono:

1) Il Comitato controlli antidoping (CCA), organismo indipendente, che provvede alla pianificazione ed organizzazione dei controlli antidoping, in competizione e fuori competizione. ${ }^{117}$

squalifica non sia stata trattata nell'ambito della procedura di gestione dei risultati ai sensi del Codice WADA, che sia stato condannato o ritenuto colpevole solo nell'ambito di un procedimento penale, disciplinare o professionale per aver assunto una condotta che costituisca violazione del regolamento antidoping ove fossero state applicati il Codice WADA e le NSA. Lo status di squalificato di tale persona sarà in vigore per un periodo di sei anni a decorrere dalla sentenza in sede penale, disciplinare o professionale ovvero per la durata della sanzione penale, disciplinare o professionale a seconda di quale periodo risulti maggiore; ovvero 2.10.3 Funga da copertura o intermediario per un soggetto di cui agli artt. 2.10 .1 o 2.10.2". Affinché questa norma trovi applicazione, è necessario che (a) l'atleta o l'altra persona siano stati informati preventivamente per iscritto da parte di NADO Italia, ovvero della WADA, in ordine allo stato di squalifica del personale di supporto dell'atleta e alle potenziali conseguenze derivanti dal divieto di associazione e (b) l'atleta o l'altra persona possano ragionevolmente evitare la consulenza o il supporto. L'organizzazione antidoping dovrà inoltre adoperarsi per informare il personale di supporto dell'atleta oggetto dell'avviso inviato all'atleta o all'altra persona, circa la possibilità di presentarsi, entro 15 (quindici) giorni, dinanzi all'organizzazione antidoping per spiegare che i criteri di cui agli articoli 2.10 .1 e 2.10 .2 non si applicano nei suoi confronti (fermo restando quanto previsto dall'articolo 23 del presente CSA, il presente articolo trova applicazione anche qualora la squalifica del personale di supporto dell'atleta sia stata comminata in data antecedente all'entrata in vigore delle presenti NSA). Spetta all'atleta o all'altra persona l'onere di dimostrare che l'eventuale associazione con il personale di supporto dell'atleta di cui agli articoli 2.10 .1 e 2.10 .2 non è di natura professionale o sportiva. Le organizzazioni antidoping che fossero a conoscenza di personale di supporto dell'atleta che risponda ai criteri di cui agli articoli 2.10.1, 2.10.2 e 2.10.3 dovranno dare comunicazione alla WADA.

116 "Il Comitato olimpico nazionale italiano (CONI), è l'autorità che disciplina, regola e gestisce le attività sportive in Italia, nonché cura l'adozione delle misure di prevenzione e repressione del doping nell'ambito dell'ordinamento sportivo con la funzione di Organizzazione nazionale antidoping (NADO). Il CONI è la Confederazione delle Federazioni sportive nazionali (di seguito FSN) e delle Discipline sportive associate (di seguito DSA) e si conforma ai principi dell'ordinamento sportivo internazionale, in armonia con le deliberazioni e gli indirizzi emanati dal Comitato olimpico internazionale (di seguito CIO). Il CONI quale NADO (di seguito anche CONI-NADO) è l'ente nazionale al quale compete la massima autorità e responsabilità in materia di attuazione ed adozione del Programma mondiale antidoping WADA ivi comprese la pianificazione ed organizzazione dei controlli, la gestione dei risultati dei test e la conduzione delle indagini e dei dibattimenti. Il CONI a tal fine ha adottato il Codice sportivo antidoping (di seguito CSA) ed i Disciplinari tecnici (di seguito DT), rispettivamente quali documenti tecnici attuativi del Codice mondiale antidoping WADA (di seguito Codice WADA) e degli Standard internazionali". Premessa al Documento tecnico attuativo del Codice mondiale antidoping e dei relativi Standard internazionali approvato dalla Giunta nazionale CONI il 18 novembre 2014. Nel merito cfr. G. Aiello, Il nuovo regolamento antidoping del CONI, in Riv. dir. sport., II-III, pp. 269-282.

${ }^{117} \mathrm{Al}$ CCA "è affidata l'attuazione del Piano di distribuzione dei controlli antidoping (TDP - Test Distribution Plan), che è elaborato con cadenza annuale dalla Giunta nazionale del CONI in base al potenziale di rischio di doping per ogni sport o disicplina sportiva. Al CCA è, altresì, assegnata l'elaborazione del Gruppo registrato ai fini dei controlli nazionali (RTP - Registered Testing Pool), nel quale sono elencati i nominativi di tutti gli atleti soggetti a controllo antidoping e, nell'ambito degli strumenti sopra detti, l'effettuazione dei controlli antidoping, sia di propria iniziativa sia, tenuto conto delle risorse economiche e delle valutazioni del rischio potenziale di doping, su richiesta delle altre strutture della NADO ITALIA, delle Federazioni sportive e delle Discipline sportive associate". Ė sua facoltà disporre controlli anche su atleti non inseriti nel Gruppo registrato o che facciano richiesta di esservi inclusi perché desiderano essere sottoposti ai controlli pur in assenza dei requisiti per l'iscrizione obbligatoria. G. LIOTTA, L. SANTORO, Lezioni di diritto sportivo, cit., p. 293. Sul piano prettamente disciplinare si rimanda, nel merito, alla lettura integrale dell'art. 16 NSA. Nella Relazione al Parlamento attività antidoping (2017) è indicato il numero dei controlli effettuati nello stesso anno rilevando che i settori sportivi più soggetti a controlli sono il ciclismo (226 atleti - 46 eventi), calcio (176 atleti - 44 eventi), pallacanestro (132 atleti - 33 eventi), atletica 
2) Il Comitato esenzioni a fini terapeutici (CEFT), organismo indipendente, che provvede all'attuazione delle procedure inerenti la richiesta di esenzione a fini terapeutici (Therapeutic use exemption - TUE) $)^{118}$

3) La Procura Nazionale Antidoping (PNA), ${ }^{119}$ già Ufficio Procura Antidoping (UPA), organismo indipendente nominato dalla Giunta nazionale del CONI con mandato quadriennale, che provvede a) alla gestione dei risultati di laboratorio, b) a compiere, in via esclusiva, tutti gli atti necessari all'accertamento delle violazioni delle NSA da parte dei soggetti sui quali il CONI-NADO ha giurisdizione, avviando la relativa azione disciplinare attraverso la convocazione dell'indagato e procedendo alla contestazione dei relativi addebiti disciplinari, c) a curare $\mathrm{i}$ rapporti con l'A.G. comunicando alla Procura della Repubblica le violazioni delle NSA contestate; ${ }^{120}$ rileva in particolar modo il dispositivo dell'art. 23 NSA, secondo cui è "fatto obbligo per chiunque dare immediata comunicazione alla PNA di tutte le violazioni in materia di doping delle quali sia in qualsiasi modo venuto a conoscenza". Si noti che la PNA oltre a dover indagare sui casi di vendita, cessione all'atleta o procacciamento di sostanze dopanti deve valutare anche le ipotesi di istigazione per fare uso di qualsiasi sostanza o metodo vietato, anche se l'accordo non viene accolto o non realizzato. ${ }^{121}$

leggera (169 atleti - 35 eventi). Si tratta degli sport che storicamente vantano il maggior numero di tesserati o che sono stati maggiormente soggetti alla diffusione delle sostanze dopanti. Un dato di particolare rilievo è quello di cui al grafico 2 (pag. 2) della Relazione in cui si osserva come la maggior attività di controllo venga fatta nel mese di ottobre, mentre i mesi in cui il numero di controlli cala in maniera significativa sono maggio e giugno, vale a dire quando si disputano le fasi finali dei campionati a squadre o iniziano le corse ciclistiche e gli eventi di atletica più importanti. Nel corso del 2017, sono stati poi effettuati controlli in gare di crossfit (CSEN), powerlifting (FIPL) e skyrunning (FISKY), mai controllate in precedenza. Nel 2018, invece, primatista tra gli sport maggiormente controllati è stata la pallacanestro (108 atleti - 27 eventi), seguita dal calcio (68 atleti - 17 eventi) e dal nuoto (66 atleti 13 eventi). Report attività antidoping 2018, p. 2. Una peculiarità che si può denotare all'interno del sistema dei controlli è che le varie FSN, pur dovendo tutte adottare tutte le NSA dettate dal CONI, possono prevedere particolari protocolli per l'effettuazione dei controlli durante le manifestazioni da loro organizzate. Ad esempio la FIP adotta un protocollo concordato tra il suo settore sanitario ed il CONINADO. La versione attualmente in vigore è del 10 maggio 2010 ed è consultabile in www.fip.it/sanitario.

118 Organo composto da tre/sei componenti di cui fa parte, di diritto, il presidente della FMSI, con funzioni di vicepresidente vicario. Al momento della nomina, i componenti del CEFT devono sottoscrivere "una dichiarazione attestante l'assenza di conflitti di interesse e l'impegno ad esercitare le proprie funzioni personalmente, con obiettività ed indipendenza ed in conformità alle disposizioni del Codice mondiale antidoping, nonché del Disciplinare per l'esenzione a fini terapeutici e del Regolamento antidoping del CONI".

${ }^{119}$ La PNA (già UPA) è composto da un procuratore capo, da due viceprocuratori e da procuratori scelti tra magistrati delle giurisdizioni superiori, ordinaria e amministrativa-contabile, in pensione, funzionari pubblici, ufficiali delle forze di polizia, avvocati, docenti universitari in materie giuridiche, ricercatori presso enti pubblici di ricerca ed esperti in materie tecnico-scientifiche, anche a riposo.

${ }^{120}$ La PNA viene attivata, in via ordinaria, dalla ricezione del referto di positività, relativo alle prime analisi o a quelle di revisione, dal coordinamento centrale attività antidoping. Diversamente, pone in essere l'attività istruttoria a seguito della ricezione di documenti trasmessi dall'A.G., ovvero sulla base di esposti o denunce presentate anche presso gli organi di stampa o, infine, a seguito di proposta del Presidente del CONI. Ai fini istruttori la PNA può assumere informazioni dall'atleta e da ogni altro soggetto dell'ordinamento sportivo, acquisire presso gli stessi ogni bene o documento probatorio, disporre l'ispezione dei luoghi e procedere ad eventuale confronto tra i soggetti dell'ordinamento sportivo in caso di divergenze. Se nel corso delle predette attività emergono elementi di responsabilità a carico dei soggetti coinvolti, la PNA procede con formale contestazione degli addebiti, affinché gli stessi possano difendersi, anche attraverso l'ausilio del difensore di fiducia. In tali casi i soggetti sottoposti a contestazione possono presentare memorie ed avanzare richieste istruttorie tese a contrastare l'impianto accusatorio. Qualora il soggetto dell'ordinamento sportivo formalmente convocato dinanzi alla PNA non si presenti senza giustificato motivo, verrà disposto un periodo di sospensione cautelare. Se nel corso del predetto procedimento emergono fatti costituenti reato, i relativi atti devono essere trasmessi alla competente Procura della Repubblica. Cfr. artt. 20-24 NSA, (titolo secondo - procedimento disciplinare). Conclusa la fase istruttoria, la PNA può proporre, ai competenti organi di giustizia delle FSN o delle DSA presso le quali risulta tesserato il soggetto indagato, l'archiviazione o il deferimento. Nell'occorso è facoltà della PNA di richiedere al giudice federale la riduzione della sanzione quando l'interessato abbia fornito una collaborazione determinante per l'accertamento delle responsabilità di altri aderenti alle FSN (cfr. art. 4.6 NSA - revoca, riduzione o sospensione del periodo di squalifica o altra sanzione per motivi diversi dalla colpa).

${ }^{121}$ Il c.p. prevede la non punibilità dell'istigazione non accolta mentre l'ordinamento sportivo la punisce dal momento che il bene su cui incide una sentenza del giudice sportivo non è tutelato costituzionalmente (art. 13 Cost.). Commissione Giudicante Nazionale Federazione Italiana di Atletica Leggera, 18 luglio 1994, e Commissione CONI di indagine sul doping, 19 gennaio 1994, con nota di G. Fontana, La Commissione d'indagine sul doping e la necessità di trovare e punire tutti i corresponsabili del doping, in Riv. dir. sport., 1994, II-III, p. 503. Nel merito si veda altresì la statuizione della Commissione federale sportiva di atletica leggera del 19 gennaio 1994 , in Riv. dir. sport., 1994, II-III, p. 495, con nota di D. Picone secondo cui "l'istigazione dell'allenatore all'assunzione di farmaci vietati, anche se non accolta dall'atleta, integra l'ipotesi di violazione alle norme in materia di doping". Alcune perplessità sorgono in merito alla corretta attribuzione della rilevanza disciplinare nel caso di ipotesi dell'accordo non attuato per l'uso della sostanza dopante, poiché 
4) Il Tribunale nazionale antidoping (TNA), organismo indipendente adito dalla PNA al termine dell'istruttoria nel momento in cui vengono ravvisati elementi di reità sufficienti per sostenere l'accusa. ${ }^{122}$ È un organo composto da due sezioni suddivise in collegi giudicanti (art. 25 NSA). La prima sezione del TNA è competente a giudicare in primo grado per tutte le violazioni NSA poste in essere da atleti non inseriti nel Registered testing pool (RTP) della FSI di appartenenza, nonché per le violazioni delle NSA poste in essere da altri soggetti tesserati e non tesserati; la seconda sezione è competente a giudicare in primo grado per le violazioni delle NSA poste in essere da atleti inseriti nel RTP della FSI di appartenenza, ovvero per violazioni correlate alla partecipazione ad un evento sportivo internazionale, e sui procedimenti disciplinari che ricadono sotto la giurisdizione di altra Agenzia antidoping, nonché, in via esclusiva, al riesame dei provvedimenti assunti dalla PNA in materia di inadempienza per "mancata comunicazione" e/o "mancato controllo" e delle decisioni del CEFT di rigetto di concessione dell'esenzione a fini terapeutici. ${ }^{123}$

anticipa eccessivamente la soglia di punibilità dell'illecito sportivo. Nel sistema penale vige infatti il principio generale della non punibilità dell'accordo per porre in essere una condotta criminosa, ove la medesima rimanga priva d'attuazione, attesa la mancanza dell'elemento oggettivo ex art. 115 c.p. G. AIELLO, Il nuovo regolamento antidoping del CONI, cit., p. 269.

122 In ordine alla composizione del TNA giova precisare che degli undici componenti complessivi, nominati dalla Giunta nazionale del CONI con mandato quadriennale, sette devono provenire dalla magistratura delle giurisdizioni superiori oppure essere professori universitari in materie giuridiche, avvocati o esperti di diritto sportivo, anche a riposo. "Qualora venga ravvisata la responsabilità in capo a soggetti, la cui competenza a decidere ai sensi del successivo articolo 25 spetterebbe a differenti Sezioni del TNA, la PNA dispone il deferimento degli indagati ovvero richiede l'archiviazione del procedimento alla Seconda Sezione del TNA, trasmettendo a quest'ultima il provvedimento assunto e copia del relativo fascicolo di indagine. La PNA provvede, altresì, a trasmettere copia del provvedimento all'indagato, ovvero al suo difensore, se nominato. Su richiesta dell'Autorità Giudiziaria la PNA trasmette copia del provvedimento e dei relativi atti dell'istruttoria. I provvedimenti di cui al comma 11 del presente articolo andranno altresì trasmessi alla WADA, alla Federazione Internazionale competente, all'Organizzazione Antidoping Nazionale dell'Atleta (se diversa da NADO Italia), al Comitato Internazionale Olimpico e al Comitato Internazionale Paralimpico (ove applicabile) quali parti del giudizio di primo grado nonché comunicati alla FSN/DSA/EPS ed alla Società di appartenenza. L'indagato, la WADA e la Federazione Internazionale hanno facoltà di prendere visione degli atti di indagine solo dopo l'avvenuto deposito presso la competente Sezione del TNA e di estrarne copia con costi a loro carico, salvo la WADA e la Federazione Internazionale interessata che non sono tenute al versamento dei relativi diritti amministrati." (art. 23 NSA). Va precisato che anche il club è sanzionabile a seguito di positività di propri tesserati, laddove la violazione delle norme sia accertata in capo a più di due membri dello stesso nel qual caso dovrà essere comminata "alla squadra una sanzione adeguata (ad es. perdita di punti, squalifica da una competizione o da un evento, o altra sanzione) in aggiunta alle eventuali sanzioni inflitte al/ai singolo/i atleta/i che ha/hanno commesso la violazione della normativa antidoping" (art. 6 NSA). Un caso limite che merita di essere brevemente menzionato riguarda i due calciatori Daniele Mannini e Davide Possanzini, deferiti dall'UPA, nel gennaio 2008, avanti alla Corte di giustizia federale FIGC, perché "calciatori, sorteggiati dopo la gara Brescia/Chievo Verona per essere sottoposti ai controlli antidoping si sarebbero presentati per l'espletamento delle relative operazioni con 25 minuti di ritardo, omettendo in tal maniera la dovuta collaborazione alle operazioni di prelievo (urina e sangue)". Nel corso del relativo procedimento di primo grado i due atleti giustificarono il ritardo dovuto ad un "ordine perentorio e tassativo loro rivolto dalla società di appartenenza di partecipazione ad una preventiva riunione con l'allenatore ed il presidente per effettuare le considerazioni e le valutazioni della grave situazione derivante dal risultato conseguito sul campo". La Corte prosciolse i deferiti, ipotizzando una mera violazione dell'art. 1 CGS, ma non delle NSA. Nel relativo appello, promosso dall'UPA, il giudice sportivo sanzionò gli atleti seppur non ritenendo perpetrata una violazione delle NSA bensì dei regolamenti relativi all'attività degli organi antidoping interni (all'epoca erano vigenti le Istruzioni operative della Procura antidoping ed il Procedimento disciplinare e istruzioni operative relative all'attività dell'Ufficio di Procura antidoping). Propose appello la WADA ritenendo essere stato violato l'allora vigente art. 2.3 NSA. In un primo momento, secondo il TAS il ritardo andava considerato alla stregua di un tentativo di aggirare il controllo e, pertanto, integrante una violazione delle NSA dal momento che era irrilevante, ai sensi dell'art. 2.3, l'effettiva manipolazione dei loro campioni biologici per mascherare l'uso di sostanze proibite durante il ritardo non autorizzato ed all'uopo irrogò una sospensione di un anno ai due calciatori. Successivamente, la sanzione venne annullata dallo stesso organo in sede di ricorso per revisione promosso dalla FIGC, stante la sopravvenienza di nuove prove che dimostrarono che gli ispettori antidoping erano stati informati della convocazione urgente della riunione senza che venisse opposto alcun diniego, venendo meno così la violazione consistente nel "ritardo non autorizzato". M. Pagliara, Possanzini-Mannini: è finita Doppia assoluzione al Tas, in www.gazzetta.it, 27 luglio 2009.

${ }^{123}$ Cfr. G. Liotta, L. Santoro, Lezioni di diritto sportivo, cit., p. 295. In pratica la seconda sezione del TNA giudica in ordine a violazioni che hanno dimensione internazionale (perché occorse durante una competizione internazionale o delegate da altra organizzazione antidoping), nonché relativamente ad atleti che la FSI di appartenenza ha inserito in un registro speciale riguardante soggetti sottoposti a controlli in and out competition. "Per i procedimenti pendenti a carico di atleti tesserati alle FSN e DSA. È, infatti, fatto obbligo alle varie FSN e DSA di istituire al proprio interno un organo giudicante cui affidare un primo grado di giudizio”. L. Di Nella, Manuale di diritto dello sport, cit. p. 318. Contro i provvedimenti di sospensione cautelare è possibile proporre impugnazione avanti alla sezione del TNA che non ha adottato la misura gravata. La seconda sezione funge altresì da giudice di appello per le decisioni adottate dalla 
All'esito del giudizio della seconda sezione è, invece, possibile presentare appello presso il Tribunale arbitrale dello sport di Losanna (TAS). ${ }^{124}$

5) Il Comitato per l'Educazione, la Formazione Antidoping e la Ricerca (CEFAR), che persegue gli obiettivi di ricerca e formazione antidoping, pianificando, monitorando e valutando annualmente i programmi di educazione posti in essere da NADO Italia. L'istituzione di tale organo ha rappresentato una novità introdotta con l'emanazione dell'ultima versione delle NSA, in vigore dal 15 aprile 2020. Ai sensi dell'art. 19.1 NSA "NADO Italia, attraverso il Comitato per l'Educazione, la Formazione Antidoping e la Ricerca (CEFAR), predispone e attua programmi di informazione e formazione finalizzati alla difesa dello spirito dello sport e alla tutela della salute degli Atleti, nell'ottica di prevenire l'uso intenzionale o non intenzionale di sostanze o pratiche vietate. Tali programmi, sempre corredati da informazioni accurate e aggiornate in materia di lotta al doping, sono rivolti agli Atleti, in particolar modo a quelli più giovani, per i quali verranno sviluppate tematiche di approfondimento dell'educazione antidoping anche nei corsi scolastici. Gli approfondimenti saranno altresì dedicati alle famiglie, ai dirigenti sportivi, agli allenatori, al personale medico e alle agenzie di comunicazione. Le attività saranno dirette allo sviluppo dei valori del singolo atleta, così da favorire un incremento della sua autonoma capacità decisionale, fondata sul principio del comportamento eticamente adeguato".

Il procedimento disciplinare sportivo si caratterizza per due rilevanti peculiarità: a) l'onere probatorio non impone di provare la responsabilità dell'incolpato "oltre ogni ragionevole dubbio", come invece accade, ad esempio, nel giudizio penale; nel procedimento disciplinare, infatti, è sufficiente che la dimostrazione della responsabilità sia superiore alla semplice valutazione della probabilità (cosiddetta "comfortable satisfaction" nella giurisprudenza del TAS) ${ }^{125}$; b) sia nella fase delle indagini che in quella dibattimentale, la mancata presenza

prima sezione; questa innovazione è stata introdotta per evitare che tutti gli atleti, anche quelli dilettanti dovessero sostenere gli ingenti costi di un procedimento internazionale di fronte al TAS.

${ }^{124}$ I provvedimenti adottati dalla seconda sezione, in funzione di giudice di primo grado, vanno impugnati, entro trenta giorni dalla data di ricevimento della decisione, avanti al TAS in virtù della dimensione internazionale della controversia. Successivamente al grado di appello è consentito soltanto il giudizio di revisione, da proporre avanti allo stesso organo che ha emesso il giudizio in ultimo grado, soltanto: a) "se dopo la pronuncia sono sopravvenute o si scoprono nuove prove che, sole o unite a quelle già valutate, dimostrano che la decisione debba essere modificata"; b) "se si dimostra che la decisione fu pronunciata in conseguenza di falsità in atti o in giudizio o di un altro fatto previsto dalla legge come reato" (art. 40 NSA). Presso Il TAS è instituita un'apposita "Anti-doping Division" e nella nuova versione del regolamento di funzionamento del Tribunale (entrata in vigore il primo gennaio 2019) è stata prevista la possibilità per il singolo incolpato di partecipare all'udienza di discussione del suo caso e di intervenire per ultimo prima che il caso venga trattenuto in decisione (R44.2-Hearing). I procedimenti in materia di doping seguono una procedura particolare dettata dalle Arbitration Rules applicable to the CAS Anti-doping Division (versione 2018) che integrano il regolamento generale e che prevedono che i casi vengano decisi in prima ed unica istanza, senza la possibilità di ricorrere ad altre sezioni del TAS. Cfr. A. Rigozzi, E. Hasler, The CAS Procedural rules, in M. Arroyo (a cura di), Arbitration in Switzerland. The Practitioner's Guide, vol. II, Olanda, Wolters Kluver, 2018, p. 1419 ss. Trattandosi di un arbitrato la cui sede si trova a Losanna, le decisioni del TAS sono impugnabili solamente di fronte al Tribunale Federale Svizzero e l'impugnazione è possibile solo per vizi di procedura o per violazione dell'ordine pubblico internazionale (art. 190 Legge federale svizzera sul diritto internazionale privato). Cfr P. Turrettini, Challenging awards of the Court of Arbitration for Sport before the Swiss Federal Tribunal, in Rdes, 2017, II, pp. 31-44. Per una rassegna sulle pronunce del TAS si rimanda a M. Coccia, La giurisprudenza del TAS in materia di doping, in J. Tognon (a cura di), Diritto Comunitario dello Sport, Torino, Giappichelli, 2009, pp. 241-255.

${ }^{125}$ Infatti, l'art. 42.1 NSA (Onere e grado della prova) prevede che "NADO Italia ha l'onere di provare se sia stata commessa una violazione delle NSA. Il criterio guida è se NADO Italia ha accertato una violazione della normativa antidoping secondo il "confortevole convincimento" del collegio giudicante, tenuto conto della gravità delle accuse presentate. Il grado di prova richiesto è comunque superiore alla semplice valutazione delle probabilità ma inferiore all'esclusione di ogni ragionevole dubbio. Quando il presente CSA affida l'onere della prova all'Atleta o all'altra Persona responsabile di una violazione delle norme antidoping, per confutare una presunzione di colpevolezza o stabilire determinati fatti o circostanze, il grado di prova sarà basato sulla valutazione delle probabilità". Inoltre, in base al successivo art. 42.2.5 "Il collegio giudicante in un dibattimento relativo ad una violazione di una norma antidoping può trarre una conclusione negativa nei confronti dell'Atleta o altra Persona che è ritenuta aver commesso una violazione di una norma antidoping, basata sul rifiuto dell'Atleta o altra Persona, a seguito di una richiesta effettuata con una tempistica ragionevole antecedente l'udienza per il dibattimento, di comparire all'udienza (sia di persona o telefonicamente come stabilito dal collegio giudicante) e di rispondere alle domande poste dal collegio o da NADO Italia". Per un approfondimento completo sui profili procedurali del processo sportivo antidoping si rinvia a L. Fiormonte, Doping e processo antidoping, Rimini, Maggioli, 2010. 
dell'incolpato non comporta né la sospensione né l'interruzione del procedimento disciplinare ${ }^{126}$, anzi, "la mancata comparizione dell'incolpato senza giustificato motivo all'udienza, può costituire comportamento valutabile da parte del Collegio giudicante ai fini del decidere" (art. 30.1.4 NSA). I controlli antidoping possono essere effettuati solo da ispettori medici della FMSI, di cui si avvale il CONI per i controlli in competizione e fuori competizione. I campioni acquisiti da questi ultimi sono sottoposti ad analisi nel laboratorio antidoping di Roma $^{127}$, ovvero presso gli altri laboratori accreditati dalla WADA ${ }^{128}$. Vengono sottoposti a prelievo, in competizione e fuori competizione (anche se stanno scontando un periodo di squalifica) gli atleti che prendono parte ad una competizione in Italia o che ricadono sotto la giurisdizione del CONI-NADO. Infatti, "all'atleta potrà essere richiesto dal personale incaricato del prelievo, di fornire un proprio campione biologico in qualsiasi momento ed in qualsiasi luogo, nei termini e nelle modalità previste nel Disciplinare dei controlli e delle investigazioni (di seguito D-CI)" (art. 16.3 NSA). Per tale fine ogni atleta inserito nel Gruppo registrato è tenuto ad informare trimestralmente la CCA in ordine ai luoghi di sua permanenza nel trimestre di riferimento in modo da poter essere rintracciato ai fini dei predetti controlli. ${ }^{129}$ Il tentativo di reperire l'atleta deve essere effettuato tra le 05:00 e le 23:00; può essere diversificato l'orario solo se l'atleta ha indicato la disponibilità a sottoporsi a controlli al di fuori di tali orari o non ha fornito alcuna indicazione sull'orario. ${ }^{130}$ Per effettuare i controlli

126 "La mancata comparizione personale dell'indagato ovvero l'esercizio della facoltà di non rispondere, non comporta alcuna sospensione, interruzione e/o rinvio dell'indagine" (art. $23.5 \mathrm{NSA}$ ); "La mancata comparizione della parte e/o di suo difensore all'udienza non comporta alcuna sospensione, interruzione e rinvio del giudizio che proseguirà in loro assenza" (art. 30.1.3 NSA). Lo stesso principio è dettato anche per quanto riguarda i ricorsi avverso i provvedimenti cautelari (art. 34.6 NSA).

${ }^{127}$ Nel 1998 il laboratorio antidoping FMSI dell'Acqua Acetosa venne privato dell'accreditamento del CIO per presunte irregolarità nei controlli effettuati. F. Magnani, La lotta al doping tra ordinamento sportivo e ordinamento statale, in C. Bottari (a cura di), La tutela della salute nelle attività motorie e sportive: doping e problematiche giuridiche, cit., pp. 40-41.

128 "La rete di laboratori in possesso dell'accreditamento WADA e accreditati in accordo con la norma UNI CEI EN ISO/IEC 17025, relativamente alle prove elencate nello scopo dell'accreditamento, comprende attualmente 35 centri, abilitati all'analisi dei campioni biologici (urina e/o sangue) prelevati in occasione di controlli antidoping ufficiali ad atleti tesserati per federazioni sportive nazionali e/o internazionali. Le nazioni che possono vantare almeno un laboratorio antidoping accreditato sono 32: Australia (Sydney), Austria (Seibersdorf), Belgio (Ghent), Brasile (Rio de Janeiro), Canada (Montreal), Cina (Pechino), Colombia (Bogota), Cuba (Havana), Repubblica Ceca (Praga), Finlandia (Helsinki), Francia (Parigi), Germania (Colonia e Kreischa), Gran Bretagna (Londra), Grecia (Atene), India (Nuova Delhi), Italia (Roma), Giappone (Tokyo), Kazakhistan (Almaty), Corea (Seoul), Norvegia (Oslo), Portogallo (Lisbona), Malaysia (Penang), Polonia (Varsavia), Sudafrica (Bloemfontein), Romania (Bucarest), Russia (Mosca), Spagna (Barcellona e Madrid), Svezia (Stoccolma), Svizzera (Losanna), Thailandia (Bangkok), Tunisia (Tunisi), Turchia (Ankara), Stati Uniti (Los Angeles e Salt Lake City). Questi centri evadono annualmente un carico analitico complessivo di circa 250.000 campioni, con tempi di risposta che variano da un massimo di 10 giorni lavorativi ad un minimo di 24 ore dal momento della ricezione dei campioni in occasione di eventi sportivi particolari (Giochi olimpici estivi e invernali, Campionati mondiali, grandi corse ciclistiche a tappe, ecc.)”. www.fmsi.it/it/laboratorio-antidoping.html.

129 "Il CCA definisce ed approva il Gruppo Registrato ai fini dei Controlli (di seguito RTP) e i relativi criteri di inclusione, pubblicandoli sul sito internet www.nadoitalia.it. Gli atleti inseriti in RTP dovranno fornire a NADO Italia le informazioni aggiornate sulla propria reperibilità - Informazioni sulla reperibilità presso il luogo di permanenza dell'atleta (di seguito Whereabouts) - secondo i tempi e le modalità contenute nel D-CI. La 'mancata/non corretta' comunicazione dei Whereabouts e/o il 'mancato controllo' costituiscono violazione delle NSA con ogni conseguente determinazione da parte della PNA” (art. 16, comma quinto, NSA). In base all'art. 5.3 del Disciplinare dei controlli e delle investigazioni (allegato NSA) "le informazioni richieste riguarderanno i seguenti dati: a) dati anagrafici; b) luogo di residenza/domicilio completi cui inviare la corrispondenza destinata all'atleta ai fini della notifica formale [...] c) nome e l'indirizzo di ciascun luogo in cui l'atleta pernotterà; d) nome e indirizzo di ciascun luogo dove l'atleta si allenerà, lavorerà 0 svolgerà qualsiasi altra attività regolare (per esempio la scuola), così come il solito orario di svolgimento di tali attività regolari; e) programma delle manifestazioni sportive, ivi compreso il nome e l'indirizzo di ciascuna sede di gara, cui l'atleta ha programmato di partecipare; f) consenso dell'atleta per la condivisione delle proprie Informazioni con altre ADO che hanno l'autorità di effettuare test nei suoi confronti; g) eventuali luoghi di permanenza temporanea; h) dettagli di una eventuale disabilità dell'atleta che può incidere nella procedura da seguire per condurre una sessione di prelievo del campione". Inoltre "l'atleta sarà tenuto altresì ad indicare, uno specifico arco di tempo di 60 (sessanta) minuti tra le ore 05:00 e le ore 23:00 per ogni giorno del trimestre nel quale si renderà disponibile e raggiungibile in un luogo indicato per essere sottoposto ai Controlli. Tale luogo dovrà essere facilmente accessibile da parte del personale incaricato del prelievo [...]" (art. 5.4). Nel caso degli sport di squadra, il relativo whereabouts dovrà essere fornito secondo le modalità di cui al successivo art. 6.

${ }^{130}$ Il CONI può reperire gli atleti professionisti per i controlli senza limiti di orario e di luogo e far compilare a questi ultimi un modulo (il whereabouts) contenente informazioni personali i cui dati devono essere gestiti nel rispetto della vigente normativa sulla privacy. Garante per la protezione dei dati personali, Provvedimento del 13 ottobre 2008, in Bollettino, n. 98, ottobre 2008. 
antidoping l'unico luogo adeguato è quello individuato dall'art. 16.1.3 del Disciplinare dei controlli e delle investigazioni, in base al quale "l'Autorità competente per la raccolta dei campioni è tenuta ad utilizzare una sala dei controlli antidoping che garantisca, quale minimo requisito, la privacy e la riservatezza dell'atleta, e che sia utilizzata esclusivamente come Sala dei controlli antidoping per tutta la durata della sessione". ${ }^{131}$ Ovviamente gli atleti possono trovarsi in condizioni di salute che richiedano l'uso di particolari farmaci o trattamenti compresi nella lista. In tale ipotesi va attivata, ai sensi degli artt. 14 e 15 NSA, la procedura per l'ottenimento di una esenzione a fini terapeutici (TUE) al CEFT, secondo quanto previsto dal Disciplinare esenzioni ai fini terapeutici (D-EFT), ovvero compilando la domanda di esenzione a fini terapeutici, corredata della prescritta documentazione, che deve essere presentata dall'atleta per il tramite della Commissione federale antidoping. ${ }^{132}$ Una precedente versione delle NSA prevedeva che "i fatti correlati alle violazioni del regolamento possono essere accertati con qualsiasi mezzo attendibile" (art. 3.2), così prevedendo, oltre all'impiego del test di sangue e/o urine (strumenti probatori privilegiati per il riscontro dell'assunzione di sostanze dopanti) anche l'eventuale biopsia muscolare. ${ }^{133}$ L'attuale Disciplinare dei controlli e delle investigazioni (attuativo dell'International standard for testing and investigations WADA) prevede, per lo svolgimento della sessione per la raccolta del campione, che il DCO è tenuto a prelevare il campione dall'atleta osservando i seguenti protocolli per il tipo specifico di campione (art. 17.5): a) appendice D - prelievo dei campioni di urina; b) appendice E - prelievo di campioni ematici. ${ }^{134}$

131 "Due osservazioni importanti [...] La prima riguarda le libertà individuali. Qualsiasi prelievo di sangue è una forma di aggressione fisica, così come qualsiasi prelievo di urina implica una forma di aggressione morale (il soggetto deve urinare nudo in un locale adeguato, in presenza di due persone abilitate). Un ciclista può essere soggetto a un numero consistente di controlli all'anno (almeno 12 esami del sangue, 4 esami delle urine e diversi esami in occasione di competizioni). Se il doping è vietato per questioni etiche, l'obbligo per uno sportivo di sottoporsi a un controllo antidoping potrebbe essere considerato una minaccia alla sua libertà. Lo stesso vale per il software ADAMS, un sistema di amministrazione e gestione antidoping, che consente di localizzare gli sportivi giorno per giorno. La seconda osservazione riguarda i costi estremamente elevati della lotta contro il doping. Un passaporto ematico relativo a 800 ciclisti costa, ad esempio, sei milioni di euro. Un solo test antidoping completo costa fino a 1000 euro. La lotta contro il doping rappresenta, pertanto, una parte non trascurabile dei bilanci delle federazioni sportive nazionali e internazionali”. C. Brissonneau, Il doping nello sport professionale, cit., p. 6.

${ }^{132}$ I criteri per il rilascio della TUE, indicati nell'art. 1 dell'allegato NSA denominato Disciplinare per l'esenzione ai fini terapeutici, sono: a) quando "l'atleta potrebbe subire un grave danno alla salute se la sostanza o il metodo proibiti fossero sospesi nel corso del trattamento di una patologia medica acuta o cronica (art. 4.1 International standard for TUE)"; b) quando "l'uso terapeutico della Sostanza o Metodo proibiti, in seguito al trattamento di una documentata patologia clinica, non dovrebbe produrre alcun miglioramento della prestazione oltre al ripristino di un normale stato di salute."; c) "non vi è alcuna ragionevole alternativa terapeutica all'uso della sostanza o del metodo altrimenti proibiti"; d) "la necessità di utilizzare la sostanza o il metodo altrimenti proibiti non è conseguenza, in toto o in parte, di un precedente utilizzo - non corredato da un'esenzione a fini terapeutici - di qualsivoglia sostanza o metodo proibiti al momento in cui se ne è fatto". La relativa domanda va presentata, attraverso le modalità di cui all'art. 3, "almeno 30 giorni prima della partecipazione all'evento sportivo" (art. 4).

${ }^{133}$ La ratio della norma risiedeva nella necessità di non tipizzare gli strumenti di accertamento ed avvalersi in tempo reale di qualsiasi mezzo messo a disposizione dal progresso scientifico. Si noti che in caso di rifiuto da parte dell'atleta non era configurabile la casistica di rifiuto o omissione di sottoporsi a prelievo del campione (biologico) di cui all'allora vigente art. 2.3 del Codice. Attualmente viene imposto all'atleta di fornire, al personale preposto, solo un proprio "campione biologico" in qualsiasi momento ed in qualsiasi luogo, nei termini e nelle modalità previste nel Disciplinare dei controlli e delle investigazioni (art. 16.3 NSA).

${ }^{134}$ Le analisi sui classici campioni liquidi di urina e sangue portano con sé diverse problematiche per quanto riguarda il prelievo, ma soprattutto il loro trasporto e la loro conservazione. Innanzitutto lo sbalzo termico durante il trasporto, nonché il trascorrere del tempo espongono ad una degradazione molto veloce, con il problema che la finestra di "detection" in cui la sostanza dopante può essere rilevata è particolarmente ridotto. Questo fa sì che sia la PNA, che ricerca la prova della sostanza, sia l'atleta che vuole far rianalizzare il proprio campione biologico si trovano costretti ad agire in un limitato periodo di tempo. I campioni liquidi richiedono poi un notevole spazio e particolari misure per il loro stoccaggio che comportano notevoli costi per i laboratori accreditati. Oltretutto i campioni liquidi possono essere facilmente soggetti a contaminazione già a partire dal momento del prelievo. Si riscontrano difficoltà anche al momento dell'analisi del campione liquido, che ad oggi avviene generalmente in una prima fase in cui si utilizzano metodi di screening, che consentono in tempi rapidi la ricerca di un ampio ventaglio di molecole e di individuare con certezza analitica i campioni negativi. È poi necessaria una successiva fase di conferma dei campioni, risultati positivi ai test di screening, attraverso l'utilizza di metodi analitici specifici come la spettrometria di massa associata ad un gas cromatografo [GC/MS], oppure la cromatografia liquida ad elevata pressione associata ad un rilevatore di massa [HPLC]. Questi metodi, dotati di elevata sensibilità e specificità, permettono di determinare la presenza di sostanze esogene nei liquidi biologici e di evitare eventuali falsi positivi, ma hanno l'inconveniente di dover essere adottati mediante l'utilizzo di macchinari particolarmente costosi. E. Emiliozzi, M. Zampi, Responsabilità derivante dall'utilizzo di metodi o sostanze dopanti, in Riv. dir. sport., 2018, I, pp. 104-115. Per tutti questi motivi la WADA ha finanziato nel 2018 un 
Mentre il successivo art. 22.1 (indagini) recita che "al fine di una efficiente ed incisiva strategia antidoping la PNA [...] pone in essere tutte le più opportune attività di indagine - nel rispetto dei principi di equità, integrità ed imparzialità - volte a prevenire ed accertare violazioni della normativa antidoping, e segnatamente: a) esiti atipici ed esiti avversi risultanti dal passaporto biologico; b) ulteriori violazioni della Normativa Antidoping con particolare riguardo a quanto previsto dall'articolo 7.7 del Codice WADA; c) coinvolgimento del personale di supporto dell'atleta o di altre persone nell'ambito di una violazione della normativa antidoping". Infatti, attualmente la WADA dispone di un nuovo strumento per rilevare la sussistenza di tracce di doping genetico: il passaporto biologico. Il relativo principio si basa sul monitoraggio delle variabili biologiche di un atleta nell'arco di un periodo di tempo prolungato. ${ }^{135}$ Il passaporto biologico, il cui obbligo di impiego è stato recepito da tutte le federazioni sportive, ${ }^{136}$ non sostituisce i controlli antidoping tradizionali, che consentono un accertamento diretto dell'assunzione di sostanze vietate, ma si combina a loro al fine di individuare violazioni alle regole antidoping, in particolar modo l'art. 2.2 del Codice WADA, che altrimenti non sarebbero perseguibili. ${ }^{137}$ In considerazione degli

progetto per la ricerca di una nuova metodologia di campionamento ed il progetto che ha ricevuto i fondi per il suo sviluppo è stato quello presentato dal Dipartimento di Farmacia e Biotecnologie insieme al Dipartimento di Chimica dell’Università di Bologna, il cui team di ricercatori ha sperimentato le tecniche di "dried microsampling" al campionamento per le analisi antidoping. In buona sostanza si tratta di un metodo di raccolta che non comporta più il trasferimento all'interno di una provetta di un liquido biologico, che viene invece essiccato in un micro volume che può essere facilmente ottenuto e trasferito su diversi supporti, come card o addirittura su piccoli chip (lab-on-a-chip). M. Protti, R. Mandrioli, L. Mercolini, Perspectives and strategies for anti-doping analysis, in Bioanalysis, 2019, XI, pp. 149-152. Il progetto corrisponde anche a quanto rilevato dalla Sezione di vigilanza e controllo sul doping che "auspica di poter intensificare gli interventi di lotta al doping sia attraverso controlli sempre più mirati $[\ldots]$ attraverso la promozione di progetti di ricerca per il miglioramento delle metodiche analitiche di laboratorio per far fronte alle nuove frontiere del doping". Relazione al Parlamento attività antidoping, anno 2017.

135 Il termine passaporto "ematologico dell'atleta" è stato introdotto per la prima volta nel 2003 da alcuni ricercatori italiani; successivamente le organizzazioni scientifiche internazionali, in collaborazione con le FSI, hanno modificato la dicitura in "passaporto biologico dell'atletica". Il documento elettronico comprende tre distinti moduli: ematologico, steroideo, endocrinologico. I marker ematologici servono ad identificare l'utilizzo di sostanze stimolanti, il potenziamento del trasporto di ossigeno, trasfusioni ematiche, altre forme di manipolazione ematica. Il passaporto biologico, introdotto dalla WADA nel ciclismo nel 2008 grazie a un accordo con l'Unione internazionale ciclisti (UCI), è una tecnica antidoping, di tipo indiretto, costituito da un documento elettronico individuale che prevede il tracciamento nel tempo dei parametri ematici dell'atleta al fine di monitorare nel lungo periodo i relativi cambiamenti. Infatti, non rileva la presenza diretta del farmaco dopante, ma individua gli effetti anomali che tali sostanze inducono sull'organismo. Quando vengono eseguiti i test-base sull'atleta delle urine (che fornisce un profilo steroideo) e del sangue (che permettono di tracciare un suo profilo ematico) le relative analisi consentono di acquisire valori che successivamente vengono utilizzati come riferimento per gli altri esami. Nel momento in cui vengono riscontrate variazioni rispetto al profilo tipico, l'atleta viene messo sotto inchiesta per individuare la causa dell'alterazione e, nel caso non sia possibile collegarla a cause naturali, è squalificato per aver infranto le norme antidoping. Successivamente, è stato impiegato nell'atletica leggera e nel calcio; in tale ultimo sport è stato utilizzato in occasione della Confederations Cup del 2013 ove la FIFA lo ha utilizzato su tutti i calciatori che hanno partecipato. A queste modalità di controllo, volte a verificare un'eventuale violazione del Codice WADA, si prevede nel tempo di affiancare un ulteriore metodo di accertamento, non ancora operativo, finalizzato a verificare l'uso dell'ormone della crescita. R. Carmina, Il passaporto biologico e il disallineamento tra il doping e l'antidoping, in www.ambientediritto.it, $1^{\circ}$ dicembre 2014.

${ }^{136}$ Anche la UEFA ha previsto controlli a sorpresa che possono includere campioni di sangue e urina così come lo screening per sostanze come EPO e ormoni della crescita umana. Infatti, nel settembre 2014 il Comitato esecutivo UEFA ha approvato l'introduzione del passaporto biologico dell'atleta nella UEFA Champions League a partire dalla stagione 2015/16. L'edizione del Regolamento antidoping UEFA del gennaio 2015 si è allineata con il Codice mondiale antidoping (WADC) e con le nuove regole antidoping della FIFA (l'ultima versione del regolamento è del 14 giugno 2018) ed insieme a questo stato approvato anche l'elenco delle sostanze e dei metodi proibiti WADA. Si noti, a titolo di esempio, che nella stagione 2013/14 sono stati raccolti più di 2.198 campioni (1.860 di urine e 338 di sangue), mentre nel 2015/16 sono stati raccolti 4.784 campioni fra tutte le competizioni (di cui 2.242 nel programma di test collegato ad EURO 2016. Cfr. https://it.uefa.com, 26 giugno 2019. Ancora oggi l'EPO resta una delle sostanze proibite maggiormente ricercate nei controlli effettuati negli sport c.d. "di fatica", infatti nel 2017 le richieste di analisi specifiche per la ricerca di EPO e similari hanno riguardato 66 atleti del ciclismo (30\% dei 220 atleti controllati in totale), 45 dell'atletica leggera (26,6\% su 169 atleti controllati), 8 del beachtrail (100\%), 4 del triathlon (20\% dei 20 atleti controllati). Relazione al Parlamento attività antidoping, anno 2017, p. 51. Nel 2018, invece, sono state richieste indagini specifiche per la ricerca di eritropoietina (EPO) e similari su 37 campioni di urina (il 6,2\% degli atleti sottoposti a controllo antidoping) raccolti in 5 manifestazioni sportive $(3,9 \%$ ) di 3 diverse discipline sportive. Nello specifico, tali richieste hanno riguardato 24 atleti dell'atletica leggera (85,7\% su 28 atleti controllati nell'atletica), 8 negli sport invernali (12,5\% dei 64 controllati in totale) e 5 atleti del ciclismo (22,7\% dei 22 controllati). Report antidoping, 2018, p. 47.

137 "L'approccio tipico del controllo antidoping, basato sul rilevamento di una sostanza vietata in un campione biologico di un atleta, pur 
elevati costi gestionali del passaporto biologico, gli atleti sottoposti a tale tecnica di controllo sono solo quelli inseriti nel Registered testing pool, cui si applica il Whereabouts system. ${ }^{138}$ Rilevano alcuni aspetti critici del passaporto biologico riguardanti: la presunta retroattività dell'applicazione delle norme, ${ }^{139}$ la valenza probatoria, ${ }^{140}$ l'indipendenza degli esperti che valutano i risultati delle analisi e gli alti costi. ${ }^{141}$ Si noti, sempre nel novero delle disposizioni relative alle procedure di controllo antidoping, che il CONI, in quanto soggetto pubblico, può trattare dati personali nell'ambito dell'attività antidoping, nel rispetto dei presupposti e dei limiti stabiliti dalla disciplina sulla protezione dei dati personali, astenendosi dal richiedere il consenso dell'interessato al trattamento dei dati. ${ }^{142}$ Infatti, ai sensi dell'art. 13 del Regolamento UE n. 679/16, il CONI-NADO, in qualità di

mantenendo la sua efficacia, presenta comunque dei limiti nelle ipotesi di utilizzazione di sostanze in modo intermittente o in basse dosi. Tanto più che alcuni nuovi composti dopanti (o certune modifiche di prodotti proibiti già noti) possono essere difficili da individuare con i mezzi analitici convenzionali. In altre parole, i controlli diretti sono spesso fallibili, in quanto in ambito agonistico sono tuttora in circolazione prodotti non tracciabili, molecole che eludono ogni tassonomia scientifica, sostanze la cui rile vazione è resa estremamente difficile dal ridotto tempo di permanenza nei fluidi umani". R. Carmina, Il passaporto biologico e il disallineamento tra il doping e l'antidoping, cit. Vi sono delle difficoltà intrinseche del c.d. test "anti-EPO", che si era rivelato fallimentare per i seguenti motivi: a) mancanza di uniformità delle procedure di analisi, b) interferenza di fattori esterni, c) mancanza di efficienza ed effettività, d) non conformità al Codice Wada delle normative di alcune Federazioni internazionali. P. Garraffa, Un nuovo strumento per la lotta contro il doping: il passaporto biologico dell'atleta. Luci e Ombre, in Riv. it. med. leg., 2018, I, pp. 71-72.

138 "Sulla tematica del whereabouts System una parte della dottrina ha manifestato forti perplessità in relazione a tale sistema, ritenendo che contrasterebbe con la dignità umana e con la normativa rilevante in materia di privacy, sia per l'invasività dei moduli whereabouts da compilare, sia perché l'atleta è costretto ad accettare i controlli anti-doping fuori competizione in ogni momento, compreso in quelli più inopportuni". F. D’urzo, La dubbia legittimità del Whereabouts system elaborato dal Codice Wada, in Rdes, 2012, III, p. 96. "Un caso estremo di invasività degli accertamenti antidoping è quello del ciclista Kevin van Impe, il quale subì un controllo antidoping a sorpresa propria prima di prendere parte al funerale del figlio". R. Carmina, Il passaporto biologico e il disallineamento tra il doping e l'antidoping, cit.

139 "La giurisprudenza del TAS (TAS 2010/A/2178 Pietro Caucchioli c. CONI \& UCI, consultabile in www.wada-ama.org/en/mediacenter/archives) ritiene che il passaporto biologico non consiste in una nuova fattispecie che amplia il novero delle condotte dopanti previste dal Codice WADA, ma rappresenta piuttosto un nuovo metodo di accertamento della violazione di questo e, come tale, non incorre nel divieto di retroattività, rientrando l'eventuale condotta antisportiva nelle ipotesi già incriminate dal sopra citato codice". Ivi.

140 "Il passaporto biologico costituisce un mezzo di prova indiretto che accerta il differenziale di scarto dai valori clinici ordinari individuali ma non la diretta assunzione di sostanze dopanti. Questa metodologia contrasterebbe quindi con l'art. 3.1 del Codice WADA che richiede una 'comfortable satisfaction', corrispondente a un onere della prova più intenso di una semplice probabilità, ma comunque meno cogente di una prova oltre ogni ragionevole dubbio". Ma il passaporto biologico "va considerato alla stregua di un mero mezzo di prevenzione per la salvaguardia della salute degli sportivi, adottato con l'obiettivo di responsabilizzare le squadre inducendole a non far partecipare alle competizioni sportive gli atleti che dovessero presentare parametri anomali e non giustificabili”. Cfr. F. D'urzo, $L a$ giustizia sportiva internazionale nel mondo del ciclismo, in G. Candela, S. Civale, M. Colucci, A. Frattini (a cura di), La giustizia sportiva Nocera Inferiore, Sport Law and Policy Centre, 2013, pp. 143-144. "Il TAS (TAS 2010/A/2178 Pietro Caucchioli c. CONI \& UCI, consultabile in www.wada-ama.org/en/media-center/archives) chiarisce che i risultati forniti dal passaporto biologico sono affidabili e quindi corrispondono a quanto richiesto dall'art. 3.2 del Codice WADA: infatti, nelle applicazioni che ne fanno le normative federali, i risultati dei test clinici dei laboratori accreditati dalla WADA prima sono sottoposti a una valutazione statistica, per accertare la sussistenza di anomalie nei valori ematici, e successivamente sono presi in esame da una giuria di esperti. In caso di spiegazioni insufficienti dell'atleta e nell'unanimità di valutazione di condanna, la giuria procede ad informare la Federazione competente per l'apertura di un procedimento disciplinare. Pertanto i valori statistici non sono ritenuti rilevanti ex se, ma sono controllati da esperti, che devono essere d'accordo all'unanimità e devono tenere conto anche delle delucidazioni degli atleti interessati”. R. Carmina, Il passaporto biologico e il disallineamento tra il doping e l'antidoping, cit.

141 "L'autonomia di giudizio di questi esperti è pregiudicata dalla considerazione che essi difettano della terzietà e, quindi, dall'equidistanza dalle parti in causa, essendo nominati dall'ADO (Anti doping organization) che, per il tramite della Giunta nazionale del CONI, designa sia i componenti del Tribunale nazionale antidoping che i membri dell'Ufficio di procura antidoping. Né l'anonimato dei campioni sottoposti ad analisi potrebbe costituire un argine sufficiente e una garanzia efficace per salvaguardare l'autonomia del giudizio: difatti, una qualche tendenza inquisitoria potrebbe comunque derivare dal ruolo stesso dei giudicanti ed essere consustanziale alla loro dipendenza funzionale dall'ADO. A nostro avviso, gli esperti dovrebbero invece essere selezionati tra soggetti che siano estranei alle $\mathrm{ADO}$, alla WADA e, in generale, al sistema del passaporto biologico; quantomeno, per garantire il più possibile la trasparenza del procedimento, sarebbe necessario che esperti della materia, estranei al sistema sportivo antidoping, fossero chiamati a confermare le valutazioni degli scienziati nominati dall'ADO. Tali esperti potrebbero essere designati da uno speciale comitato costituito da esponenti delle società scientifiche internazionali e/o da rappresentanti dell'OMS (Organizzazione mondiale della sanità)". Ivi.

${ }^{142}$ Cfr. artt. 6, 7, 8 e 9 del Regolamento UE n. 679/16 in materia di dati personali. 
titolare del trattamento, informa l'atleta che tratterà alcuni suoi dati personali ${ }^{143}$ al fine di: a) tutelare il suo diritto fondamentale alla pratica di uno sport libero dal doping e quindi promuovere la salute, la lealtà e l'uguaglianza di tutti gli atleti; b) garantire l'applicazione di programmi antidoping armonizzati, coordinati ed efficaci sia a livello mondiale che nazionale, al fine di individuare, scoraggiare e prevenire la pratica del doping. Ovviamente, è sempre riconosciuto all'atleta il diritto di accedere ai suoi dati personali di cui all'art. 15 del Reg. UE 679/16. Nel merito, invece, delle azioni poste in essere dalle associazioni dei sodalizi sportivi, gli stessi approvano codici di comportamento ${ }^{144}$ in base ai quali si prevede: a) la responsabilità personale del medico sociale per le prescrizioni dei trattamenti sanitari e dei farmaci agli atleti; b) la responsabilità indiretta della società per le eventuali violazioni delle norme contenute nel codice stesso da parte dei medici sociali; c) il divieto a carico degli atleti di assumere qualsiasi tipo di farmaco o altra sostanza attiva senza il controllo di un medico sociale e, qualora lo stesso voglia avvalersi di altro specialista, l'obbligo di informare preventivamente il medico sociale, con il conseguente esonero di responsabilità di quest'ultimo. Infine, per quanto riguarda i controlli antidoping sugli animali, una precedente versione del codice antidoping WADA prevedeva la diretta applicazione anche alle discipline sportive che prevedono l'impiego degli animali: in tal caso, le FSI ed FSN competenti per quel dato sport avevano l'obbligo di applicare il relativo regolamento antidoping. ${ }^{145}$ La più recente versione del codice antidoping non ha ribadito l'estensione dei controlli sugli animali, soffermandosi soltanto sugli atleti e sulle squadre, così demandando la specifica attività alle federazioni di settore. ${ }^{146}$ Infine, l'accertamento della

${ }^{143}$ Il CONI è legittimato a trattare i seguenti dati personali: a) dati anagrafici ed identificativi dell'atleta, (nome e cognome, nazionalità, sesso, sport e disciplina praticata, organizzazioni e federazione di appartenenza, livello); b) dati sui luoghi di permanenza dell'atleta (art. 14.3 del Codice mondiale antidoping), per consentire test fuori dalle competizioni; c) dati relativi alle esenzioni ai fini terapeutici; d) dati relativi all'esame dei campioni prelevati durante i controlli in or out of competition. Il trattamento di cui ai punti c) e d) può riguardare dati sensibili, idonei a rivelare lo stato di salute, riguardanti in particolare le informazioni di tipo medico contenute nei risultati di laboratorio dei campioni prelevati e nelle certificazioni risultanti dalle esenzioni ai fini terapeutici. Il CONI comunica i dati di cui ai punti b), c) e d) alla WADA ed alla FSI di appartenenza dell'atleta. Ai fini dell'effettuazione dei controlli all'estero su atleti italiani e/o tesserati a FSN/DSA, il CONI è tenuto a trasmettere i dati sulla reperibilità alla corrispondente organizzazione antidoping del Paese destinatario la quale provvederà a trasmettere le informazioni antidoping direttamente al CONI. Su specifica richiesta delle FSI d'appartenenza dell'atleta, in caso di positività o in pendenza di un procedimento disciplinare che vede lo stesso coinvolto, potranno essere inviati i dati di cui al punto c). In ottemperanza alle NSA ed al Disciplinare dei controlli, i dati di cui ai punti a), c) e d) saranno comunicati dal CONI alla FSN/DSA/EPS di appartenenza dell'atleta, ai fini della gestione del risultato. www.coni.it.

${ }^{144}$ Approvati sulla base del Codice di comportamento sportivo, deliberato dal Consiglio nazionale del CONI il 30 ottobre 2012 , il cui art. 4 prevede che "è fatto divieto ai tesserati, gli affiliati e agli altri soggetti dell'ordinamento sportivo di tenere comportamenti comunque in violazione $\mathrm{o}$ in contrasto con la disciplina antidoping in vigore. I tesserati, gli affiliati e gli altri soggetti dell'ordinamento sportivo devono astenersi da qualsiasi altra condotta atta a recare pregiudizio alla salute dell'atleta". Cfr., per tutti, quello siglato nel 2001 fra tutte le componenti del settore calcio (Associazione italiana calciatori, Lega nazionale professionisti, Federazione italiana gioco calcio, Lega professionisti serie C, Associazione italiana allenatori calcio, Associazione medici sportivi, Associazione italiana preparatori atletici). G. Liotta, L. Santoro, Lezioni di diritto sportivo, cit., p. 280.

${ }^{145}$ Cfr. L. Di Nella, Manuale di diritto dello sport, cit., p. 309. Appare opportuno menzionare il testo dell'art. 16 indicato dall'autore: "16.1 In qualsiasi disciplina sportiva che preveda l'impiego di animali per le competizioni, la competente Federazione Internazionale è tenuta a istituire e applicare un regolamento antidoping per i suddetti animali. Il regolamento antidoping deve comprendere una lista delle sostanze vietate, le procedure adatte per l'esecuzione dei controlli e un elenco di laboratori accreditati per le analisi dei campioni biologici. 16.2 Per quanto riguarda l'accertamento delle violazioni al regolamento antidoping, la gestione dei risultati, l'imparzialità delle udienze, le sanzioni e gli appelli relativi agli animali impiegati nelle discipline sportive, la competente Federazione Internazionale è tenuta a istituire e attuare un regolamento che sia conforme con gli Articoli 1, 2, 3, 9, 10,11, 13 e 17 del Codice".

${ }^{146}$ Per esempio, l'obiettivo primario della Federazione equestre internazionale (FEI), ente sovraordinato alla FISE, e perseguito in ogni regolamento, veterinario incluso, è la salvaguardia della salute e benessere dell'animale. Il nuovo regolamento FEI chiamato EADCM regulations differenzia tra: 1) sostanze "banned" (proibite), il cui rinvenimento è assolutamente proibito in qualsiasi circostanza e la cui presenza nei liquidi biologici del cavallo costituisce doping (EAD violation); 2) sostanze "medication" (di uso legittimo in terapia), la cui presenza nei liquidi biologici è sì sempre vietata ma il cui utilizzo è normalmente ammesso per fini di trattamento terapeutico $(E C M$ violation). Per gli animali vige l'ETUE (Equine therapeutic use exemption form) che, al pari dell'equivalente per l'atleta-umano, ammette l'uso di sostanze per scopo medicale. Con riferimento alla tutela della salute del cavaliere, alle normative e procedure per i controlli antidoping sull'atleta-uomo, la FEI si riporta integralmente ai principi sanciti dalla WADA. Dal 5 aprile 2010 sono entrate in vigore le regole antidoping FEI e con esse una lista di sostanze proibite denominata "Prohibited list". Il cambiamento più importante riguarda la netta distinzione tra doping e medicazione controllata. A questo scopo si distinguono due appositi regolamenti: a) "Equine 
responsabilità di comportamento violante le NSA, durante un evento sportivo o nel corso delle fasi di preparazione dello stesso, può comportare l'irrogazione, da parte degli organi di giustizia sportiva, di sanzioni individuali (art. $4 \mathrm{NSA})^{147}$ ma anche a carico della squadra (art. 6 NSA) o di soggetti non tesserati o ritirati dall'attività sportiva (art. $8 \mathrm{NSA}$ ), ${ }^{148}$ fra queste l'invalidazione dei risultati, inclusa la perdita di medaglie, punti e premi (art. 10); in caso di seconda violazione la sanzione è aumentata (art. 4.7.1 NSA) mentre in caso di terza violazione della normativa antidoping, la sanzione da applicare sarà sempre la squalifica a vita (art. 4.7.2 NSA), fatto salvo il disposto di cui all'art. 4.4. NSA "Qualora un Atleta o altra Persona dimostri di non avere colpa o commesso negligenza, il periodo di squalifica teoricamente applicabile sarà eliminato". Può essere irrogata una sanzione economica che costituisce pena accessoria alla sanzione della squalifica (art. 9 NSA). L'armonizzazione delle sanzioni, in ambito nazionale e internazionale, è, invece, un obiettivo che deve essere ancora perfezionato. ${ }^{149}$ Il CONI può, attraverso la procedura di cui all'art. 11 NSA, sospendere, fino ad un massimo di tre quarti, il periodo di squalifica comminato qualora l'atleta o l'altra parte, previa ammissione delle proprie responsabilità, abbiano fornito una collaborazione fattiva a favore del Comitato, dell'A.G. o di un organo disciplinare professionale. Si noti che l'azione disciplinare si prescrive dopo dieci anni (in precedenza otto) dalla data di commissione della violazione (art. 24 NSA) mentre vige il principio di irretroattività ${ }^{150}$ delle disposizioni

anti doping rule" (EADr); b) "Equine controlled medication rule" (ECMr) www.fise.it. A livello internazionale vige la seconda versione in vigore dal $1^{\circ}$ gennaio 2019. Cfr. www.inside.fei.org.

${ }^{147}$ Le sanzioni vanno dal semplice richiamo con nota di biasimo, per le violazioni più lievi, a pene particolarmente severe, come la squalifica a vita, per le violazioni più gravi. L'atleta sanzionato non potrà partecipare, per tutto il periodo di squalifica, a qualsiasi competizione $o$ attività che sia autorizzata o organizzata da un Firmatario del Codice mondiale antidoping WADA, da un'organizzazione ad esso affiliata, da una società o altra organizzazione affiliata ad una organizzazione affiliata a un Firmatario, oppure a competizioni autorizzate o organizzate da una lega professionistica o da una qualsiasi organizzazione di eventi sportivi a livello nazionale o internazionale. La durata della squalifica sarà di quattro anni: a) nei casi intenzionali di violazione degli artt. 2.1 (presenza di una sostanza vietata o dei suoi metaboliti o marker), 2.2 (uso o tentato uso di una sostanza vietata o di un metodo proibito) o 2.6 (possesso di sostanze vietate e ricorso a metodi proibiti). Per i casi in cui non è dimostrata l'intenzionalità di anni due. Sarà altresì di quattro anni per le violazioni degli articoli 2.3 (eludere, rifiutarsi od omettere di sottoporsi al prelievo dei campioni biologici) o 2.5 (manomissione o tentata manomissione del controllo antidoping). Nel caso di mancata presentazione alle operazioni di prelievo del campione biologico, qualora l'atleta sia in grado di dimostrare che la violazione delle norme antidoping non è stata intenzionale il periodo di squalifica sarà di due anni. Per le violazioni degli articoli 2.7 (traffico o tentato traffico) o 2.8 (somministrazione o tentata somministrazione di sostanze vietate o metodi proibiti), il periodo di squalifica comminato va da un minimo di quattro anni fino alla squalifica a vita (art. 4.3.2). Laddove la violazione degli artt. 2.7 e 2.8 coinvolga un minore o se commessa dal personale di supporto dell'atleta, comporta la squalifica a vita del personale coinvolto. Per la violazione dell'articolo 2.4 (mancata reperibilità), il periodo di squalifica sarà di 2 (due) anni, con possibilità di riduzione ad un periodo minimo di un anno a seconda del grado di colpa dell'atleta. Per le violazioni dell'art. 2.9 (assistenza) il periodo di squalifica va da un minimo di due anni, fino ad un massimo di quattro anni, a seconda della gravità della violazione (art. 4.3.4). per le violazioni dell'articolo 2.10 (divieto di associazione) la sanzione dovrà essere di 2 (due) anni con possibilità di riduzione ad un periodo minimo di un anno a seconda del grado di colpa dell'atleta o dell'altra persona e di altre circostanze del caso. Per le altre violazioni delle NSA (art. 7) il periodo di squalifica e/o inibizione va da un minimo di una nota di biasimo a un massimo di sei mesi (aumentata per i casi di reiterazione fino a due anni), per la violazione dell'art. 3.2, mentre per la violazione dell'art. 3.3, il periodo di squalifica e/o inibizione va da un minimo di una nota di biasimo a un massimo di sei mesi (aumentata in caso di reiterazione fino a un anno).

148 "Per le violazioni delle NSA, commesse da soggetti non tesserati per l'ordinamento sportivo italiano, si applicano le sanzioni dell'inibizione a tesserarsi e/o a rivestire in futuro cariche o incarichi in seno al CONI, alle FSN, alle DSA o agli EPS, ovvero a frequentare in Italia gli impianti sportivi, gli spazi destinati agli atleti ed al personale addetto, prendere parte alle manifestazioni od eventi sportivi che si tengono sul territorio nazionale o sono organizzati dai predetti enti sportivi, per il periodo di squalifica corrispondente alla violazione commessa" (art. 8.1).

149 "Gli atleti non sono soggetti alle stesse sanzioni a seconda delle federazioni di appartenenza. Nel caso della cannabis, l'Associazione internazionale delle Federazioni di atletica Leggera (IAAF) prevede fino a sei mesi di sospensione, mentre la FIFA ne prevede soltanto due. Lo stesso può essere constatato se si confrontano le diverse nazionalità, poiché la metà dei casi di cannabis viene punita con una sospensione di sei mesi in Francia, mentre due terzi dei casi vengono puniti con un semplice richiamo in Belgio o in Germania. Lo stesso vale per il delta-cortisone, per il quale un terzo dei casi in Francia viene punito con un divieto di quattordici mesi, mentre la totalità dei casi in Belgio viene punita solo con tre mesi di sospensione". C. Brissonneau, Il doping nello sport professionale, cit., p. 7.

${ }^{150} \mathrm{Nel}$ nostro ordinamento il principio di irretroattività delle sanzioni trova fondamento nell'art. 25, commi secondo e terzo, Cost.: "Nessuno può essere punito se non in forza di una legge che sia entrata in vigore prima del fatto commesso. Nessuno può essere sottoposto a misure di sicurezza se non nei casi previsti dalla legge"), nell'art. 11 disp. prel. c.c.: "la legge non dispone che per l'avvenire", nell'art. 2 del c.p.: "nessuno può essere punito per un fatto che, secondo la legge del tempo in cui fu commesso, non 
disciplinari. ${ }^{151}$ Di particolare interesse la previsione in base alla quale "laddove la violazione degli articoli 2.7 (traffico o tentato traffico) o 2.8 (somministrazione o tentata somministrazione di sostanze vietate o metodi proibiti) comporti contestualmente l'inosservanza di leggi e regolamenti di natura non sportivi, l'Organizzazione antidoping è tenuta a darne comunicazione alle competenti autorità amministrative, professionali o giudiziarie" (art. 4.3.2.2 NSA). Infine, di sicura rilevanza l'ipotesi per la quale anche i non tesserati possono diventare destinatari di un provvedimento di squalifica che comporta il divieto di rivestire cariche in seno al CONI, FS, DSA, EPS, ecc., come anche il divieto di frequentare impianti sportivi o prendere parte a manifestazioni sportive organizzare. L'ipotesi produce effetti nel medio e lungo periodo spesso sottovalutati. Si pensi al caso in cui un non tesserato venga convocato nel corso delle indagini preliminari ravvisandosi a suo carico mere ipotesi disciplinari. Al termine del relativo procedimento giudiziario viene data facoltà alla PNA di acquisire gli atti e procedere ad autonoma valutazione disciplinare con conseguente convocazione dell'interessato. A questo punto l'interessato, non più soggetto all'obbligo giuridico di presentarsi su richiesta degli organi di polizia giudiziaria, se non dovesse presentarsi all'audizione fissata dalla PNA potrebbe comunque essere destinatario di un provvedimento di deferimento al TNA col rischio di essere sottoposto alle predette sanzioni sportive dal momento che la mancata comparizione non costituisce una causa di sospensione o interruzione del procedimento (art. 23.5 NSA). Inoltre, qualora, l'incolpato omettesse di presentarsi anche all'udienza del dibattimento innanzi al TNA, la sua mancata presentazione può essere valutata dal collegio giudicante e ritenuta circostanza sufficiente per l'emissione di una sanzione (art. 30.1.4 NSA).

costituiva reato. Nessuno può essere punito per un fatto che, secondo una legge posteriore, non costituisce reato; e, se vi è stata condanna, ne cessano l'esecuzione e gli effetti penali", nell'art. 7, comma primo, della Convenzione europea dei diritti dell'uomo del 1950, ratificata e resa esecutiva in Italia con legge 4 agosto 1955 n. 848: "nessuno può essere condannato per un'azione o un'omissione che, al momento in cui è stata commessa, non costituiva reato secondo il diritto interno o internazionale. Parimenti, non può essere inflitta una pena più grave di quella applicabile al momento in cui il reato è stato commesso" e nell'art. 15, comma primo, del Patto internazionale relativo ai diritti civili e politici adottato a New York il 16 dicembre 1966, ratificato e reso esecutivo in Italia con legge 25 ottobre 1977, n. 881: "nessuno può essere condannato per azioni od omissioni che, al momento in cui venivano commesse, non costituivano reato secondo il diritto interno o il diritto internazionale. Così pure, non può essere inflitta una pena superiore a quella applicabile al momento in cui il reato sia stato commesso. Se, posteriormente alla commissione del reato, la legge prevede l'applicazione di una pena più lieve, il colpevole deve beneficiarne".

${ }^{151} \mathrm{Nel} 2009$ la ciclista professionista A. Cucinotta venne squalificata per due anni dal TNA per una positività alla sostanza dopante nota in commercio con il nome di "boldenone" accertata nel dicembre 2008. Dal 10 dicembre 2010 l'atleta ha potuto riprendere l'attività agonistica ma il 30 maggio del 2011 il presidente della FCI, con la delibera n. 30 assunta in via d'urgenza, disponeva la modifica del Regolamento dei campionati italiani di ciclismo di ogni specialità e categoria, ratificata da parte del Consiglio federale con delibera $\mathrm{n}$. 150 del 23 giugno 2011, inserendo il divieto di partecipazione a tali campionati per gli atleti sanzionati per doping in ossequio alla cosiddetta Osaka Rule, la regola 45, inserita nel giugno 2008 dal CIO nella Carta olimpica. In base a tale norma, un'atleta che avesse commesso una qualsiasi violazione della normativa antidoping, sanzionato per un periodo di almeno sei mesi nel corso di un quadriennio olimpico, non avrebbe potuto partecipare alle successive Olimpiadi. La stessa norma è stata però dichiarata invalida dal TAS, a seguito di ricorso presentato dall'atleta presso la Corte federale FCI, con sentenza del 4 ottobre 2011 (Lodo TAS CAS 2011/O/2422 USOC v IOC, consultabile in www.tas-cas.org), e, successivamente, il CIO, in ottemperanza alla decisione del TAS, ha provveduto alla sua abrogazione. L'Osaka Rule per il TAS era in contrasto con l'art. 23.2.2 del Codice WADA che prevedeva che gli enti firmatari (in base all'articolo 23.1.1 del Codice WADA lo sono: il CIO, le FSI, il Comitato paralimpico internazionale, i Comitati olimpici nazionali, i Comitati paralimpici nazionali, le Organizzazioni nazionali antidoping, la WADA e le Organizzazioni di grandi eventi), in sede di recepimento del Codice WADA non possono modificare la sostanza dei relativi articoli e non possono inserire disposizioni in grado di modificarne gli effetti. M. Vigna, La caduta dell'Osaka Rule: il fine non giustifica i mezzi o "Summum ius, summa iniuria"?, nota a Lodo TAS CAS 2011/O/2422 USOC v IOC, in www.giustiziasportiva.it, 2011, 3. Sul punto si è pronunciata anche la Corte Federale della FCI che ha chiarito che la convocazione in nazionale è subordinata alla discrezionalità degli organi tecnici di riferimento ed il loro apprezzamento non può essere sindacato dalla stessa Corte se non quando sussistano specifici requisiti che condizionano l'eleggibilità. Questo comporta che qualora vi sia una sistematica esclusione per gli atleti già squalificati per doping si concretizzerebbe lo stesso effetto sostanziale della predisposizione di una normativa che permetta l'esclusione sistematica e di conseguenza vi sarebbe una discriminazione rispetto ad altri paesi che non tengono conto di pregresse squalifiche per doping. In questo modo si inciderebbe sulla tanto auspicata armonizzazione che si ricerca tra gli organismi nazionali protagonisti della lotta al doping. In sostanza una volta terminato il periodo di squalifica dovrebbe essere concesso all'atleta di reinserirsi nel circuito delle competizioni, anche internazionali senza dover essere costantemente soggetto all'arbitrio della sua Federazione nazionale di appartenenza. Corte Federale FCI, n. 1, 2012, in www.federciclismo.it/it/section/giustizia-sportiva. 


\section{Evoluzioni delle indagini penali antidoping}

Non rientra fra gli obiettivi del presente studio analizzare le numerose indagini condotte in materia antidoping dalle vare Procure della Repubblica in Italia ma di sicuro interesse è l'approccio degli organi inquirenti in sede di valutazione delle condotte criminose che vengono rilevate nell'ambito delle relative indagini preliminari. Abbiamo precisato che ai sensi dell'art. 4.3.2.2. NSA le organizzazioni sportive antidoping sono tenute a dare comunicazione all'A.G. di notizie da cui sono ravvisabili ipotesi di reato, così come già avveniva, ai sensi dell'art. 3 della legge 13 dicembre 1989, n. 401, ${ }^{152}$ per le ipotesi di frode in competizione sportiva. Peraltro, è tuttora vigente il dettato dell'art. 116 c.p.p., in base al quale "durante il procedimento e dopo la sua definizione, chiunque vi abbia interesse può ottenere il rilascio a proprie spese di copie, estratti o certificati di singoli atti". ${ }^{153}$ Il combinato disposto crea un circolo virtuoso in base al quale l'esito delle indagini degli organi sportivi può essere utilizzato dalla Procura della Repubblica, durante le indagini preliminari, ${ }^{154}$ e viceversa. Spesso accade che quanto comunicato all'A.G. non necessariamente si configuri e venga rubricato quale ipotesi delittuosa ai sensi dell'art. 586-bis c.p. Infatti, con il compimento del reato di doping si possono intrecciare fatti analoghi, come nel caso di quello previsto e punito dall'art. 73 del d.lgs. n. 309/1990, in materia di stupefacenti, nel caso in cui la sostanza dopante inserita nelle tabelle ministeriali sia al contempo contenuta in quella sui prodotti psicotropi o stupefacenti (come potrebbe ad es. avvenire con riferimento all'efedrina o la cocaina). In questo caso potrebbe configurarsi lo schema del concorso formale di reati ma è evidente che la norma in materia di sostanze stupefacenti risulterà prevalente in base alla particolare modalità di risoluzione del conflitto di norme delineata nell'art. 9, diretta a sancire l'applicazione della fattispecie sanzionata più gravemente. ${ }^{155}$ Il reato di doping potrebbe, inoltre, concorrere con quello di

${ }^{152}$ Legge 13 dicembre 1989, n. 401 "Interventi nel settore del giuoco e delle scommesse clandestini e tutela della correttezza nello svolgimento di manifestazioni sportive", in G.U. 18 dicembre 1989, n. 294.

${ }^{153}$ A titolo di mero esempio si riporta parte della sentenza TAS di condanna del ciclista Gianni Da Ros che stabilisce: "In data 5 marzo 2009, il Giudice per le Indagini Preliminari del Tribunale di Milano, un'autorità giudiziaria statale, emetteva nei confronti del Ricorrente un'ordinanza di applicazione di misure cautelari personali con relativa custodia in carcere. Alla base di tale provvedimento vi erano le risultanze di un'indagine di polizia relativa al doping negli ambienti del culturismo milanese. Il giorno 11 marzo 2009 , il Nucleo Antisofisticazioni dei Carabinieri di Milano arrestava il Ricorrente mentre si trovava a Padova, in ritiro con la Nazionale Italiana di Ciclismo su pista. In data 12 marzo 2009, l'UPA, avendo appreso la notizia dell'arresto del ricorrente, richiedeva alla Procura della Repubblica presso il Tribunale di Milano la trasmissione degli atti utili al procedimento disciplinare, aperto dall'UPA a carico del Ricorrente. Il 14 marzo 2009, il Giudice per le Indagini Preliminari ordinava che il Ricorrente fosse sottoposto agli arresti domiciliari, in luogo della custodia cautelare in carcere. Tale misura veniva revocata il 23 marzo 2009. Il 24 marzo 2009, la Procura della Repubblica sopra menzionata trasmetteva all'UPA una copia degli atti dell'ordinanza cautelare emessa nei confronti del Ricorrente. Da tali atti emergevano, in particolare, dei testi di intercettazioni telefoniche, dalle quali risultavano delle conversazioni e lo scambio di messaggi di testo del Ricorrente con altri soggetti, tra i quali il Sig. Davide Lucato, anch'egli coinvolto nella menzionata inchiesta di polizia, ed il Sig. Alberto Corazzin [...]". Come si può notare l'UPA apprese l'11 marzo dell'esistenza di un'indagine penale a carico di un tesserato FCI, il giorno dopo avanzò richiesta di copia degli atti che venivano trasmessi dodici giorni dopo, così consentendo una rapida istruttoria disciplinare che terminava, con sentenza in ultimo grado, il 17 agosto 2010. Cfr. lodo arbitrale TAS CAS 2009/A/2023 Gianni Da Ros c. CONI.

${ }^{154}$ Cfr. M. Pittalis, Sport e diritto, cit., p. 734.

${ }^{155} \mathrm{Si}$ noti che, nel caso in cui per uno specifico evento si configuri sia il reato di doping che quello in materia di stupefacenti, previsto dall'art. 73 del d.P.R. n. 309/1990, si ritiene applicabile esclusivamente quest'ultimo, dal momento che prevede un trattamento sanzionatorio più gravoso, a meno che non si concretizzi un caso di danno alla salute, posto in essere da un componente del CONI o di un organismo da questo riconosciuto, nel qual caso prevarrà il reato di doping. R. Carmina, Appunti e considerazioni critiche sul doping nella sua duplice dimensione penalistica e disciplinare, cit., p. 75. "Una coincidenza tra le due fattispecie (in materia di doping e di stupefacenti), potrà aversi solo nel caso in cui soggetto attivo non sia l'atleta, perché l'art. 75 del d.P.R. n. 309/90 esclude la punibilità del soggetto assuntore. Quindi tutte le volte in cui la sostanza stupefacente dopante venga direttamente assunta dall'atleta al fine di alterare le prestazioni agonistiche, questi sarà punito unicamente ai sensi della normativa antidoping (anche se potranno trovare applicazione le sanzioni amministrative, quali ad es. la sospensione della patente di guida, del passaporto, del porto d'armi ecc.)". G. Ariolli, V. Bellini, Disposizioni penali in materia di doping, cit., p. 110. Pertanto, nel caso in cui un medico sportivo procuri all'atleta delle anfetamine per eliminare il senso di fatica risponderà del reato di doping mentre, nel caso in cui l'atleta stesso ceda ad un compagno di squadra la sostanza per fini diversi da quelli previsti dalla legge n. 376/2000 dovrà applicarsi quella tra le due discipline che prevede una sanzione più grave. Si è in presenza, in questo secondo caso, di trattamenti sanzionatori diversi riferiti a condotte aventi ad oggetto la medesima sostanza e lesive del medesimo bene. Dinanzi a due soggetti, uno dei quali assume sostanze stupefacenti 
frode sportiva ma stante la minore gravità della comminatoria edittale prevista dall'art. 1 legge n. 401/1989, la clausola di riserva non potrà operare, con il risultato di dover affermare il concorso formale tra i reati in oggetto. Inizialmente l'orientamento giurisprudenziale maggioritario escludeva la possibilità di estensione della norma alle ipotesi di assunzione di sostanze dopanti, ${ }^{156}$ ritenendo che l'unico possibile autore del reato fosse un soggetto estraneo alla competizione sportiva e che il compimento di atti fraudolenti fosse azionabile solo dal soggetto non partecipante alla gara sportiva. ${ }^{157}$ Successivamente, la Corte ha esteso la responsabilità anche agli atleti stessi rilevando in particolare che "nulla autorizza a ritenere, a priori, che l'atleta dopato debba essere considerato la vittima della fattispecie incriminatrice" e, quindi, "una rigorosa interpretazione della norma non consente di escludere, sempre a priori, la loro punibilità, salvo l'accertamento in fatto della consapevolezza della illecita assunzione e/o somministrazione". ${ }^{158}$ Un ulteriore ambito di fattispecie con cui la norma

/dopanti (ad es. cocaina) al fine di ottenere una "eccellente prestazione in discoteca", mentre l'altro assume la medesima sostanza al fine di ottenere una migliore prestazione agonistica, la risposta dell'ordinamento è diversa: la condotta del primo sarà solo amministrativamente censurabile, la condotta del secondo sarà, invece, penalmente rilevante. Si noti che le sostanze rilevate ai controlli antidoping ed inserite anche nelle Tabelle delle sostanze stupefacenti o psicotrope soggette alla vigilanza e al controllo del Ministero della Salute contengono solitamente i seguenti principi attivi: la cannabis e derivati, la cocaina e la cocaina in associazione con la 3,4metilenediossimetanfetamina o MDMA. Relazione al Parlamento attività antidoping, anno 2017, all. 1, p. 57.

${ }^{156}$ Cfr. Cass. pen., sez. VI, 26 marzo 1996, n. 3011, in www.pluris-cedam.utetgiuridica.it, secondo cui il reato di frode in competizione sportiva comprende l'ipotesi di somministrazione di sostanze dopanti (art. 1, comma primo), non anche l'auto somministrazione delle stesse (c.d. doping autogeno). Infatti, "i comportamenti fraudolenti previsti dalla suddetta norma invero consistono in attività proiettate all'esterno delle persone che le hanno deliberate in qualche modo sinallagmatiche posto che collegano alla distorsione della gara, che il soggetto esterno persegue, denaro o altra utilità perseguita dall'altro soggetto partecipante alla gara: dette caratteristiche mancano nei fenomeni autogeni di doping che trovano adeguata sanzione negli ordinamenti sportivi”. Rileva, altresì, la sentenza di merito relativa all'assunzione di sostanze dopanti posta in essere da Marco Pantani; infatti, "l'inchiesta a carico di Pantani si è conclusa con la sentenza dell'11.12.2000 del giudice monocratico del Tribunale di Forlì [...] Dalla motivazione della sentenza emerge che il giudice abbia condiviso pienamente la tesi della riconducibilità del doping al delitto di frode sportiva [...] Il giudice della prima sezione della Corte d'Appello di Bologna con la sentenza 23.10.2001 ha stabilito che non ci sono prove evidenti che Pantani non si sia dopato. Al riguardo, la stessa modalità di somministrazione dell'eritropoietina, esclusivamente per via endovenosa, esige una collaborazione del soggetto che ne è destinatario e rende non verosimile l'ipotesi di un'assunzione inconsapevole di tale sostanza. Conseguentemente il giudice ha assolto 1'appellante Marco Pantani non con formula di proscioglimento più favorevole ex art. 129 c.c.p. per insussistenza del fatto addebitato o perché l'imputato non lo ha commesso, ma con la formula del "perché il fatto non era previsto dalla legge come reato". Il suddetto episodio, infatti, non era punibile in base alla legge 401 del 1989, la legge sulla frode sportiva, che aveva portato in primo grado alla condanna di Pantani da parte del Giudice monocratico del Tribunale di Forlì”. S. Pagliara, La tutela della salute nelle attività sportive ed il divieto di doping, in Giust. pen., 2004, V, pp. 263-264. In senso contrario, R. Guariniello, Per la legge la salute è un vizio, in Micromega, 2000, I, p. 191, il quale ritiene che anche l'assunzione di doping lede il bene giuridico tutelato dal reato di frode in competizioni sportive e cioè il regolare svolgimento delle competizioni sportive.

${ }^{157}$ La somministrazione di sostanza dopante a un cavallo partecipante ad una competizione sportiva organizzata da UNIRE integra il reato previsto dall'art. 1 legge n. 401/1989, che punisce non soltanto le offerte o promesse di denaro, utilità o vantaggi a taluno dei partecipanti al fine di alterare l'esito della manifestazione, ma anche qualsiasi diverso atto fraudolento volto al medesimo scopo, e cioè a raggiungere un risultato diverso da quello conseguente al corretto e leale svolgimento della competizione. Pertanto, la somministrazione di sostanza dopante ad un cavallo non riceve il medesimo trattamento riservato ai "fenomeni autogeni di doping", e cioè alla somministrazione a sé stesso di sostanze dopanti da parte dell'atleta, che sono puniti ai sensi della legge n. 376 del 2000 . Cass. pen., sez. III, 3 aprile 2007, n. 16619, in www.pluris-cedam.utetgiuridica.it.

158 Inoltre "la somministrazione delle sostanze dopanti continua a costituire reato anche dopo l'emanazione della nuova normativa (l. 376/2000, n.d.r.) con conseguente applicabilità, per i fatti commessi prima dell'entrata in vigore della normativa antidoping, dell'art. 1, legge n. 401/1989". La Suprema Corte ha stabilito che integra la fattispecie della frode sportiva la somministrazione di sostanze dopanti capaci di alterare il genuino svolgimento della competizione sportiva. Nell'impianto motivazionale della sentenza si legge che l'extraneus che somministra ai partecipanti alla competizione, sostanze atte ad alterarne le prestazioni, e che fraudolentemente mira a menomare o ad esaltare le capacità atletiche del giocatore, pone in essere una condotta che consiste in un espediente occulto per fare risultare una prestazione diversa da quella reale, in un artifizio capace di alterare il genuino svolgimento della competizione, con palese violazione dei principi di lealtà e di correttezza. Ne consegue che gli atti posti in essere sono agevolmente riconducibili alla nozione di atti fraudolenti. Rileva quanto evidenziato dalla Corte secondo cui il fatto di punire oltre alla somministrazione di sostanze dopanti "anche l'assunzione diretta [...] consente di affermare che il bene presidiato non può essere esclusivamente la tutela della salute dello sportivo, ma anche la regolarità e la correttezza delle competizioni, beni posti in pericolo dalla sleale alterazione chimica della propria capacità di prestazione, nozione estesa dell'interesse protetto della norma che, peraltro, trova un significativo elemento di riscontro proprio nel dolo specifico espressamente previsto che è quello di alterare le prestazioni agonistiche degli atleti". Cass. pen., sez. II, sentenza del 2 febbraio 20007, n. 21324, con nota di S. Beltrani, Il reato di frode sportiva, in Cass. pen., 2008, V, pp. $2080-2088$. 
incriminatrice di cui all'art. 9, risulterà spesso concorrente, è quella relativa alla tutela della vita e dell'incolumità individuale, quando dalla pratica doping derivino danni per l'integrità fisica dello sportivo. ${ }^{159}$ Bisogna ulteriormente precisare che nel corso delle indagini poste in essere per accertare i casi di violazione della norma antidoping, spesso viene riscontrato anche il configurarsi dei seguenti reati o illeciti: 1) esercizio abusivo di una professione (art. 348 c.p.), che persegue colui che, senza essere in possesso della prescritta abilitazione professionale (di farmacista, o di medico), commercia o prescrive farmaci e sostanze dopanti; ${ }^{160} 2$ ) commercio o somministrazione di medicinali guasti (art. 443 c.p.), con cui viene perseguita anche la mera detenzione, oltre la somministrazione e la vendita; 3 ) somministrazione di medicinali in modo pericoloso per la salute pubblica (art. 445 c.p.), qualora le sostanze medicinali vengano commerciate in specie, qualità o quantità non corrispondenti alle ordinazioni mediche; 4) falsità ideologica commessa da p.u. in atti pubblici (art. 479 c.p.), per la stesura di una prescrizione medica non rispondente al vero se il sanitario rivestiva in quel momento il ruolo di p.u.; 5) falsità ideologica in certificati commessa da persone esercenti un servizio di pubblica necessità (art. 481 c.p.), nel caso di medico generico; 6) ricettazione (art. 648 c.p.), col quale viene punito chi riceve cose provenienti da altro reato come nel caso di furto di medicinali ${ }^{161}$; 7) importazione non autorizzata di farmaci (artt. 6, 50, 55 e 147 del d.lgs. 24 aprile 2006, n. 219) ${ }^{162}$; 8) violazione della legge sulla

${ }^{159}$ In questi casi ci troveremo normalmente di fronte a situazioni di concorso formale, destinate però a divenire concorso apparente, per la presenza della prevista clausola di riserva, ogni qual volta la norma che tutela l'integrità física risulti più gravemente sanzionata. Di fatto gli spazi entro i quali è possibile ipotizzare, almeno dal punto di vista astratto, un concorso di reati, sono stati ulteriormente ridotti dall'opportuna introduzione della clausola espressa di sussidiarietà dei delitti, da ultimo citati, qualora il fatto costituisca più grave reato. A. Traversi, Diritto penale dello sport, cit., p. 114.

160 "Sul piano del concorso di reati, si è riconosciuto l'assorbimento nel commercio di sostanze dopanti sia della somministrazione di medicinali in modo pericoloso per la salute pubblica (art. 445 c.p.) sia dell'abusivo esercizio di una professione (art. 348 c.p.)". S. Bonini, Doping tra sanzione penale e giustizia sportiva: il ruolo discriminante del dolo specifico, cit., p. 2.

${ }^{161}$ Se è vero che il risarcimento deve essere riconosciuto nell'ambito delle conseguenze immediate e dirette del reato è anche vero, secondo la Suprema corte, che può essere parte civile anche chi non è parte offesa del reato ma subisce solo un danno, sia pure morale, dalla perpetrazione del crimine. Pertanto, il CONI può ottenere il risarcimento del danno, in quanto soggetto istituzionale che organizza le gare. In questo caso il CONI è danneggiato in quanto portatore dell'interesse al corretto svolgimento delle manifestazioni sportive che il ciclista ha alterato assumendo sostanze dopanti e cedendole ad altri atleti partecipanti. Cass. pen., sez. II, 29 marzo 2011, n. 12750, in www.pluris-cedam.utetgiuridica.it. Si noti che nel caso di concorso tra il reato di uso di sostanze dopanti, previsto dall'art. 9, comma primo, della legge n. 376/2000, e quello di ricettazione, di cui all'art. 648 c.p., la prima ipotesi di reato deve intendersi assorbita dalla seconda, per via della clausola di riserva (salvo che il fatto costituisca più grave reato) espressamente prevista dalla prima fattispecie. Cfr. Cass. pen., sez. II, 19 dicembre 2012, n. 3234, in www.pluris-cedam.utetgiuridica.it. Successivamente, la Suprema Corte ha stabilito che "il reato di commercio di sostanze dopanti attraverso canali diversi da farmacie e dispensari autorizzati (art. 9, comma settimo, legge 14 dicembre 2000, n. 376) può concorrere con il reato di ricettazione (art. 648 c.p.), in considerazione della diversità strutturale delle due fattispecie - essendo il reato previsto dalla legge speciale integrabile anche con condotte acquisitive non ricollegabili ad un delitto - e della non omogeneità del bene giuridico protetto, poiché la ricettazione è posta a tutela di un interesse di natura patrimoniale, mentre il reato di commercio abusivo di sostanze dopanti è finalizzato alla tutela della salute di coloro che partecipano alle manifestazioni sportive (Cass., sez. unite, 29 novembre 2005, n. 8047, Cass, sez. II, 11 marzo 2010, n. 12744)”. Cass. pen., sez. II, 9 gennaio 2013, n. 843, in www.pluris-cedam.utetgiuridica.it. La Cass. ha riconosciuto che l'acquisto di sostanze dopanti per questioni estetiche può integrare il reato di ricettazione in quanto "L'acquisto consapevole di beni provenienti da delitto (nel caso in esame sostanze dopanti attraverso canali diversi dalle farmacie e dai dispensari autorizzati) effettuato con il fine specifico, non disconosciuto, di procurarsi il vantaggio di un miglioramento del proprio aspetto estetico realizza il reato di ricettazione nelle sue componenti: oggettiva e soggettiva". In tal senso si è espressa anche Cass. Sez. $2^{\mathrm{a}}$ n. 15680 del 2016, Rv. 266516), in www.dejure.it. Cfr. Cass. pen., sez. II, 19 gennaio 2017, n. 2640, in Riv. it. med. leg., 2017, II, pp. 770-775 con nota di M. Miglio. In tema di ricettazione è intervenuta ancora di recente la Cass. riconoscendo la sussistenza del reato ex art. 648 c.p. quando l'acquisto di anabolizzanti sia finalizzato anche solo per fine edonistico, in quanto: "il profitto va individuato nella ricezione di beni (sostanze dopanti) che prima non avevano e che non potevano acquistare in modo legale, beni che, avendo un valore economico, hanno incrementato il loro 'patrimonio' potendo trarre da essi un vantaggio e, quindi, idonei a soddisfare un proprio bisogno (materiale o spirituale)". Cass. pen., sez. II, 25 gennaio 2019, n. 3661, in www.dejure.it.

162 L'Ufficio centrale stupefacenti (UCS) del Ministero della salute ha precisato quali sono i quantitativi massimi di medicinali che gli stranieri possono portare con sé durante il soggiorno in Italia: 1) per tutte le categorie di farmaci che vengono portati personalmente dallo straniero al momento dell'ingresso nel territorio nazionale, ad eccezione degli stupefacenti, delle sostanze psicotrope e della sostanze dopanti, non esistono prescrizioni normative (art. 25 del d.lgs. n. 178/1991), anche se per prassi per quantitativi che eccedano un presumibile consumo mensile le autorità sanitarie e doganali di frontiera richiedono al passeggero l'esibizione della prescrizione medica; 2) per viaggiatori che devono prolungare la permanenza o soggiornare a lungo in Italia è possibile importare farmaci non 
sperimentazione dei farmaci non registrati (d.1. 17 febbraio 1998, n. 23); 9) infrazione alla regola deontologica che impone di somministrare solo farmaci sperimentati (artt. 12, 46 e 47 del Codice deontologico); 10) infrazione alla regola deontologica che vieta al medico di prescrivere farmaci ad individui perfettamente sani. ${ }^{163}$ Infine, per quanto riguarda i casi di somministrazioni di sostanze dopanti agli animali, rileva la configurabilità del delitto di maltrattamento di animali (art. 544-ter c.p. ${ }^{164}$ ), norma introdotta dalla legge n. 189/2004 nell'ambito del nuovo titolo IX-bis ("Dei delitti contro il sentimento per gli animali") e successivamente modificata con legge n. 201/2010. Il comma secondo dell'articolo in esame punisce, per la prima volta, l'ipotesi del c.d. "reato di doping a danno di animali", al fine di reprimere in particolar modo le scommesse clandestine e le competizioni tra animali, disponendo che le stesse pene previste dal comma primo, si applichino "a chiunque somministra agli animali sostanze stupefacenti o vietate, ovvero li sottopone a trattamenti che procurano un danno alla salute degli stessi". ${ }^{165}$

registrati in Italia (per posta o corriere) su richiesta di un medico residente in Italia ai sensi del d.m. Sanità 11 febbraio 1997; 3) per i farmaci stupefacenti, limitatamente ai paesi aderenti gli accordi di Schengen, è previsto in applicazione dell'art. 75 della Convenzione (decisione del comitato esecutivo del 22 dicembre 1994 - G.U. n. L 239 del 22 settembre 2000, pp. 463-468), che il viaggiatore si procuri, prima della partenza, un certificato (all. 2 della decisione) redatto dall'Autorità sanitaria nazionale individuata dal predetto accordo, certificato che viene rilasciato dietro presentazione della prescrizione medica; 4) per i farmaci ad azione dopante, indicati nella relativa lista, è obbligatorio esibire la prescrizione medica per qualsiasi quantitativo.

${ }^{163}$ Scatta la sanzione, prevista dal Codice deontologico, per il medico che prescrive farmaci ad atleti perfettamente sani anche se non per fargli vincere una gara ma al solo fine di far loro recuperare il tono fisico ed assicurargli, così, le condizioni per riavere il posto in squadra. Lo sottolinea la Corte di Cassazione che ha confermato il verdetto di quattro mesi di sospensione dall'attività professionale per un medico di Rimini. L'interdizione temporanea era stata decisa, nel 2005, dalla Commissione centrale per gli esercenti le professioni sanitarie. Secondo i giudici, il mancato collegamento della terapia prescritta con un evento di tipo agonistico, fa venir meno l'addebito relativo al doping, ma non la violazione delle norme deontologiche che non consentono "l'esclusiva finalizzazione della terapia prescritta al recupero di un posto in squadra". Cass. civ., sez. III, 23 agosto 2011, n. 17496, in www.pluris-cedam.utetgiuridica.it. L'idea che il medico debba limitare le sue prescrizioni solamente a quanto necessario ad avere cure efficaci, sicure e di qualità sembra una posizione condivisa da parte dei Codici deontologici di diversi Paesi membri dell'Unione Europea e per questo pare essere interessante lavorare per la realizzazione di un codice deontologico europeo sul tema del doping che possa aiutare ad armonizzare le norme sportive e le norme statali in questa materia. E. Ferioli, La declinazione del fenomeno doping secondo i codici deontologici dell'unione europea: analisi comparativa, in Medicina e morale, 2013, IV, pp. 739-766.

164 Che punisce "chiunque, per crudeltà o senza necessità, cagiona una lesione ad un animale ovvero lo sottopone a sevizie o a comportamenti o a fatiche o a lavori insopportabili per le sue caratteristiche etologiche" con la reclusione da tre a diciotto mesi o con la multa da 5.000 a 30.000 euro. Per integrare il reato è sufficiente la sofferenza degli animali che si configura anche con la sottoposizione, derivante da comportamento commissivo o omissivo, a sevizie o a comportamenti, fatiche o lavori insopportabili per le caratteristiche etologiche dell'animale. Cass. pen, sez. III, 3 dicembre 2003, n. 46291 con nota di P. Mazza, Inadeguatezza della normativa a tutela degli animali, in Dir. giur. agr. amb., 2004, XI, pp. 708-709. Assume così valenza anche qualsiasi azione caratterizzata da una evidente e conclamata incompatibilità con il comportamento della specie di riferimento come ricostruito dalle scienze naturali, tenuta per crudeltà e senza necessità. Cass. pen., sez. III, 7 febbraio 2013, n. 5979, con nota di P. Mazza, Il delitto di maltrattamento di animali: più ombre che luci negli interventi della cassazione, in Riv. pen. econ., 2014, II, pp. 461-481. Il comma terzo dell'art. 544-ter prevede la circostanza aggravante in base alla quale in caso di morte dell'animale, derivante dalle condotte di cui ai commi precedenti, la pena sia aumentata della metà; questo nel caso in cui la morte dell'animale sia stata colposa: qualora sia dolosa si configura il reato di uccisione di animali ex art. 544-bis c.p.

${ }^{165}$ La Suprema Corte si è espressa in merito al sequestro preventivo di un cavallo a cui erano state somministrate sostanze dannose per la salute: gli indizi di colpevolezza furono considerati sussistenti in base al fatto che il cavallo era custodito in locali ove erano state rinvenute sostanze stupefacenti idonee al doping (cinque confezioni di morfina cloridrato e altri farmaci di natura anabolizzante), così potendosi desumere "uno sfruttamento anomalo dell'animale con conseguenti danni alla salute dello stesso, e, quindi, maltrattamento. Inoltre, era stato dimostrato che il cavallo era detenuto all'interno di un box in pessime condizioni igienico-sanitarie e in cattivo stato di denutrizione, con evidenti ferite non curate. Quanto al periculum in mora, il requisito era motivato dal fatto che la perdurante disponibilità dei cavalli avrebbe costituito occasione di protrazione o aggravamento del reato ipotizzato". Cass. pen., sez. III, 3 febbraio 2011, n. 23449, in in www.dejure.it. La somministrazione di sostanze anabolizzanti a dei cavalli può anche integrare il reato di frode sportiva, previsto dall'art. 1 della legge 13 dicembre 1989, n. 401, anche quando le sostanze somministrate siano in grado di indurne la debilitazione, trattandosi di una condotta di per sé idonee ad alterare fraudolentemente i risultati della gara. Cass. pen., sez. III, 23 settembre 2015, n. 40648, in www.dejure.it. 